\title{
PHYSICAL PROPERTIES OF DENTAL MATERIALS (GOLD ALLOYS AND ACCESSORY MATERIALS)
}

\author{
By R. L. Coleman
}

\begin{abstract}
The physical properties of dental gold alloys used in the wrought and cast states, investments, and pattern waxes were investigated. Practicable methods of testing these materials were developed, and these methods and the apparatus used are described. The properties of a large number of representative commercial materials were determined and the values reported. Especial attention was given to those properties having a direct bearing on the usefulness of these materials in the construction of mechanical dental appliances and to the effects of variations in manipulative procedures. Improvements in methods of manipulation, especially in the dental-casting processes and in the heat treatment of gold alloys, were developed. It was found that the dental gold alloys on the market vary widely in their mechanical properties and fusion temperatures as well as in chemical composition. This emphasizes the necessity for selecting suitable materials for specific purposes on the basis of tests of physical properties. The methods of testing developed and described herein provide the dental profession and schools with a means of grading and selecting materials on this basis.
\end{abstract}

CONTENTS

I. Introduction

Page

868

II. Gold alloys

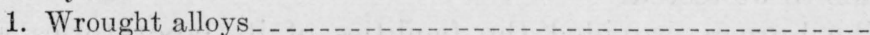

871

(a) Chemical composition _.................... 871

(b) Microstructure _..._._._. 872

(c) Fusion temperatures_._._._._._. 875

(d) Heat treatment................. 878

(e) Mechanical properties_._.

(1) Static flexure test_........... 882

(2) Tensile tests _.............. 886

(3) Brinell hardness _................. 890

(4) Life tests (repeated stresses) _.......... 891

2. Cast alloys_..... 893

(a) Chemical composition _.............. 893

(b) Melting ranges_............... 894

(c) Mechanical properties _.................. 896

(d) Casting shrinkage_............. 908

3. Selection of dental gold alloys _... 911

III. Accessory materials used in the dental casting process _...

1. Pattern waxes_.

2. Investments

(a) Dimensional changes caused by setting _......... 918

(b) Dimensional changes caused by heating._._._... 919

(c) Compressive strength _._.

(d) Porosity of investments................. 931

(e) Surface roughness _...

3. Casting to dimension

IV. Summary

$\begin{array}{lll}5619^{\circ}-28-1 & 867\end{array}$ 


\section{INTRODUCTION}

In 1919 the National Bureau of Standards was asked to assist one of the Government departments in grading or selecting satisfactory amalgam alloys for its use and in establishing specifications upun which such alloys could be purchased. This was done, and the results ${ }^{1}$ were published in 1920 .

These reports were favorably received, and numerous requests were made by individuals and organizations that the work be extended to include the problems met in the use of gold alloys. Owing to a lack of sufficient funds the bureau was unable to assume full responsibility for such an elaborate program as appeared necessary. The research associate plan ${ }^{2}$ in operation at the bureau, by which outside organizations may cooperate in financing and carrying on research of especial interest to them, was available to the dental societies or associations, but only one of the interested organizations, the Weinstein Research Laboratories, of New York, N. Y., offered to provide the necessary cooperation. This offer was accepted and the work started in January, 1922.

The conditions under which this work was carried on were briefly as follows:

1. The cooperating laboratory paid the salaries of the associates, provided all special equipment, and supplied funds for purchasing materials to be tested.

2. The bureau provided the facilities of its laboratories and the cooperation and advice of its scientific staff, supervised the work, and published the results.

A tentative outline of the program of research ${ }^{3}$ was published in the Journal of the American Dental Association with a request for criticisms and suggestions from interested members of the profession. A number of valuable suggestions were received, and these were incorporated into the final program. This program included studies of the important properties of dental gold alloys in the wrought and cast forms, pattern waxes, investments, impression and cast materials, and the effects on these materials of variations in manipulative procedure. The purposes of these studies were: (1) To establish methods of testing these materials; (2) to determine the important properties of a number of representative products; and (3) to develop such improvements in the methods of manipulating these materials as might be suggested by a better understanding of their properties.

1 Souder, W. H., and Peters, C. G., An Investigation of the Physical Properties of Dental Materials, B. S. Tech. Paper No. 157; 1920; Dental Cosmos, 62, p. 305; March, 1920.

2 For a description of this plan see Bureau of Standards Circular No. 296, Research Associates at the Bureau of Standards.

3 "Dental research"; J, A. D. A.; March, 1924, 
A number of progress reports ${ }^{4}$ on various phases of the work were published in the dental journals from time to time as data were obtained. The present paper consists of a collection and correlation of the data previously reported with such additional data as are now available.

The author wishes to make the following acknowledgments, in addition to those made in the text:

1. The cooperative research by the Bureau of Standards and the Weinstein Research Laboratories reported in this paper was planned jointly by Louis J. Weinstein, director of the Weinstein Research Laboratories, and Wilmer Souder, physicist, of the Bureau of Standards, who is actively in charge of this work. Their continued aid throughout has been essential to its success. Doctor Weinstein, by reason of his pioneer work and long experience in this field, has been able to contribute valuable aid on the dental problems involved. Doctor Souder directed the scientific phases of the research. Acknowledgment is also made of their assistance in interpreting the results and preparing the material for publication.

2. W. A. Poppe, research assistant, Bureau of Standards, assisted in this work.

\section{GOLD ALLOYS}

In the investigation of the physical properties of dental gold alloys those properties having a direct bearing on the usefulness of the alloys as materials of dental construction were given major consideration. Among the more important of these are the various mechanical properties, such as strength, hardness, ductility, and others. An extensive investigation was undertaken to determine these properties and the manner in which they are affected by various heat treatments and manipulative procedures. Other important properties studied are chemical composition, melting range or fusion temperature, and, in the case of alloys used in the cast state, casting shrinkage. Microscopic examinations were made chiefly to help explain variations in the mechanical properties and to supplement chemical analysis as an identification of the material.

In determining the mechanical properties of these alloys it is essential that the test specimens be of such size and produced under such conditions as to be representative of the materials as actually used for dental purposes. Thus, tests of an alloy intended for use as

4 (a) Souder, Wilmer, "Physical properties of dental materials"; J. A. D. A.; May, 1925. (b) Coleman R. L., 'Physical properties of dental materials II (wrought gold alloys)"; J. A. D. A.; May, 1925. (c) Coleman, R. L., "Physical properties of dental materials III (progress report of research on the dental casting, process)"; Dental Cosmos, August, 1926. (d) Swanger, William H., Analysis of Dental Gold Alloys, B. S. Sci. Paper No. 532; J. Dental Research, December, 1927. (e) Souder, Wilmer, "The selection of dental materials"; J. A. D. A.; February, 1927. ( $f$ ) Coleman, R. L., "Physical properties of dental materials IV (cast gold alloys)"; Dental Cosmos, October, 1927. (g) Souder, Wilmer, "Summary of reports on dental alloys"; J. A. D. A.; April, 1928. 
clasp or orthodontia wire would not be conclusive if test specimens of the size commonly recommended for structural steel were employed. Nor would the results of tests of an alloy in the wrought condition be a reliable index of the usefulness of that alloy when employed in the cast state.

In selecting apparatus and methods of test these considerations were kept in mind. In a number of instances it was necessary to modify the usual methods or to develop special apparatus adapted to the peculiar characteristics of the materials being tested. It was found that much of the equipment suitable for testing small wires, plate, and band material was unsatisfactory when applied to cast specimens. For this reason it was deemed advisable, for the purposes of this investigation, to divide the dental gold alloys into two groups according to the form in which they are used; namely, wrought alloys and cast alloys. This grouping will be adhered to in the following discussion of these materials.

The alloys tested were selected from those on the market and are believed to be representative of the better grade of materials available for the construction of mechanical dental appliances. The selections were made chiefly on the basis of the manufacturers' claims of superiority for specific uses. Except where otherwise stated, the samples were purchased in the open market and were received in original packages.

Eighteen wrought alloys were selected as being representative of the materials available for use in this form. Included in this list are alloys recommended by their respective manufacturers for use as wire or flat clasps, orthodontia arch and spring wires, and plate and bands of varying properties intended for a number of different uses. Eight of these alloys were tested in the form of round wire and 10 in the form of flat strip.

The group of cast alloys tested consists of 35 alloys selected as being representative of each of the general types of casting golds in use. Included in this list are a number of the so-called hard alloys intended for clasps, bars, and similar uses, and others of the types intended for such uses as hard inlays or three-quarter crowns, partial dentures, full dentures, and soft inlays. Gold solders of three grades commonly employed in dental practice are also included.

It should be pointed out that most of the alloys tested were purchased during or prior to 1925 . Since that time some of these alloys have been modified or discontinued, and new alloys have been put on the market. However, it is believed that the list selected is still representative of the materials available.

In accordance with a general policy of the bureau the trade names of these alloys are not given. Instead each alloy is designated by a letter or number. The designations are entirely arbitrary and have 
no reference to the trade names or to the relative merits of the alloys. If the trade names are desired, they may be obtained from the manufacturers who will recognize their product from the chemical analysis.

Descriptions of the methods of testing used as well as the values obtained will be presented in the following sections. No attempt will be made to give all details of the usual routine methods and requirements for accurate testing. These may be had by reference to any standard text ${ }^{5}$ of the testing laboratory or engineering school.

\section{WROUGHT ALLOYS}

(a) CHEMICAL COMPOSITION

Chemical analyses of all the wrought alloys tested were made for purposes of identification and in order to correlate variations in physical properties with corresponding variations in chemical composition. The analyses were made by William H. Swanger, research associate. For the purposes of this investigation it was desirable that the compositions be determined with the highest possible accuracy. For this reason it was necessary to modify many of the analytical methods previously used and in some instances to develop new methods. A description of the methods used is given in a previous publication, ${ }^{6}$ reference to which should be made for the detailed procedure. In order to indicate the accuracy attained, it may be stated that in most instances the agreement between duplicate determinations of the major constituents was better than 0.1 per cent (calculated on the sample) with a proportional precision for minor constituents. All analyses were made in duplicate, and the average values reported.

The compositions are given in Table 1. A study of these values reveals that alloys of this group are composed chiefly of gold, silver, copper, and platinum or palladium. In most instances small amounts of one or more other metals, such as zinc, tin, nickel, manganese, iron, magnesium, iridium, and rhodium, are present. Some of these are added intentionally to alter the properties of the alloy, while others are undoubtedly present as impurities in the major constituents. As many as nine of the above-named metals were found in a single alloy.

The proportionate amounts of the major constituents were found to vary widely even in alloys intended for the same or similar uses. A striking example of this is found in the group of alloys supplied in wire form; namely, alloys $\mathrm{A}$ to $\mathrm{H}$, inclusive. These were intended for use as clasps or orthodontia arch or spring wires, the requirements for which, from a consideration of the mechanics involved, are very

s The following are examples of such textbooks. Mechanical Testing. Two volumes. Batson and Hyde, E. P. Dutton \& Co., New York; 1923. Handbuch des Material Prüfungswesens, Otto Wawziniok, Julius Speringer, Berlin, Geimany; 1923.

${ }^{6}$ See footnote $4(d)$, p. 869. 
similar. The wide variations in the compositions of these alloys are obvious from an inspection of Table 1 . It will be noted that the total gold, platinum, and palladium content of the alloys of this group, alloys $\mathrm{A}$ to $\mathrm{H}$, inclusive, varies, in general, from about 75 to about 85 per cent. There are, however, two notable exceptions; namely, alloys $\mathrm{B}$ and $\mathrm{G}$. In the case of alloy $\mathrm{B}$ the total of these three metals is only about 50 per cent, while in the case of alloy $\mathrm{G}$ it is about 99 per cent.

TABLE 1.-Chemical composition of wrought alloys (per cent by weight)

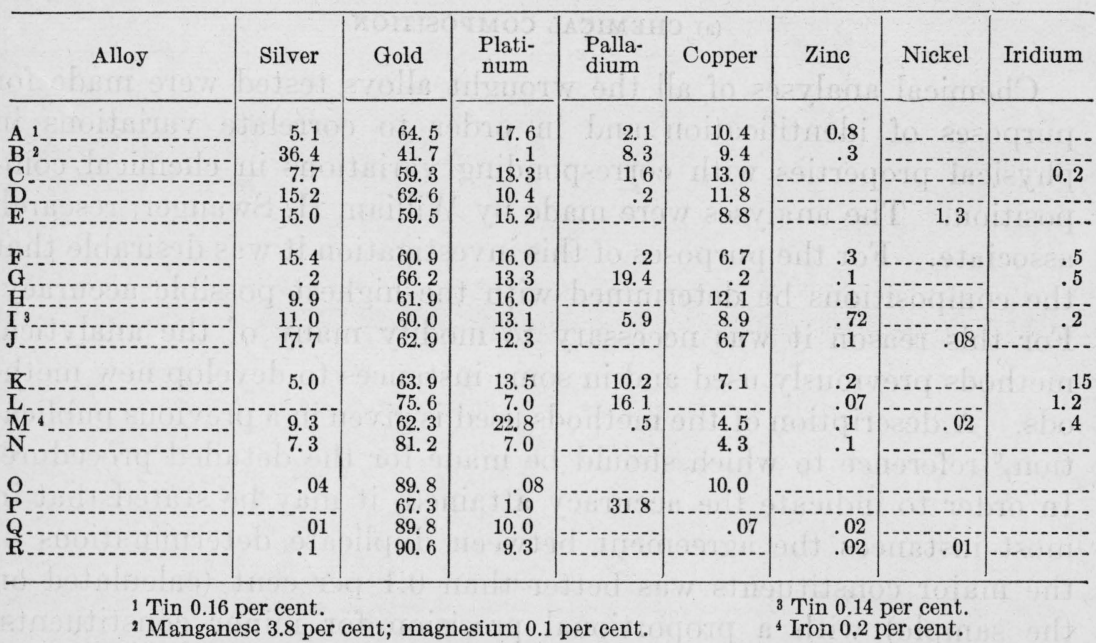

The complexity of the compositions of these alloys and the apparent lack of systematic ratios for the elements present indicate that their formulas are largely empiric.

The effects of some of the variations in composition on the physical properties of these alloys will be discussed as the various properties are reached.

\section{(b) MICROSTRUCTURE}

In view of the questionable manner in which this subject has been treated in some of the dental literature it is deemed advisable to preface this section with a brief statement of some of the practical applications and limitations of the study of microstructure as applied to the complex gold alloys. This should serve to obviate the possibility of misinterpretation of the micrographic data presented in this paper.

The suitability of an alloy for any mechanical use whatever, not alone its applications in dentistry, should be judged principally by its mechanical properties. The study of microstructure, when correlated with data on chemical composition and other characteristics, is 
B. S. Journal of Research, RP32

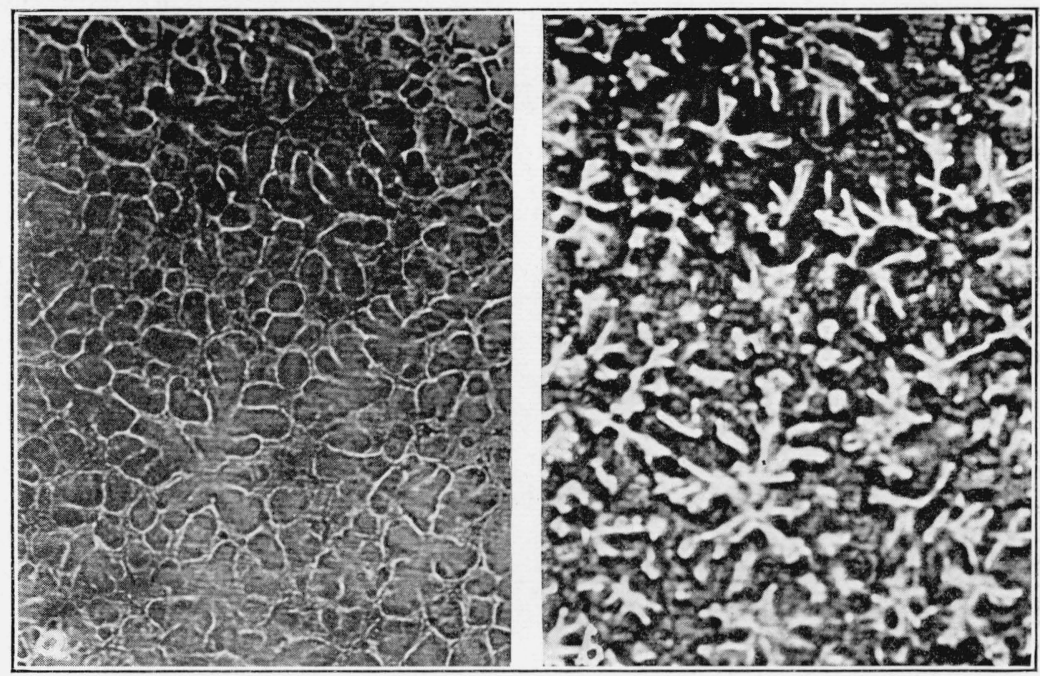

FIG. 1.-Deceptive micrographs of a cast gold alloy $a$ and $b$ are identical except for change in focus, $\times 90$

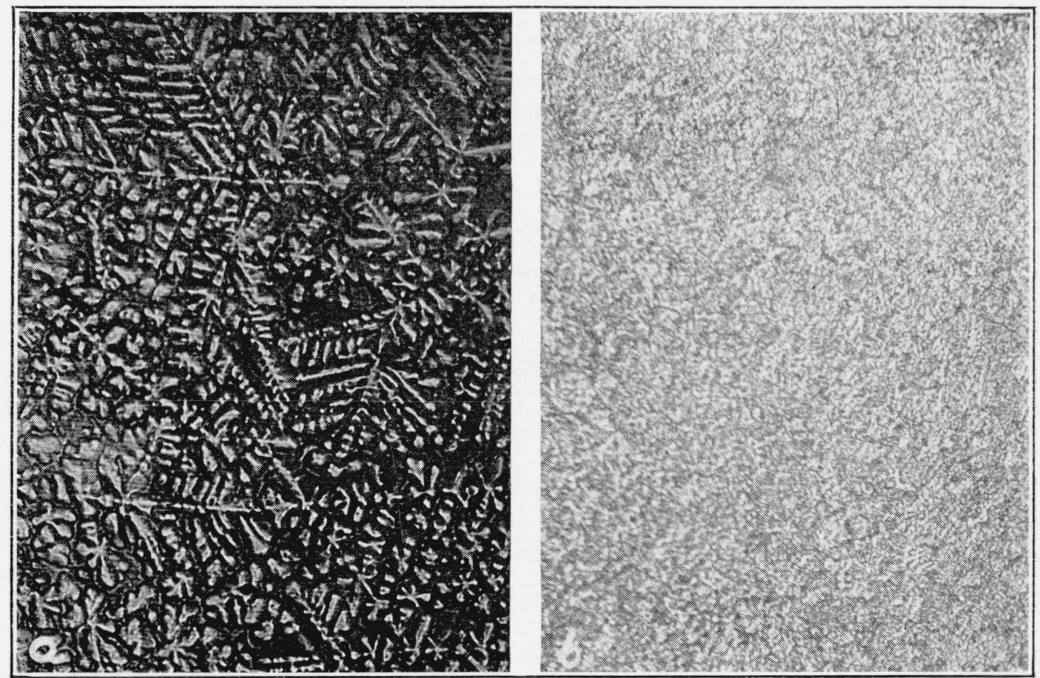

FIG. 2.-Microstructure of alloy $A$

$a$ Cast and slowly cooled, $\times 50$. The dendritic structure is characteristic of solid solutions. $b$, Cross-sectional structure of a wire of alloy $\mathrm{A}$ hardened, $\times 450$. 
B. S. Journal of Research, RP32

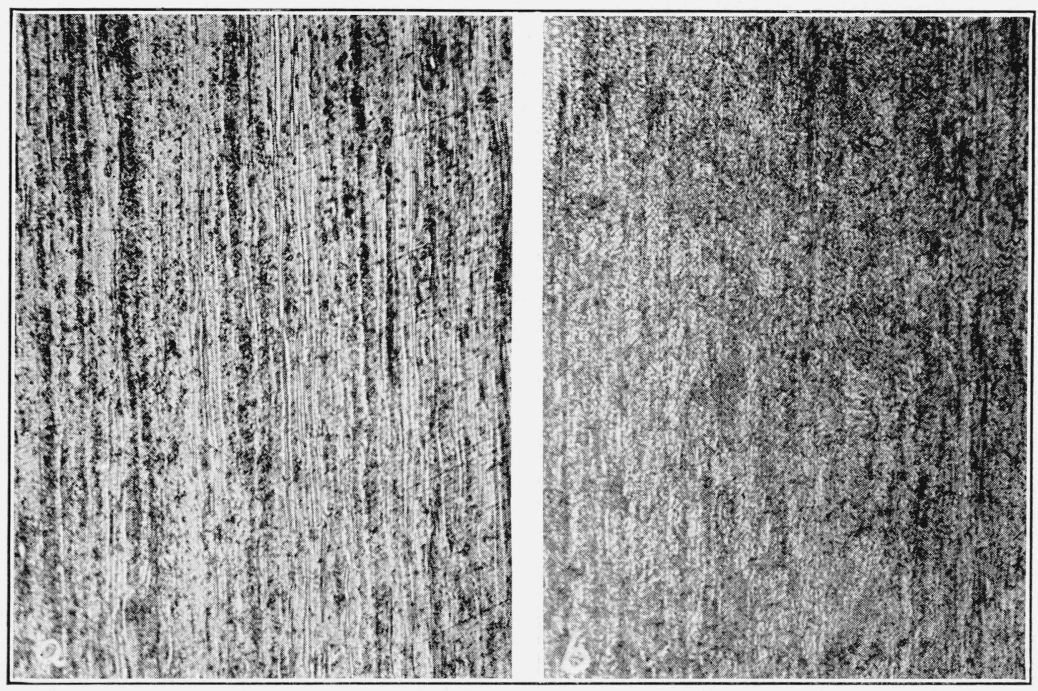

FIg. 3.-Microstructure of alloy A; longitudinal sections of wire, $\times 450$

The dendrites of the solid solution shown in Figure 2(a) have been elongated and ruptured in the drawing process and now appear as light portions elongated in the direction of drawing. $a$, Softened; $b$, Hardened.

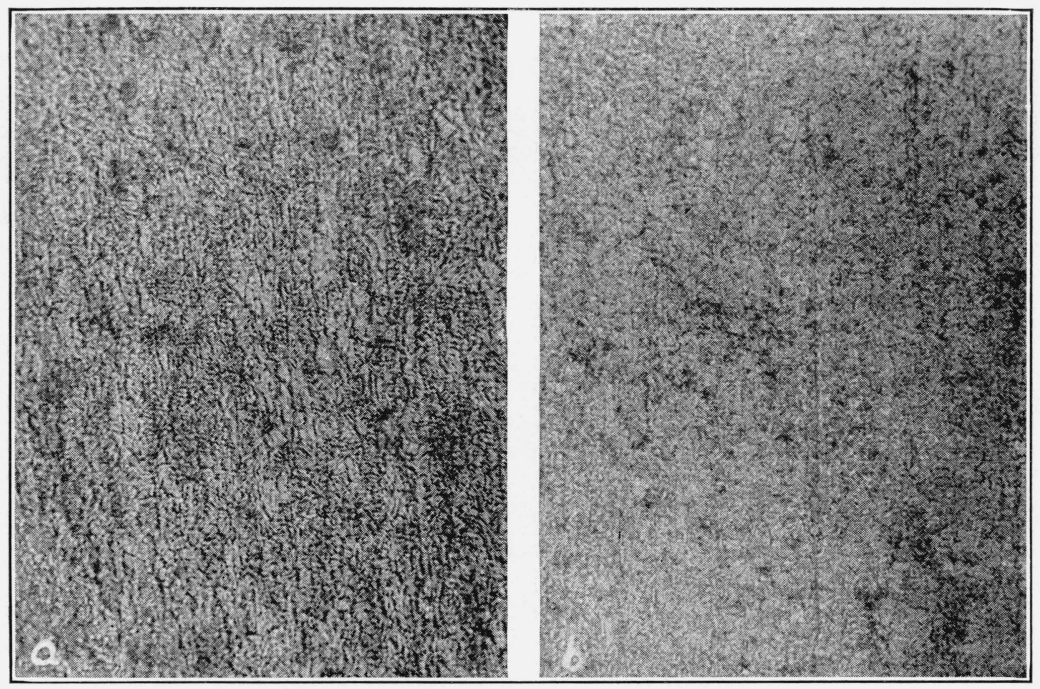

FIG. 4.-Microstructure of alloy A; longitudinal section, $\times 450$

Heat treatments; $a$, Softening followed by hardening; $b$, Softening, followed by hardening and a second softening. These structures appear to be quite similar, but the mechanical properties are very different. 
of value, but the final criterion must be the mechanical properties or the behavior of the material under service conditions.

In undertaking the study of microstructure of these alloys it was hoped to attain the following objects:

1. To supplement chemical analyses as an identification of the materials tested. It is well known that the properties of an alloy are affected by mechanical and heat treatments. Thus, the mechanical properties of a cast rod would not be expected to be the same as those of a wrought rod of identical composition, nor would the properties of the wrought rod be identical with those of the same rod after being subjected to certain heat treatments. The micrograph should help to define the condition of the alloy with respect to these factors.

2. To reveal microscopic defects, if present, due to casting or mechanical working.

3. To determine the homogeneity of the alloys and the presence of certain impurities.

4. To obtain some information concerning the constitution of the alloys that might help explain how and why their properties may be changed by heat treatment.

It should be borne in mind that while the microscope may reveal the existence of certain conditions it does not determine the effects of these conditions on the mechanical properties of these complex alloys. This can be done only by determining the mechanical properties themselves.

In obtaining micrographs truly representative of the specimens under test the preparation of the alloy surface, the etching, the method of illuminating, the focusing and various other factors are of great importance. Accidental or intentional errors in any one of the steps are sure to vitiate the result. Figures $1(a)$ and $(b)$ are included to illustrate this. The two micrographs are from the identical surface and position. The marked difference in the appearance of the structure is due entirely to a slight change in focus.

From the foregoing it is evident that the value of a study of microstructures is very limited unless this study is correlated with that of the other important characteristics of the material and that micrographs presented without sufficient data would be meaningless. The following micrographs are presented with the foregoing conditions fully in mind.

There appeared to be some lack of uniformity of materials as received, perhaps owing to differences in mechanical working or heat treating at the factory. It was found that this could be largely eliminated and in many instances the alloy made either hard or soft at will by proper heat treatment. The methods of heat treating and the corresponding effects on the mechanical properties are described in detail in following sections of this paper. Briefly, the heat treat- 
ments employed were as follows: For softening the alloy was heate $P$ to $700^{\circ} \mathrm{C}$. $\left(1,290^{\circ} \mathrm{F}\right.$.) and quenched in water; for hardening the alloy was heated to $450^{\circ} \mathrm{C}$. $\left(840^{\circ} \mathrm{F}\right.$.) and cooled slowly.

The microstructure of the material as received was considered of little interest since it is usually advantageous to soften the alloy before shaping it into the desired form and later to harden the finished appliance. For this reason micrographs were made of the alloys after heat treating as indicated above. All the samples reported in this section were etched with aqua regia.

Figure $2(a)$ shows the structure of alloy A when cast and cooled slowly. The dendritic structure shown is characteristic of solid solutions. This structure does not preclude the presence of intermetallic compounds which may be present, but not shown by the microscope.

Figure $2(b)$ shows the cross-section structure of a wire of alloy A 0.035 inch in diameter, and Figures 3 and 4 show longitudinal sections of the same wire. The parallel lighter grain structure shown in Figure $3(a)$ and some of the following micrographs is the dendrite elongated and distorted in the drawing, rolling, or swaging process. Such structures have been referred to in some of the dental literature as indicating segregation of some of the constituents. While it may be possible to call these lines segregations in a very special sense, they are not segregated in the sense of defects due to melting, casting, or working, but are normal characteristic structure for this type of alloy when subjected to this treatment.

The specimen shown in Figure $3(a)$ was given the softening heat treatment, and that shown in Figure $3(b)$ was given the same treatment followed by the hardening heat treatment. In the case of the latter specimen the severely worked structure has been changed to the more nearly homogeneous structure of an annealed alloy. This structure appears to be permanent as giving the specimen a second hardening heat treatment, as shown in Figure $4(a)$, or a second softening treatment, as shown in Figure $4(b)$, did not appreciably modify the microstructure, although, as will be shown later, such treatment does change the mechanical properties.

Figure 5 shows the structure of alloy B. Figure $5(a)$ shows the structure of the alloy quenched in water from $700^{\circ} \mathrm{C}$. $\left(1,290^{\circ} \mathrm{F}\right.$.) and Figure $5(b)$ that of the alloy quenched, reheated to $700^{\circ} \mathrm{C}$. $\left(1,290^{\circ}\right.$ F. $)$, and then air cooled. These treatments correspond to the recommendations of the manufacturer so far as we are able to interpret them.

The heat treatments given the alloys shown in the remaining sets of micrographs, Figures 6 to 11, were the softening treatment, shown at $(a)$, and the softening treatment followed by the hardening treatment, shown at $(b)$. All of these micrographs were made at a magnification of 450 . 


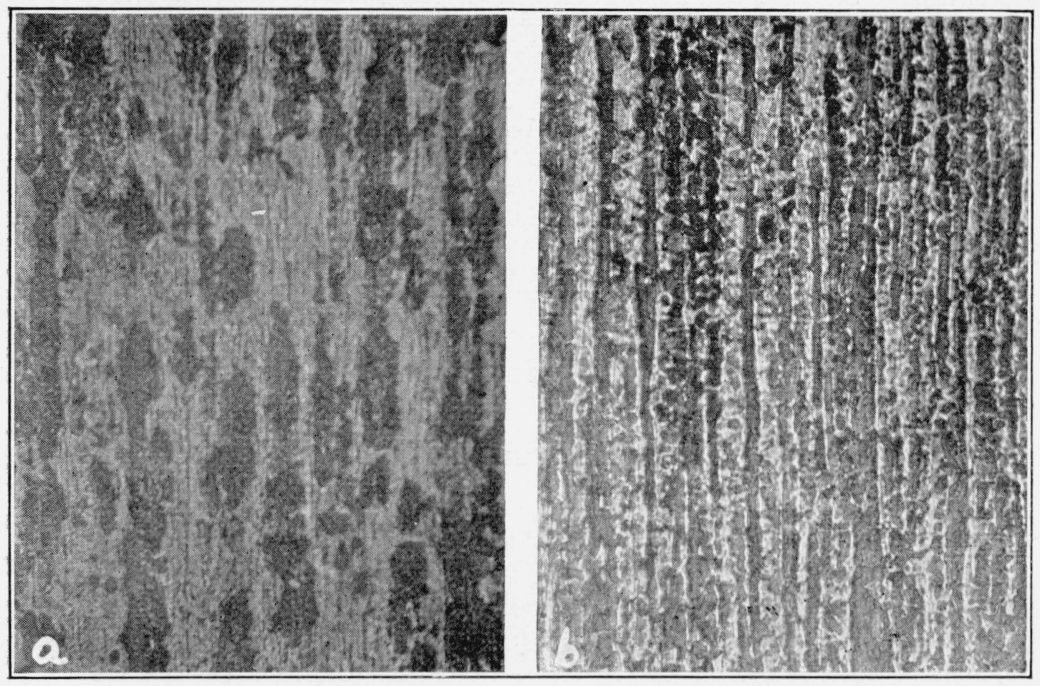

Fig. 5.-Microstructure of alloy $B$; longitudinal section, $\times 450$

$a$, Softened; $b$, Cooled in air from $700^{\circ} \mathrm{C}$.

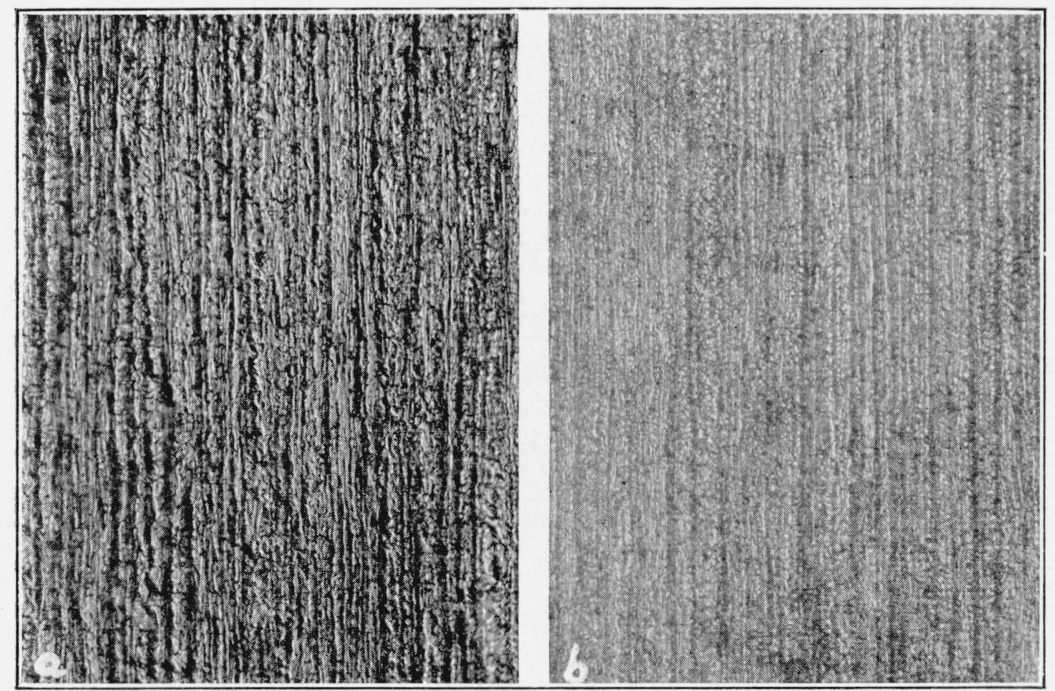

FIG. 6.-Microstructure of alloy $C$; longitudinal section, $\times 450$

$a$, Softened; $b$, Hardened 
B. S. Journal of Research, RP32

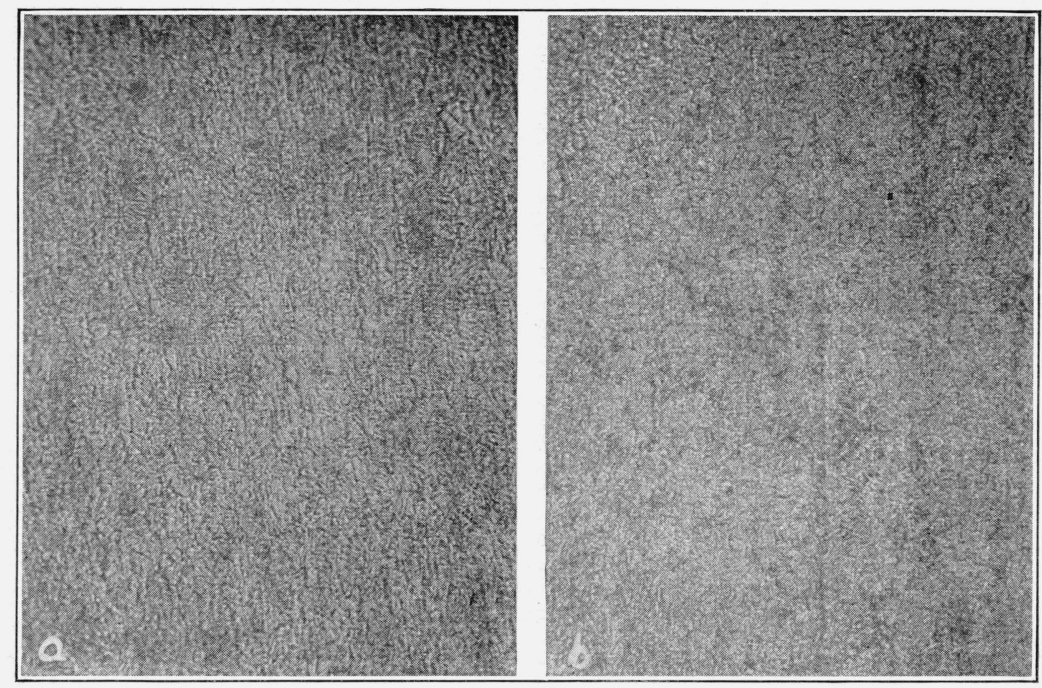

FIG. 7.-Microstructure of alloy D; longitudinal section, $\times 450$ $a$, Softened; $b$, Hardened

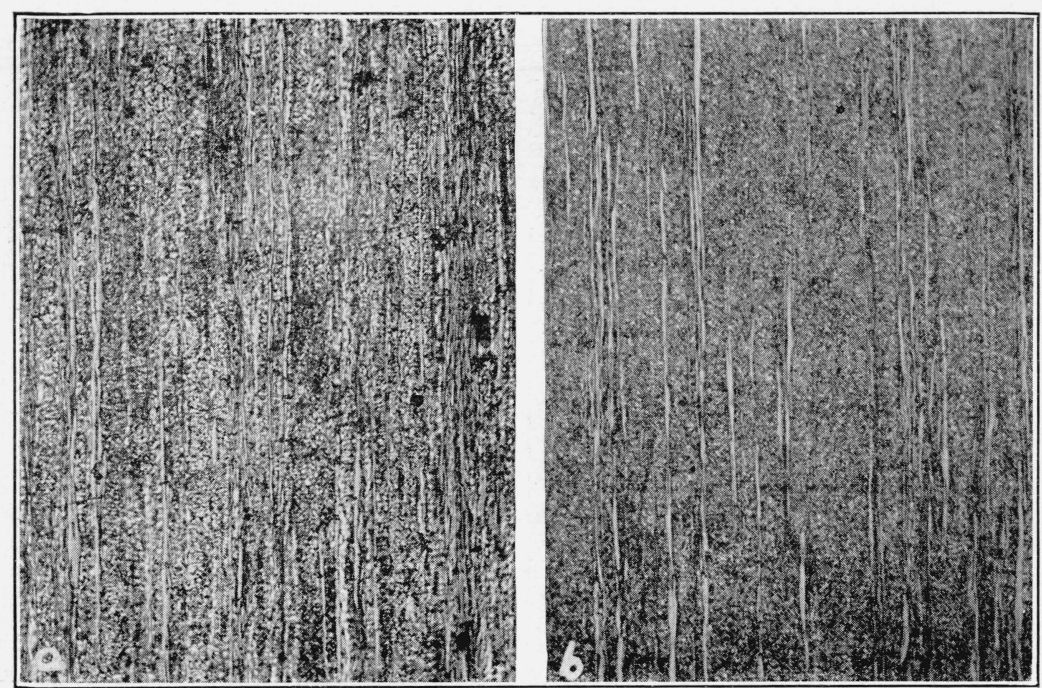

FIG. 8.-Microstructure of alloy $E$; longitudinal section, $\times 450$ $a$, Softened; $b$, Hardened 
B. S. Journal of Research, RP32

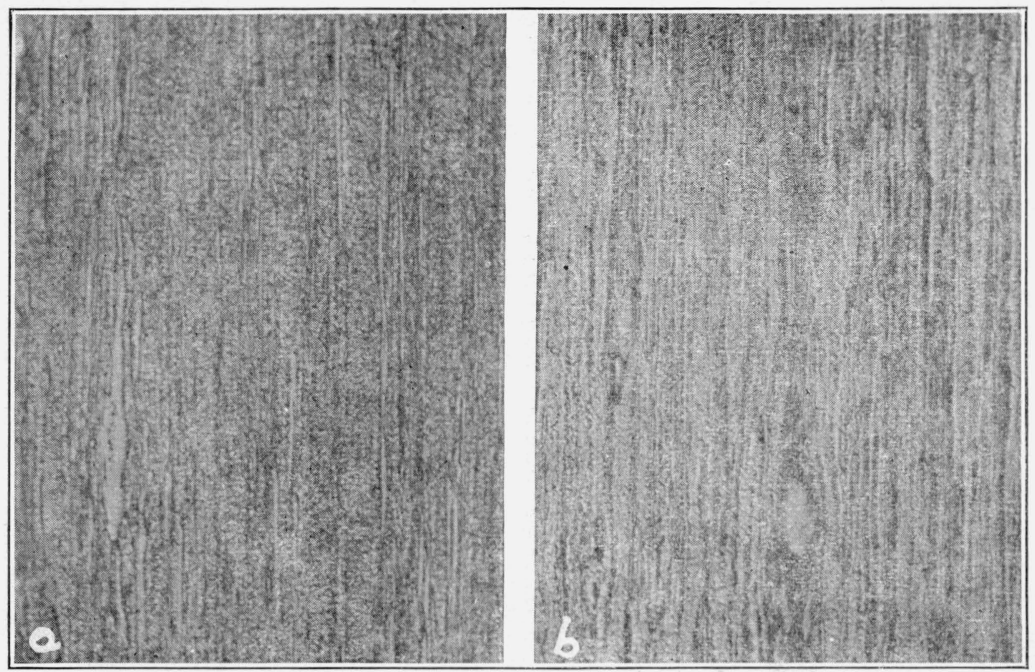

Fig. 9.-Microstructure of alloy $F$; longitudinal section, $\times 450$

$a$, Softened; $b$, Hardened

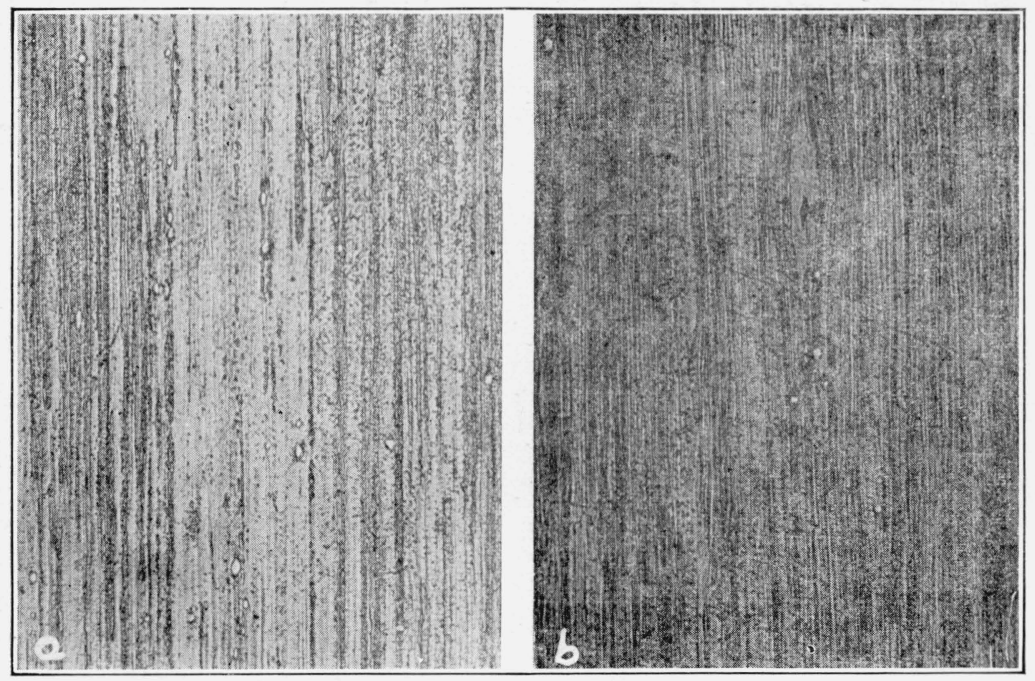

FIG. 10.-Microstructure of alloy $G$; longitudinal section, $\times 450$

$a$, Softened; $b$, Hardened 
B. S. Journal of Research, RP32

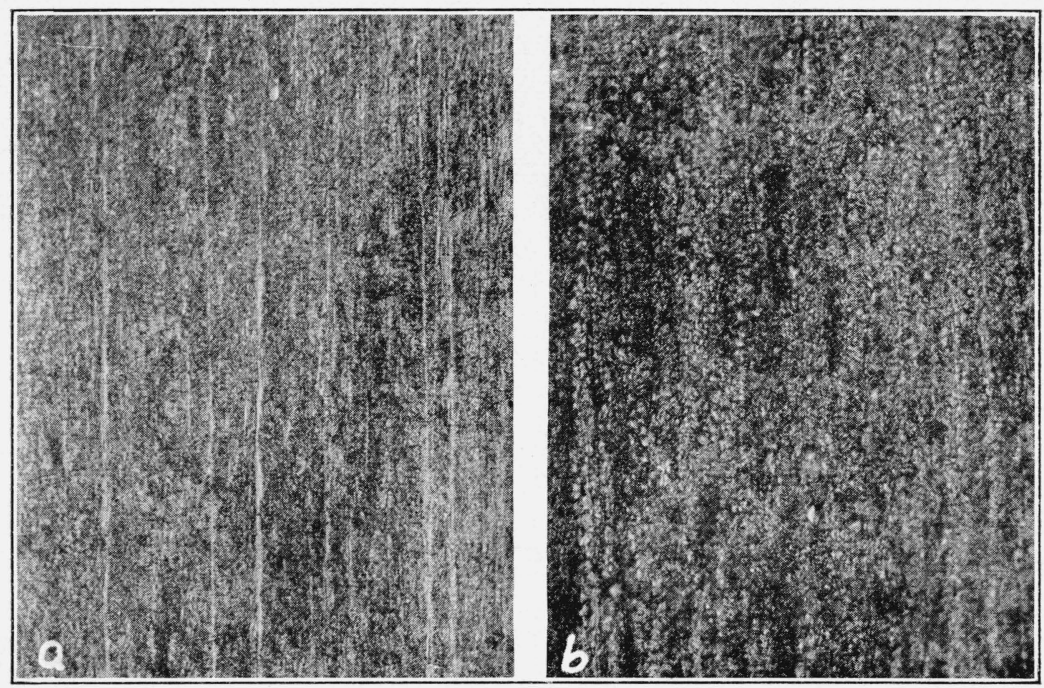

FIG. 11.-Microstructure of alloy $H$; longitudinal section, $\times 450$ $a$, Softened; $b$, Hardened

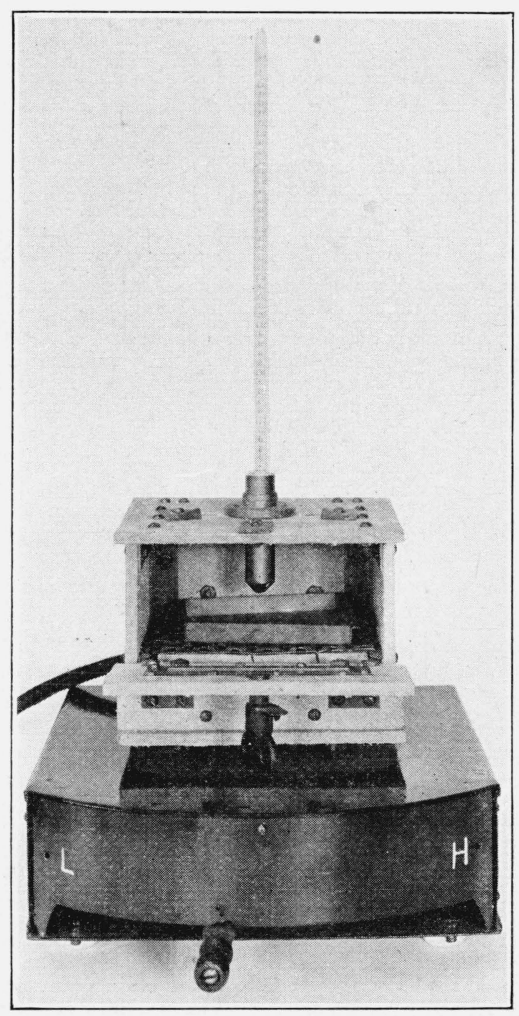

FIG. 14.-Box-type electric furnace used for heat treating short wires 
The micrographs of alloy $\mathrm{D}$ in the softened and hardened conditions, shown in Figure 7, are very similar and do not show the typical worked structure. It is concluded that the heating to $700^{\circ} \mathrm{C}$. $\left(1,290^{\circ} \mathrm{F}\right.$.) incident to the softening treatment is sufficient to change the worked structure of this alloy, or that this wire was heat treated before leaving the factory. This pair of micrographs is not unlike those of Figure 4.

In many cases the softened specimens still retained some evidences of severe working in drawing or swaging. To some extent this structure was modified by the later and more prolonged hardening heat treatment. The prominent lines representing the elongated dendrites of the worked alloy became less distinct, probably due to diffusion, resulting in a more nearly homogeneous structure. In some instances there were indications of incipient grain growth or recrystalization. This is more noticeable in Figures $4(a), 7(a)$, $7(b)$, and $11(b)$. Evidences of serious defects due to casting or working, oxide or other inclusions, or to segregations were not found.

It was noted that in the case of those alloys capable of being appreciably hardened by heat treatment the specimens in the hardened condition were more resistant to etching than those in the softened condition. This indicates that these alloys may have their resistance to the actions of mouth fluids increased by the hardening heat treatment. As will be shown later this treatment will greatly improve their mechanical properties.

(c) FUSION TEMPERATURES

Complex alloys seldom have a single, definite melting temperature such as the pure metals have, but usually have a definite melting range or temperature interval within which part of the alloy is in the liquid and part in the solid state. The alloy begins to melt at the temperature of the lower limit of the range but is not completely melted until the temperature of the upper limit is reached. Table 2, giving the melting points of some of the metals used in dental alloys and the melting ranges of a binary alloy of each of these metals with gold, is included to illustrate this and for reference purposes. It will be noted that the length of the melting range of an alloy varies widely, depending upon the metals of which it is composed. The range for an alloy containing 90 per cent gold and 10 per cent silver is only $6^{\circ} \mathrm{C}$, while that of an alloy containing 90 per cent gold and 10 per cent platinum is nearly $130^{\circ} \mathrm{C}$. Some of the complex alloys used in dentistry have melting ranges even longer than this. Such temperature ranges are usually determined by observing changes in the time rate of cooling of the alloy as it passes from the liquid to the solid state. Two determinations of this kind are illustrated in Figure 12. 
TABLE 2.-Melting points and ranges of a few elements used in dentistry and some of their binary alloys

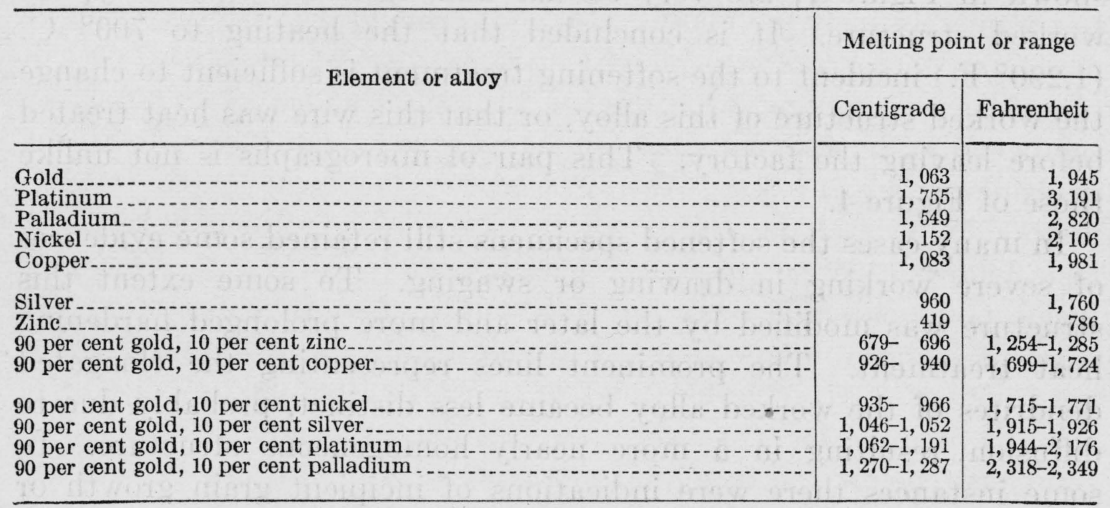

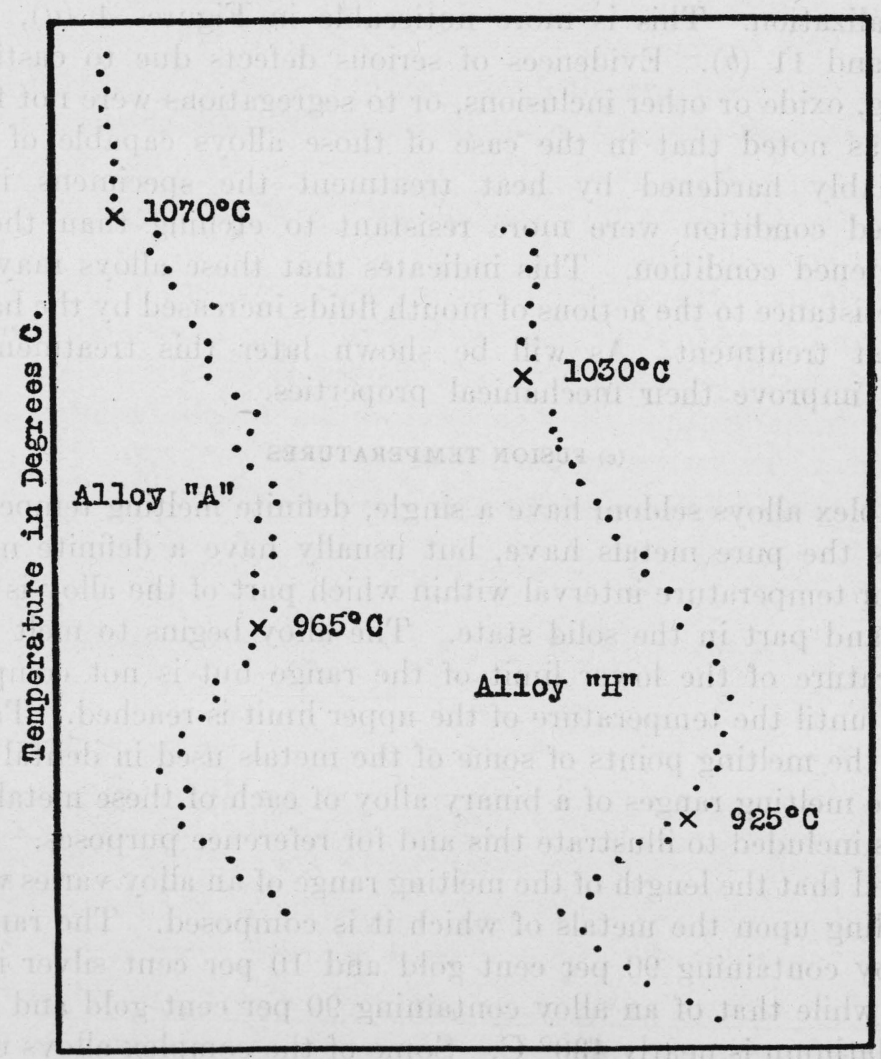

\section{Time in Seconds}

Fig. 12.-Cooling curves for alloys $A$ and $H$

The time required for the alloy to cool equal temperature intervals is plotted against temperature. This is known as the inverse rate method and locates the freezing range. The temperature at which the molten alloy begins to freeze is indicated by a decrease in the rate of cooling: $1,070^{\circ} \mathrm{C}$. for alloy $\mathrm{A}$ and $1,030^{\circ} \mathrm{C}$. for alloy $\mathrm{H}$. Solidification of the alloy is complete when the rate of cooling shows a sudden increase; $965^{\circ} \mathrm{C}$. for alloy A and $925^{\circ} \mathrm{C}$. for alloy $\mathrm{H}$ 
In the case of a wrought alloy the upper limit of the melting range is of little practical importance to the user, since he seldom has occasion to completely melt the alloy. However, it is important to know the maximum temperature at which the alloy may be soldered, bent, or otherwise manipulated with safety. For the purpose of locating this temperature it was felt that sufficient data could be secured by determining a point within the melting range by means of the "wire" method. ${ }^{7}$ A brief description of this method as employed in these tests follows. A short piece of the alloy (from 3 to $4 \mathrm{~mm}$ long), the fusion point of which was to be determined, was welded between the wires of a platinum and platinum-rhodium thermocouple to form the hot junction. After connecting this thermocouple to a potentiometer the hot junction was inserted in an electric furnace at a temperature somewhat below the fusion temperature of the alloy under test and the temperature raised at a uniform rate not exceeding $5^{\circ} \mathrm{C}$. per minute. The temperature was indicated by the potentiometer. Care was taken to prevent a temperature gradient across the sample that might cause serious error in the indicated temperature. The fusion of the sample, causing a break in the connection between the wires of the thermocouple, was indicated by the potentiometer registering an open circuit.

Both limits of the melting range were determined for a few wrought alloys, and it was found that they were of no more value than the temperatures 'determined by the "wire" method and, perhaps, not so reliable in indicating the temperature at which failure could be expected. The "wire" method was, therefore, adopted. The fusion temperatures as determined by this method are given in Table 3.

TABLE 3.-Fusion temperatures of alloys ${ }^{1}$

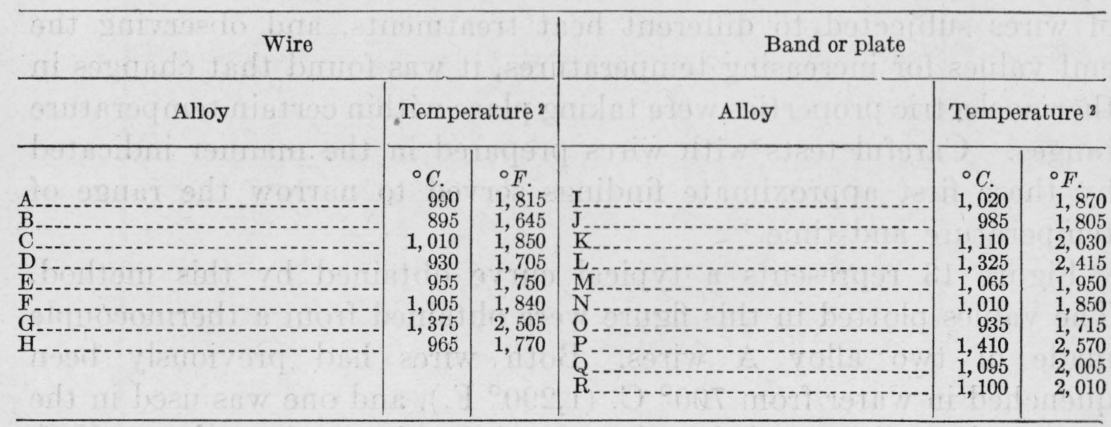

1 The author is indebted to H. M. Schmitt and W. F. Roeser for assistance in determining these fusion temperatures.

2 Observations are to nearest $5^{\circ}$.

No comments are offered as to the most appropriate working temperature for such alloys. Certainly soldering, heat treating, or

\footnotetext{
${ }^{7}$ A detailed description of this method is given in B. S. Tech. Paper No. 170; 1921.
} 
manipulating should not be attempted above the fusion temperature. For most purposes the temperature should be kept below this point. The nearness to which the fusion temperature may be approached with safety will depend upon the skill of the operator, the control of the furnace or flame, the quality of the solder used, and other factors. The temperature given may be taken as a maximum which should never be exceeded in any operation.

\section{(d) HEAT TREATMENT}

At the time this investigation was begun some data had been published on the subject of heat treatment of dental gold alloys, but it was found impossible to coordinate the findings of the different observers. The devices and methods for heat treatment recommended by most lecturers and clinicians were so general in their nature and lacked so much in detail that it was decided to make an independent investigation of this subject.

Preliminary experiments indicated that these alloys could be softened by heating to a temperature of about $700^{\circ}$ to $800^{\circ} \mathrm{C}$. $\left(1,290^{\circ}\right.$ to $1,470^{\circ} \mathrm{F}$.) and quenching in water, and that some, though not all of them, could be hardened by heating to the same temperature and cooling slowly. It was necessary to determine the proper temperatures and times or rates of cooling to produce these results efficiently under the practical working conditions of the dental laboratory.

Attempts to determine these constants by changes in cooling curves and thermal expansivity, induced by different heat treatments, were not conclusive. The most promising method appeared to be that of determining changes in thermal electromotive force. By making thermocouples of heat treated and untreated wires, and of wires subjected to different heat treatments, and observing the emf values for increasing temperatures, it was found that changes in thermoelectric properties were taking place within certain temperature ranges. Careful tests with wires prepared in the manner indicated by these first approximate findings served to narrow the range of temperature and time.

Figure 13 represents a typical curve obtained by this method. The values plotted in this figure were obtained from a thermocouple made of two alloy A wires. Both wires had previously been quenched in water from $700^{\circ} \mathrm{C}$. $\left(1,290^{\circ} \mathrm{F}\right.$.), and one was used in the quenched condition and the other after it had been reheated to $700^{\circ} \mathrm{C}$. $\left(1,290^{\circ} \mathrm{F}\right.$.) and cooled slowly. One end of the couple was placed in a furnace, the temperature raised at a rate of approximately $13^{\circ} \mathrm{C}$. per minute, and the emf of the alloy A couple corresponding to various temperatures was recorded. It will be noted that the emf increases as the temperature is raised up to about $425^{\circ} \mathrm{C}$. $\left(800^{\circ} \mathrm{F}\right.$.) and then 
remains approximately constant, indicating that a transformation has occurred and the portions of the two wires inside the furnace are now in the same condition. The indicated emf does not drop to zero, as might be expected after the furnace has reached the temperature at which the transformation is completed, because as the wires extend outside the furnace they pass through a temperature which is just below that at which the transformation is completed; hence, as the temperature inside the furnace is raised the indicated emf becomes approximately constant at the maximum value.

The temperature at which this transformation is completed, in this case approximately $425^{\circ} \mathrm{C}$. $\left(800^{\circ} \mathrm{F}\right.$.), was recognized as that at which the maximum change in the mechanical properties of the alloy was most likely to occur. Similar tests on this and other alloys using thermocouple elements that had been subjected to various heat treatments indicated that for these alloys the maximum

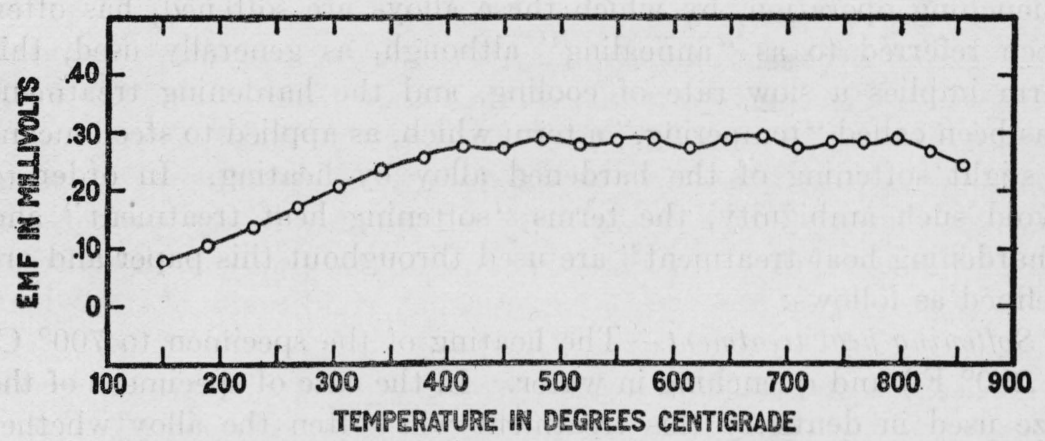

Fig. 13.-Temperature emf relation for a thermocouple made of two wires of the same chemical composition but given different heat treatments

softening effect could be secured by quenching from a temperature ranging from $700^{\circ}$ to $800^{\circ} \mathrm{C}$. $\left(1,290^{\circ}\right.$ to $1,475^{\circ} \mathrm{F}$.) and the maximum hardening effect by prolonged heating at a temperature ranging from $400^{\circ}$ to $450^{\circ} \mathrm{C}$. $\left(750^{\circ}\right.$ to $840^{\circ} \mathrm{F}$.) or by slow cooling from a temperature within or slightly above this range. These tests also indicated that varying degrees of hardening could be secured by prolonged heating at, or slow cooling from, temperatures both above and below the range specified and by varying the length of time the temperature was maintained or by varying the rate of cooling. It was also found that the time required to produce a given degree of hardening was practically the same whether the alloy was held at a constant temperature or allowed to cool slowly. For example, cooling the alloy from $450^{\circ} \mathrm{C}$. $\left(840^{\circ} \mathrm{F}\right.$.) to $250^{\circ} \mathrm{C}$. $\left(480^{\circ} \mathrm{F}\right.$.) in 30 minutes produced practically the same effect as heating at $450^{\circ} \mathrm{C}$. $\left(840^{\circ} \mathrm{F}\right.$.) for 30 minutes. These findings were verified by tests of the various mechanical properties. A description of these tests and further 
details of the effects of heat treatment are given in a following section on mechanical properties.

From the standpoint of practical application in the dental laboratory the method of hardening by slow cooling has two very marked advantages in that when this method is employed it is not necessary to know so precisely the temperature most suitable for hardening a given alloy nor to measure the temperature of the work very accurately during the heat treatment. This method was therefore adopted as standard for this investigation and used for all alloys except those for which special heat treatments were recommended by their manufacturers. The rate of cooling found most efficient for this purpose was the rate obtained by allowing the specimen to cool from $450^{\circ} \mathrm{C}$. $\left(840^{\circ} \mathrm{F}\right.$.) to $250^{\circ} \mathrm{C}$. $\left(480^{\circ} \mathrm{F}\right.$.) in 30 minutes.

There has been some ambiguity in the terms used in the dental literature to describe the heat treatments of gold alloys. The quenching operation, by which these alloys are softened, has often been referred to as "annealing" although, as generally used, this term implies a slow rate of cooling, and the hardening treatment has been called "tempering," a term which, as applied to steel, means a slight softening of the hardened alloy by heating. In order to avoid such ambiguity, the terms "softening heat treatment" and "hardening heat treatment" are used throughout this paper and are defined as follows:

Softening heat treatment.- The heating of the specimen to $700^{\circ} \mathrm{C}$. $\left(1,290^{\circ} \mathrm{F}\right.$.) and quenching in water. In the case of specimens of the size used in dentistry this treatment will soften the alloy whether it has been hardened by mechanical working or by previous heat treatment.

Hardening heat treatment.-The gradual cooling of the specimen from $450^{\circ} \mathrm{C}$. $\left(840^{\circ} \mathrm{F}\right.$.) to $250^{\circ} \mathrm{C}$. $\left(480^{\circ} \mathrm{F}\right.$.) over a period of 30 minutes.

In the case of certain alloys variations from these rates of cooling are permissible and sometimes produced more desirable properties. Thus, for some alloys air cooling from $700^{\circ} \mathrm{C}$. $\left(1,290^{\circ} \mathrm{F}\right.$.) will produce a condition almost as soft as that produced by quenching, while for others air cooling will produce a marked hardening effect. Those alloys that are decidedly hardened by air cooling may become quite brittle if cooled from $450^{\circ}$ C. $\left(840^{\circ} \mathrm{F}\right.$.) to $250^{\circ} \mathrm{C}$. $\left(480^{\circ} \mathrm{F}\right.$.) in 30 minutes, and greater ductility may be obtained by cooling at a faster rate. However, for practical purposes the maximum softening and hardening effects may be obtained by the treatments specified above.

A consideration of the heating devices used by some technicians and demonstrators for carrying out these heat treatments leads to the conclusion that some of the devices employed are totally inadequate. In some cases these heat treatments are attempted 
using only an open gas flame or an electric hot plate while in others an inclosed box type electric oven, such as the one illustrated in Figure 14, is used.

In the case of small pieces of wire or plate, such as are ordinarily used in the construction of dental applicances, the heating preliminary to quenching for the softening treatment may be done successfully over a gas flame, provided care is taken to heat the work as uniformly as possible and to avoid overheating. An experienced technician may judge the temperature with sufficient accuracy by observing the color of the work. However, a much safer and more reliable method is to use a properly designed electric furnace provided with a pyrometer. For the hardening heat treatment, which requires that the work be held at a definite temperature for a definite length of time or that it be cooled at a definite rate, the open flame is obviously inadequate.

The temperatures at various distances above an electric hot plate and above the shelf of an inclosed box type electric oven are recorded in Table 4. When it is remembered that a dental appliance supported on a hot plate would ordinarily extend at least 5 to $10 \mathrm{~mm}$ above the plate, it is obvious that the temperature variations from one part of the appliance to another would be so great that the appliance could not be hardened uniformly. Furthermore, no means is provided for measuring the temperature of the work or for allowing the work to cool slowly. The hot plate, therefore, is not a suitable heating device for carrying out this heat treatment.

TABLE 4.-Comparative temperature gradient above hot plate and inclosed shelf of oven

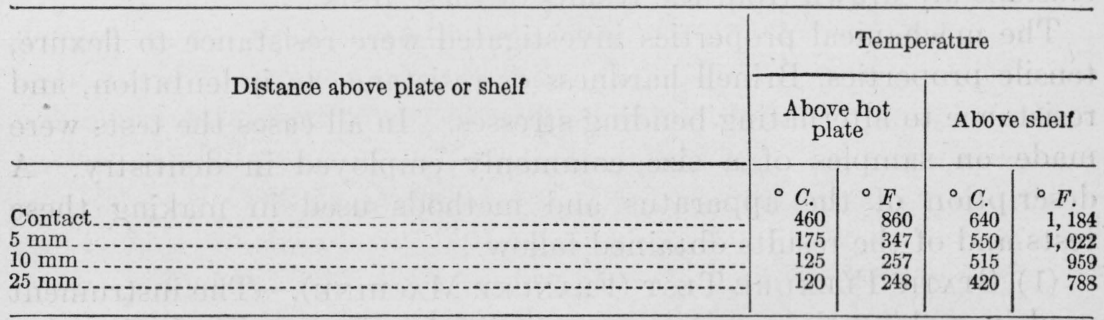

As will be seen from Table 4 the temperature above the shelf of the inclosed box-type oven is much more uniform. Further advantages of such a device are that it can readily be equipped with a rheostat for temperature control and a thermometer or other suitable device for measuring the temperature. Such a heating device when properly equipped and standardized has proved very satisfactory for hardening short specimens. For heat treating long test specimens the equipment shown in Figure 15 was used. The temperature 
in this furnace is very uniform and can be measured and controlled accurately.

It should be noted that the purpose of this investigation of the heat treatment of dental gold alloys was to develop efficient and practicable methods. No attempt was made to develop a theoretical explanation of the effects produced on the mechanical properties. Several authors of articles appearing in dental journals have stated that the hardening of these alloys, due to heat treatment, is caused by the formation of intermetallic compounds of gold and copper. Apparently these statements are based on the results of the extensive investigation of the binary alloys of gold and copper by Kurnakow, ${ }^{8}$ Zemczuzny, and Zasedatelev. While it seems probable that these statements are at least partly correct, it should be borne in mind that most of the dental gold alloys contain metals other than gold and copper, and that in some cases these other metals appear to have a marked influence on the hardening effect. A thorough investigation of the cause or causes of the hardening of the complex dental gold alloys, resulting in authoritative information on this subject, should prove a valuable contribution to the science of dental metallurgy.

(e) MECHANICAL PROPERTIES

As was stated in a previous section, the suitability of an alloy for any mechanical use should be judged principally by its mechanical properties. For this reason in the investigation of the wrought gold alloys the major part of the work was devoted to the determination of the mechanical properties of the various alloys and the possibility of improving these properties by heat treatment. Most of the conclusions are drawn from the results of these tests.

The mechanical properties investigated were resistance to flexure, tensile properties, Brinell hardness or resistance to indentation, and resistance to alternating bending stresses. In all cases the tests were made on samples of a size commonly employed in dentistry. A description of the apparatus and methods used in making these tests and of the results obtained follow.

(1) Static Flexure Test (Francke Machine).-The instrument used in making these tests was invented by the late W. J. Francke, of New Brunswick, N. J., and is fully described in a paper by Mr. Francke. ${ }^{9}$ The instrument is shown in Figure 16. A brief description of the test follows. One end of the sample under test is fastened in jaws, $J$, and the other carries a contact-indicating device, $C$. A pan and weight are added at $W$. The weight causes a deflection of the specimen, which is measured with the micrometer. If the point

\footnotetext{
8 Kurnakow, N.; Zemczuzny, S.; and Zasedatelev, M., "The transformations in alloys of gold with copper," J. Inst. of Metals, London, 15 p. 305; 1916.

Proc. Am. Soc. for Testing Materials, 20, p. 372; 1920.
} 


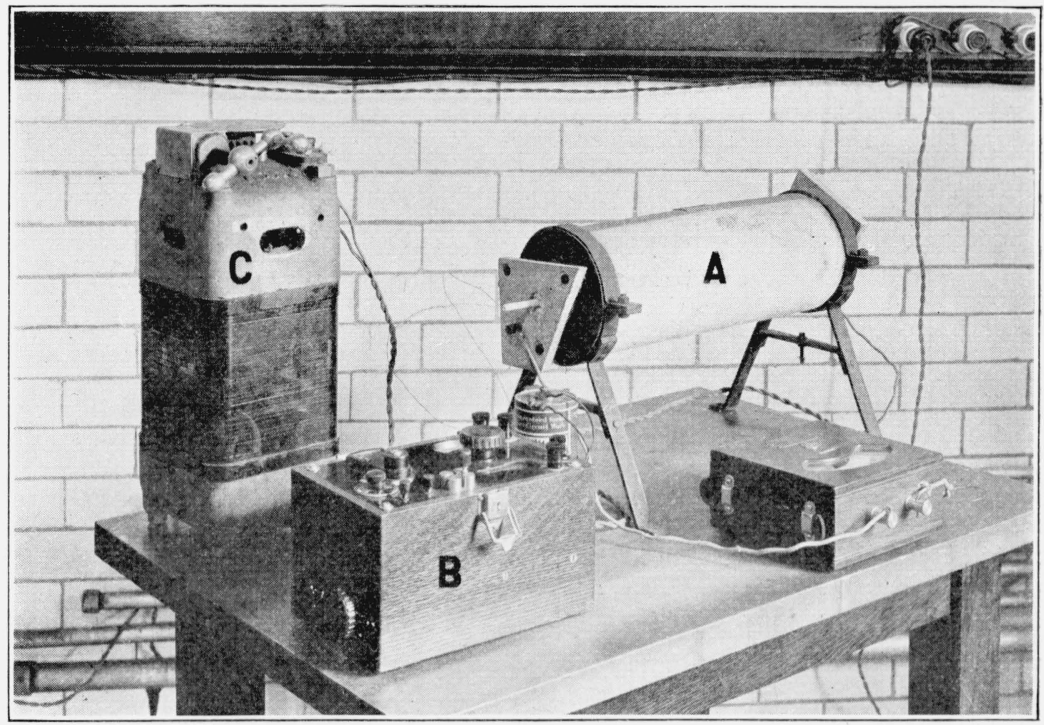

FIG. 15.-A pparatus for heat treating long wire test specimens

$A$, Electric furnace; $B$, Potentiometer and thermocouple used for measuring temperature; $C$, voltage regulator for controlling temperature.

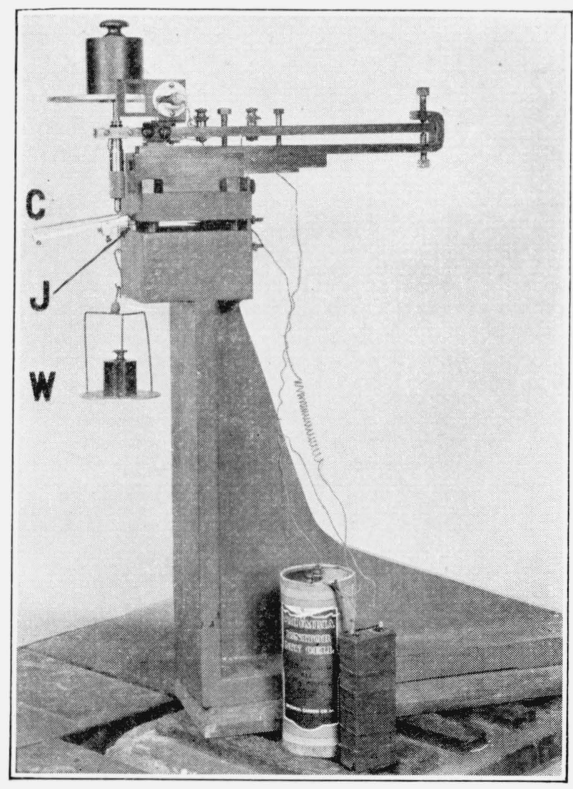

FIG. 16.-Francke machine for static flexure tests 
of the micrometer and the contact indicating device do not meet at the axis of the specimen, a correction must be applied to the observed deflection in order to obtain the true deflection. After the deflection is measured the weight is removed and the return of the sample is measured with the micrometer. The difference between the deflection and the return is the set or permanent deformation. By using samples of uniform dimensions and increasing the load by small increments it is possible to obtain relations between load, deflection, and set that furnish a basis of comparison of the different alloys, the effects of heat treatment, and other factors.

The samples used in this test were round wires 0.035 inch in diameter, and the effective length or the distance from the jaws to the point at which the load was applied was one-half inch. In order to eliminate variations in the size of wires of different manufacture all wires were purchased as No. 19 gauge ( 0.036 inch) and drawn to 0.035 inch in diameter through a diamond die.

This test was used as a check on the thermal emf method, described in a previous section, in establishing the proper heat treatments for the various alloys. The values obtained for some of the heat treatments given a single alloy (alloy A) are given in Table 5, and a summary of the values for all the wires tested is presented in Table 6 . In all cases at least three duplicate samples were tested and the average value reported. The relations between load, deflection, and set for two alloy A wires, one given the softening heat treatment and the other the hardening heat treatment, are represented graphically in Figure 17.

TABLE 5.-Effect of heat treatments on mechanical properties of alloy $A$

\begin{tabular}{|c|c|c|c|}
\hline Heat treatment & $\begin{array}{l}\text { Deflection } \\
\text { causing } \\
\text { set of } \\
0.005 \text { inch }\end{array}$ & $\begin{array}{l}\text { Load (A) } \\
\text { causing } \\
\text { set of } \\
0.005 \text { inch }\end{array}$ & $\begin{array}{l}\text { Load (B) } \\
\text { causing } \\
\text { set of } \\
0.010 \text { inch }\end{array}$ \\
\hline $\begin{array}{l}\text { Hard drawn } \\
325^{\circ} \mathrm{C} \text {, } 10 \text { minutes, quenched twice } \\
450^{\circ} \mathrm{C} \text {, } 10 \text { minutes, quenched } \\
600^{\circ} \mathrm{C} \text {., } 2 \text { minutes, quenched } \\
700^{\circ} \mathrm{C} \text {, } 2 \text { minutes, quenched }\end{array}$ & $\begin{array}{l}\text { Inch } \\
0.0585 \\
.0730 \\
.0785 \\
.0685 \\
.0420\end{array}$ & $\begin{array}{r}\text { Pounds } \\
1.32 \\
1.65 \\
1.76 \\
1.54 \\
.88\end{array}$ & $\begin{array}{r}\text { Pounds } \\
1.54 \\
1.87 \\
1.65 \\
.99\end{array}$ \\
\hline $\begin{array}{l}800^{\circ} \mathrm{C} ., 2 \text { minutes, quenched., } \\
700^{\circ} \text { C., quenched, } \\
325^{\circ} \text { C., } 10 \text { minutes, furnace cooled } \\
700^{\circ} \text { C., quenched. } \\
320-410^{\circ} \text { C., } 30 \text { minutes, air cooled in pan }\end{array}$ & $\begin{array}{r}.0480 \\
.0560 \\
.0510\end{array}$ & $\begin{array}{r}.88 \\
1.21 \\
1.10\end{array}$ & $\begin{array}{r}.99 \\
1.32 \\
1.27\end{array}$ \\
\hline $\begin{array}{l}700^{\circ} \mathrm{C} . \text {, quenched } \\
400^{\circ} \mathrm{C} ., 5 \text { minutes, furnace cooled. } \\
700^{\circ} \mathrm{C} \text {, quenched } \\
450^{\circ} \text { C., } 5 \text { minutes, furnace cooled. }\end{array}$ & $\begin{array}{r}.0600 \\
.0630\end{array}$ & $\begin{array}{l}1.21 \\
1.49\end{array}$ & $\begin{array}{l}1.38 \\
1.65\end{array}$ \\
\hline $\begin{array}{l}700^{\circ} \mathrm{C} \text {, quenched. } \\
450^{\circ} \mathrm{C} \text {., } 5 \text { minutes, air cooled in pan (room temperature in } 2 \frac{1}{2} \text { minutes) } \\
700^{\circ} \mathrm{C} \text {., quenched. } \\
500^{\circ} \mathrm{C} \text {., } 20 \text { minutes, furnace cooled } 20 \text { minutes }\end{array}$ & .0570 & $\begin{array}{l}1.27 \\
1.21\end{array}$ & $\begin{array}{l}1.38 \\
1.38\end{array}$ \\
\hline
\end{tabular}

$5619^{\circ}-28-2$ 
TABLE 6.-Results of flexure tests (Francke)

\begin{tabular}{|c|c|c|c|c|}
\hline Alloy & $\begin{array}{l}\text { Deflection } \\
\text { causing } \\
\text { set of } \\
0.005 \text { inch }\end{array}$ & $\begin{array}{l}\text { Load (A) } \\
\text { causing } \\
\text { set of } \\
0.005 \text { inch }\end{array}$ & $\begin{array}{l}\text { Load (B) } \\
\text { causing } \\
\text { set of } \\
0.010 \text { inch }\end{array}$ & B-A \\
\hline $\mathrm{A}\left\{\begin{array}{l}\text { Softened } \\
\text { Hardened }\left\{\begin{array}{l}\text { Softened } \\
\text { Hardened }{ }^{1}\end{array}\right.\end{array}\right.$ & $\begin{array}{l}\text { Inch } \\
0.0400 \\
.0510 \\
.0335 \\
.0595\end{array}$ & $\begin{array}{r}\text { Pounds } \\
0.88 \\
1.21 \\
.66 \\
1.21\end{array}$ & $\begin{array}{r}\text { Pounds } \\
0.99 \\
1.43 \\
.77 \\
1.54\end{array}$ & $\begin{array}{r}\text { Pounds } \\
0.11 \\
.22 \\
.11 \\
.33\end{array}$ \\
\hline $\mathrm{C}\left\{\begin{array}{l}\text { Softened } \\
\text { Hardened } \\
\mathrm{S}\left\{\begin{array}{l}\text { Softened } \\
\text { Hardened }\end{array}\right.\end{array}\right.$ & $\begin{array}{l}.0500 \\
.0600 \\
.0455 \\
.0490\end{array}$ & $\begin{array}{r}.99 \\
1.43 \\
.99 \\
1.10\end{array}$ & $\begin{array}{l}\text { 1. } 21 \\
1.76 \\
1.21 \\
1.32\end{array}$ & $\begin{array}{l}.22 \\
.33 \\
.22 \\
.22\end{array}$ \\
\hline $\mathbf{E}\left\{\begin{array}{l}\text { Softened } \\
\text { Hardened. }\left\{\begin{array}{l}\text { Softened } \\
\text { Hardened }\end{array}\right.\end{array}\right.$ & $\begin{array}{l}.0360 \\
.0385 \\
.0385 \\
.0510\end{array}$ & $\begin{array}{r}.77 \\
.88 \\
.77 \\
1.21\end{array}$ & $\begin{array}{r}.94 \\
1.10 \\
.99 \\
1.43\end{array}$ & $\begin{array}{l}.17 \\
.22 \\
.22 \\
.22\end{array}$ \\
\hline $\mathbf{H}\left\{\begin{array}{l}\text { Softened } \\
\text { Hardened } \\
\text { Hoftened } \\
\text { Hardened } 1 \text { [ardened }\end{array}\right.$ & $\begin{array}{l}.0380 \\
.0475 \\
.0390 \\
.0439 \\
.0630\end{array}$ & $\begin{array}{r}.99 \\
1.16 \\
.88 \\
.99 \\
1.49\end{array}$ & $\begin{array}{l}1.21 \\
1.43 \\
1.05 \\
1.21 \\
1.82\end{array}$ & $\begin{array}{l}.22 \\
.27 \\
.17 \\
.22 \\
.33\end{array}$ \\
\hline
\end{tabular}

1 Air cooled from $700^{\circ} \mathrm{C}$.

The values reported in Tables 5 and 6 are the deflection and load corresponding to a permanent set of 0.005 inch and the load necessary to produce a set of 0.010 inch. In Table 6 the difference between the load necessary to produce a set of 0.010 inch and that necessary to produce a set of 0.005 inch is given also. The load required to cause a set of 0.005 inch may be considered as an index of the stress to which the wire may be subjected without serious injury or without causing it to lose its shape. This is equivalent to the maximum force the wire may be made to exert without being permanently deformed when used as a spring. The deflection caused by this load is the distance through which the spring will exert force and one-half the product of these two (force times distance) is the work the spring will do or its resilency. The difference between the load necessary to cause a set of 0.005 inch and that to cause a set of 0.010 inch furnishes a basis for judging the relative manipulative qualities of the wires. If the difference is small, it indicates that, after an initial set $(0.005$ inch) has been produced, an additional load causes a relatively large deformation, or the wire is easily manipulated. If the difference is large, it has been found that in most cases the wire is brittle and will break readily when a large deformation or sharp bend is attempted.

Referring to Table 5, it will be noted that quenching alloy $\mathrm{A}$ from $600^{\circ}$ C. $\left(1,110^{\circ} \mathrm{F}\right.$.) or lower temperatures not only does not soften, but the heat treatment incident to the operation actually hardens or increases the resistance to flexure of the hard-drawn wire, as is evidenced by the increased load necessary to cause a permanent set of 0.005 inch. Quenching from $700^{\circ}$ C. $\left(1,290^{\circ}\right.$ F.) or over produced the greatest softening effect. Other tests not included in this table 
seemed to indicate that quenching from temperatures higher than $800^{\circ}$ C. $\left(1,470^{\circ}\right.$ F. $)$ is not desirable because of a slight deterioration in the mechanical properties of the alloy. In the lower part of the table values are given showing the effect of additional heat treatment after quenching from $700^{\circ} \mathrm{C}$. $\left(1,290^{\circ} \mathrm{F}\right.$.). Heating to temperatures below $300^{\circ}$ C. $\left(570^{\circ}\right.$ F.) had little, if any, effect. Heating at temperatures ranging from $325^{\circ}$ to $500^{\circ} \mathrm{C}$. $\left(615^{\circ}\right.$ to $1,110^{\circ} \mathrm{F}$.) or slow cooling from these temperatures had a marked hardening effect, the magnitude of the effect increasing as the temperature was raised to

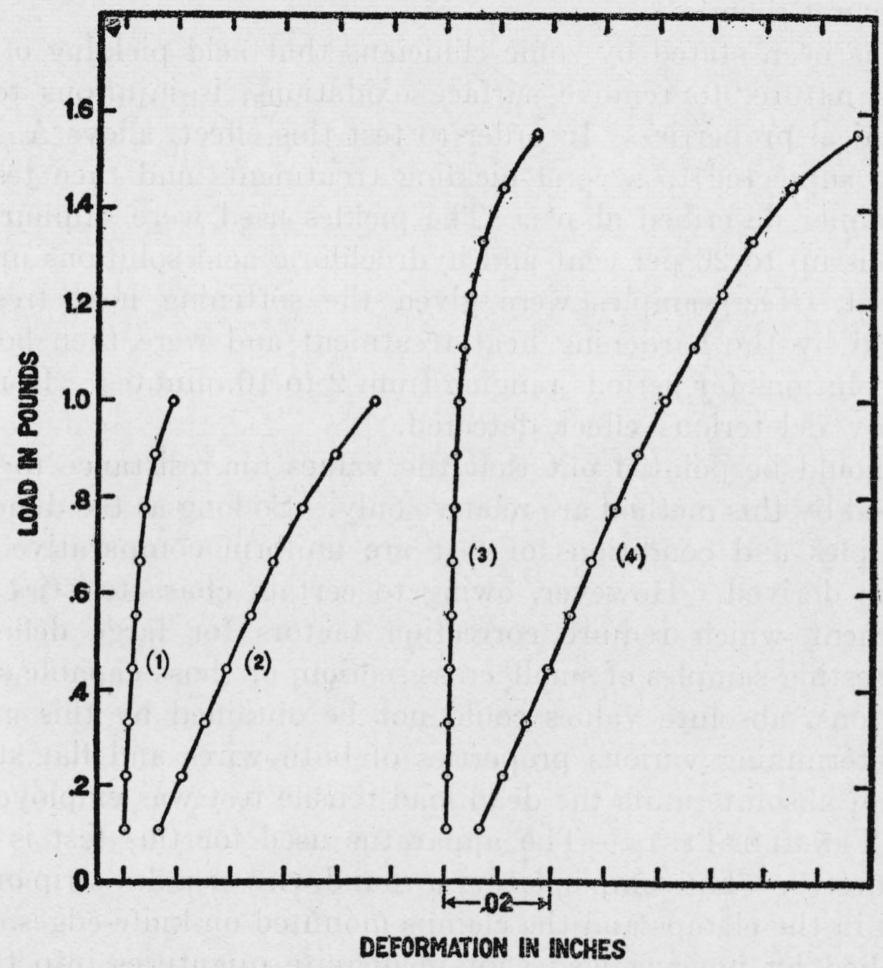

Fig. 17.-Graphical representation of results of static flexure tests

(1) and (2) represent the permanent set and total deformation, respectively, of a sample of alloy A softened; (3) and (4) represent the permanent set and total deformation, respectively, of a sample of alloy A hardened.

$450^{\circ} \mathrm{C}$. $\left(840^{\circ} \mathrm{F}\right.$.) and also as the rate of cooling was decreased. The maximum effect was obtained by cooling from $450^{\circ} \mathrm{C}$. $\left(840^{\circ} \mathrm{F}\right.$.) to room temperature in about three hours, this being the slowest rate of cooling employed. As the temperature was raised above $450^{\circ} \mathrm{C}$. $\left(840^{\circ}\right.$ F.) no additional hardening was noted when the alloy was cooled slowly, and when it was held at a constant temperature the effect was decreased. These findings were verified by similar tests on other alloys. The rate of cooling adopted was from $450^{\circ} \mathrm{C}$. $\left(840^{\circ} \mathrm{F}\right.$.) to $250^{\circ} \mathrm{C}$. $\left(480^{\circ} \mathrm{F}\right.$.) in one-half hour, as it was found that 
slower rates gave only very slightly increased effects unless a rate so slow as to be impracticable was used.

By referring to Table 6 it will be noted that all the wires in this group were tested in both the softened and hardened conditions. The heat treatments, except in the case of alloy B, hardened, and one series of alloy $\mathrm{H}$ wires, were those defined in the section on heat treatment. The two alloys mentioned were hardened by air cooling from $700^{\circ} \mathrm{C}$. $\left(1,290^{\circ} \mathrm{F}\right.$.), as this treatment corresponds to the recommendations of their respective manufacturers in so far as we were able to interpret them.

It has been stated by some clinicians that acid pickling of alloys of this nature, to remove surface oxidations, is injurious to their mechanical properties. In order to test this effect, alloys $\mathrm{A}, \mathrm{E}$, and $\mathrm{F}$ were subjected to several pickling treatments and then tested in the manner described above. The pickles used were sulphuric acid solutions up to 20 per cent and hydrochloric acid solutions up to 33 per cent. The samples were given the softening heat treatment followed by the hardening heat treatment and were then boiled in these solutions for periods ranging from 2 to 10 minutes. In no case was any deleterious effect detected.

It should be pointed out that the values for resistance to flexure obtained by this method are relative only. So long as the dimensions of samples and conditions of test are uniform comparative values may be derived. However, owing to certain characteristics of the instrument which require correction factors for large deflections, when testing samples of small cross section, or those capable of large deflections, absolute values could not be obtained by this method. For determining various properties of both wires and flat stock in terms of absolute units the dead load tensile test was employed.

(2) Tensile Tests.-The apparatus used for this test is shown in Figure 18. The sample, either a round wire or a flat strip or band, is held in the clamps and the clamps mounted on knife-edges. Load is applied by pouring lead shot in definite quantities into the pail suspended from the lower end of the sample. The extensometer shown in the figure indicates the deformations by means of the dial micrometer. The extensometer illustrated was used for wires. A modification of this employing two dial micrometers, one on each flat side, was used for strips. Loads and the corresponding deformations were recorded in the usual manner until a stress well above the proportional limit was reached. The extensometer was then removed and loads applied until the sample failed.

All wires tested were purchased as No. 19 gauge (0.036 inch in diameter) and drawn through the 0.035 inch diamond die previously mentioned. The strips were purchased as 0.23 inch wide and 0.006 inch thick. The variations in dimensions were determined by meas- 
B. S. Journal of Research, RP32

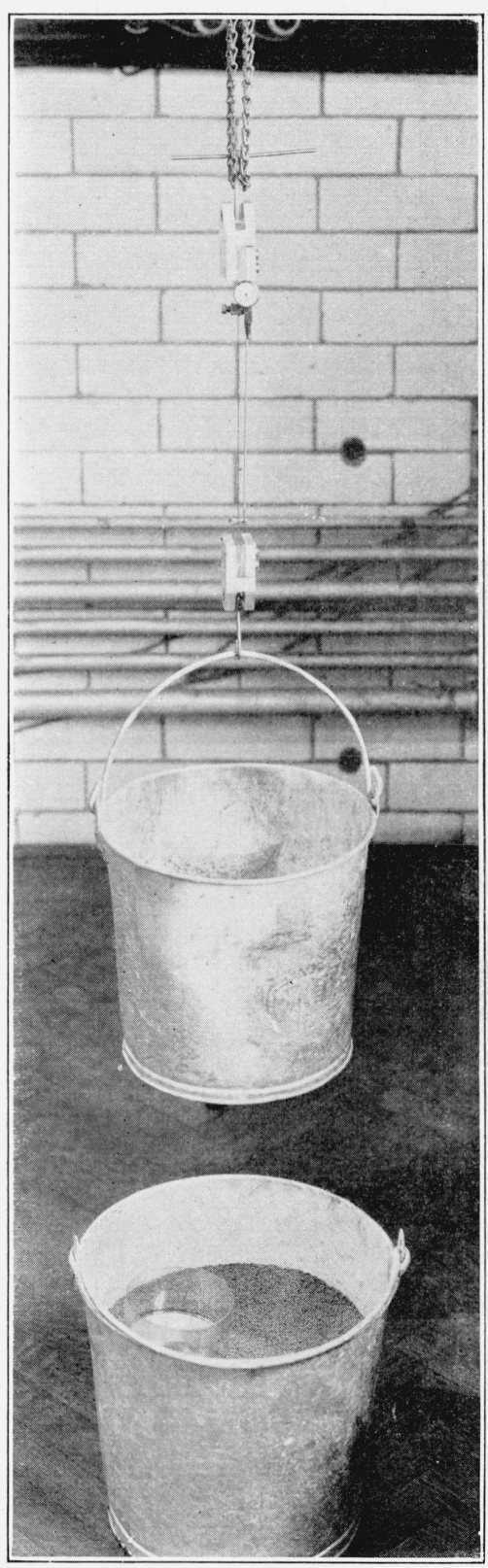

FIG. 18.-Equipment for making deadload tensile tests on wires and strips 
uring each strip at several points. All samples, except where otherwise stated, were 12 inches long and the gauge length over which deformation was measured was 8 inches. The errors in the loads did not exceed 0.1 per cent, and errors in the readings of the extensometer did not exceed 0.0002 inch. Tests were made on at least three duplicate samples for each heat treatment of each alloy and the average value for each heat treatment reported.

Definitions of the properties determined by this test are listed below. Brinell hardness also is defined at this time because it is closely associated with the tensile properties. A brief discussion of the practical significance of these properties is included.

Proportional limit.- The stress at which the deformation as determined by the extensometer ceases to be proportional to the load. In the case of the wrought alloys tested, it was found that deformation was not strictly proportional to stress even for very low stresses. In these tests the load increments were uniform and the proportional limit was taken as that stress at which the next increase in load caused an increase in deformation exceeding the previous mean increment by 10 per cent. For practical purposes this may be regarded as the stress at which the initial permanent deformation occurs. Remembering that when a clasp, bar, or similar appliance is distorted or bent out of its proper shape by the forces to which it is subjected in use, certain parts of the appliance are subjected to tensile stress, it is readily seen that the proportional limit of the material of which the appliance is made is an index of the ability of the appliance to maintain its proper shape in service. It is equally true that the proportional limit is an index of the resistance of the material to bending or adjusting to the desired shape.

Ultimate strength.-The stress causing rupture of the specimen. This is an index of the stress an appliance will withstand without failing due to breakage.

Elongation.-The increase in length measured after rupture expressed in percentage of the original gauge length. The elongation is an index of the extent to which the material may be permanently stretched or bent before failure. This property has a direct bearing on the suitability of materials for making appliances that must be bent, swaged, or burnished to shape.

Modulus of elasticity.-Ratio of stress within the proportional limit to the corresponding strain or deformation. It is a measure of stiffness or the force required to produce a given elastic deformation.

Modulus of resiliency.-The potential energy stored up in unit volume of material stressed to the proportional limit. The value depends upon the proportional limit and the modulus of elasticity and is a measure of the work the material can do with safety when used as a spring. 
Brinell hardness.- Ratio of load on a sphere used to indent the material tested to the area of the spherical indentation produced. Usually the hardness number is derived from measurements of the diameter of the indentation, from which the spherical area can be computed. It is an index of the resistance of the material to indentation and should be considered in selecting suitable materials of which to make crowns, inlays, or other appliances which are to be subjected to direct stresses such as may be set up by the cusps of opposing teeth.

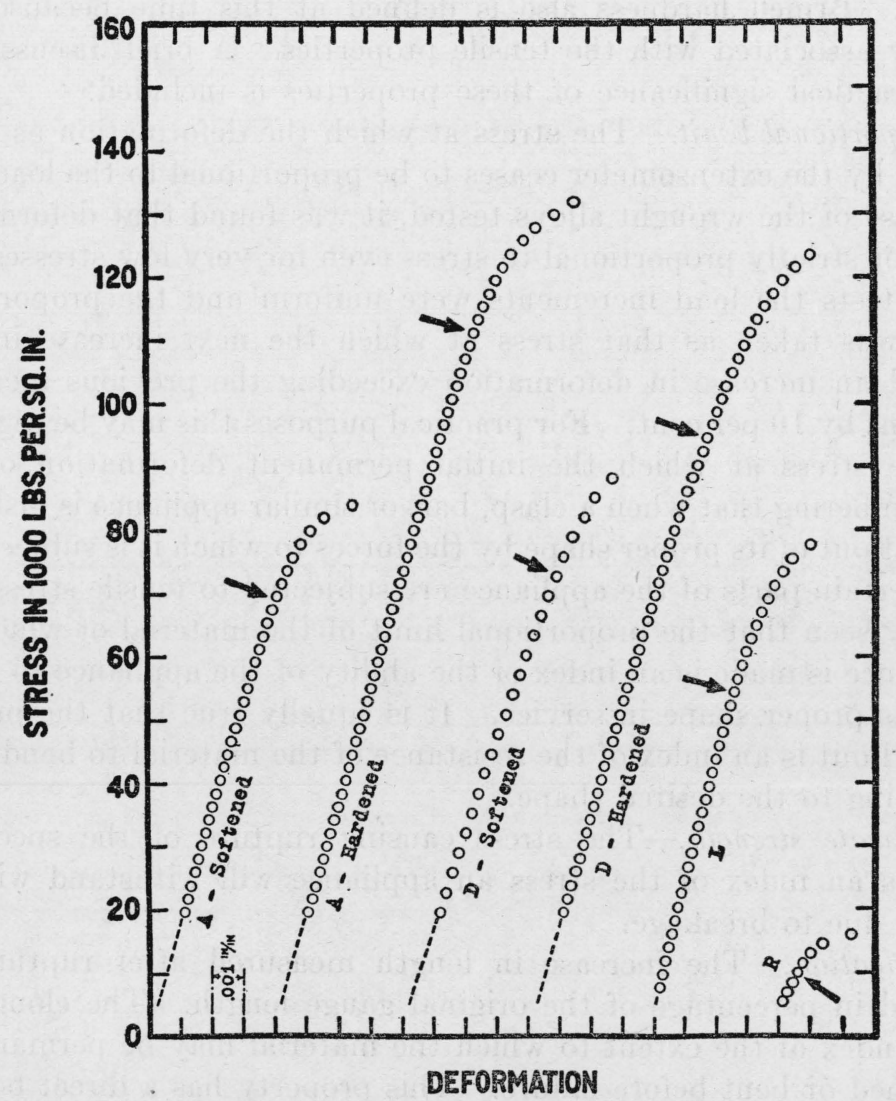

FIG. 19.-Stress-strain curves derived from tensile tests of wrought gold alloys

Proportional limits are indicated by the arrows

The values obtained for all wires and strips tested are summarized in Tables 7 and 8. The stress-strain relations for four wires, $\mathbf{A}$ softened, A hardened, D softened, and D hardened, and two strips, $L$ and $R$, are shown graphically in Figure 19.

By referring to Table 7 it will be noted that the hardening heat treatment caused an increase in proportional limit and tensile strength for all wires tested except alloy G. The hardening heat treatment 
previously described was employed for all of these alloys except alloy $\mathrm{B}$ and one series of alloy $\mathrm{H}$. These were given the treatment recommended by their respective manufacturers, namely, cooling in air from approximately $700^{\circ}$ C. $\left(1,290^{\circ}\right.$ F.). The wires developing the highest tensile strengths in the hardened condition were alloys $\mathrm{H}, \mathrm{C}$, and $\mathrm{A}$ in the order named. Of these, alloy $\mathrm{A}$, with an ultimate strength of $153,000 \mathrm{lbs} . / \mathrm{in} .^{2}$, had the highest elongation, 7.5 per cent in 8 inches. This was the highest elongation of any hardened wire tested, with the exception of alloy $\mathrm{H}$, air cooled from $700^{\circ} \mathrm{C}\left(1,290^{\circ}\right.$ F.), which developed a much lower ultimate strength.

TABLE 7.-Tensile properties of wire ${ }^{1}$

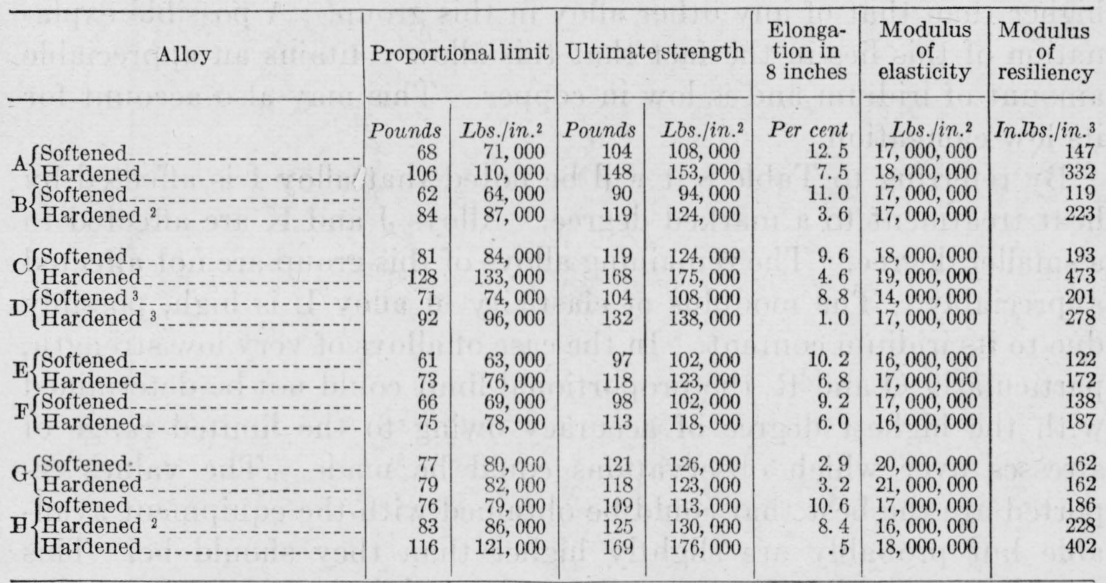

1 All wires of 0.035 inch diameter.

${ }^{3} 10$ inches total length; 6 inches gauge length.

${ }^{2}$ Air cooled from $700^{\circ} \mathrm{C}$

TABLE 8.-Tensile properties and hardness of band and plate material ${ }^{1}$

\begin{tabular}{|c|c|c|c|c|c|c|c|}
\hline All & $\begin{array}{l}\text { Propor- } \\
\text { tional } \\
\text { limit }\end{array}$ & $\begin{array}{l}\text { Ultimate } \\
\text { strength }\end{array}$ & $\begin{array}{l}\text { Elonga- } \\
\text { tion in } \\
8 \text { inches }\end{array}$ & $\begin{array}{c}\text { Modulus } \\
\text { of } \\
\text { elasticity }\end{array}$ & $\begin{array}{c}\text { Modulus } \\
\text { of } \\
\text { resiliency }\end{array}$ & $\begin{array}{c}\text { Brinell } \\
\text { hardness } \\
\text { number }\end{array}$ & $\frac{\text { U. T. S. }{ }^{2}}{\text { B. H. N. }{ }^{3}}$ \\
\hline $\begin{array}{l}\mathrm{I}\left\{\begin{array}{l}\text { Softened } \\
\text { Hardened }\end{array}\right. \\
\mathrm{J}\left\{\begin{array}{l}\text { Softened } \\
\text { Hardened }\end{array}\right.\end{array}$ & $\begin{array}{r}\text { Lbs./in. }{ }^{2} \\
58,000 \\
116,000 \\
56,000 \\
89,000\end{array}$ & $\begin{array}{r}\text { Lbs./in. }{ }^{2} \\
98,000 \\
157,000 \\
90,000 \\
118,000\end{array}$ & $\begin{array}{r}\text { Per cent } \\
12.1 \\
4.6 \\
10.1 \\
2.2\end{array}$ & $\begin{array}{c}\text { Lbs./in. }{ }^{2} \\
16,000,000 \\
18,000,000 \\
15,000,000 \\
16,000,000\end{array}$ & \begin{tabular}{|r|} 
In.lbs./in..$^{3}$ \\
103 \\
384 \\
102 \\
249
\end{tabular} & $\begin{array}{l}155 \\
230 \\
145 \\
185\end{array}$ & $\begin{array}{r}0.63 \\
.68 \\
.62 \\
.64\end{array}$ \\
\hline $\begin{array}{c}\mathrm{K}\left\{\begin{array}{l}\text { Softened } \\
\text { Hardened }\end{array}\right. \\
\mathrm{I}\left\{\begin{array}{l}\text { Softened } \\
\text { Hardened }\end{array}\right.\end{array}$ & $\begin{array}{l}57,000 \\
69,000 \\
50,000 \\
54,000\end{array}$ & $\begin{array}{r}94,000 \\
104,000 \\
88,000 \\
91,000\end{array}$ & $\begin{array}{r}19.2 \\
15.5 \\
4.6 \\
3.7\end{array}$ & $\begin{array}{l}17,000,000 \\
18,000,000 \\
20,000,000 \\
21,000,000\end{array}$ & $\begin{array}{r}94 \\
132 \\
62 \\
70\end{array}$ & $\begin{array}{l}140 \\
150 \\
145 \\
150\end{array}$ & $\begin{array}{l}.67 \\
.69 \\
.61 \\
.61\end{array}$ \\
\hline $\begin{array}{c}\mathrm{M}\left\{\begin{array}{l}\text { Softened } \\
\text { Hardened }\end{array}\right. \\
\mathrm{N}\left\{\begin{array}{l}\text { Softened } \\
\text { Hardened }\end{array}\right.\end{array}$ & $\begin{array}{l}31,000 \\
44,000 \\
25,000 \\
29,000\end{array}$ & $\begin{array}{l}86,000 \\
90,000 \\
59,000 \\
60,000\end{array}$ & $\begin{array}{r}9.9 \\
10.6 \\
18.8 \\
15.6\end{array}$ & $\begin{array}{l}16,000,000 \\
15,000,000 \\
13,000,000 \\
14,000,000\end{array}$ & $\begin{array}{l}31 \\
64 \\
23 \\
30\end{array}$ & $\begin{array}{r}140 \\
140 \\
85 \\
90\end{array}$ & $\begin{array}{l}.61 \\
.64 \\
.69 \\
.67\end{array}$ \\
\hline $\begin{array}{l}\mathrm{O}\left\{\begin{array}{l}\text { Softened } \\
\text { Hardened }\end{array}\right. \\
\mathrm{P}\left\{\begin{array}{l}\text { Softened } \\
\text { Hardened }\end{array}\right.\end{array}$ & $\begin{array}{l}21,000 \\
21,000 \\
13,000 \\
13,000\end{array}$ & $\begin{array}{l}55,000 \\
54,000 \\
48,000 \\
48,000\end{array}$ & $\begin{array}{l}28.9 \\
26.2 \\
23.9 \\
20.0\end{array}$ & $\begin{array}{l}13,000,000 \\
13,000,000 \\
14,000,000 \\
17,000,000\end{array}$ & $\begin{array}{r}17 \\
17 \\
6 \\
5\end{array}$ & $\begin{array}{l}90 \\
90 \\
70 \\
65\end{array}$ & $\begin{array}{l}.61 \\
.60 \\
.69 \\
.74\end{array}$ \\
\hline $\begin{array}{l}\mathrm{Q}\left\{\begin{array}{l}\text { Softened } \\
\text { Hardened }\end{array}\right. \\
\mathrm{R}\left\{\begin{array}{l}\text { Softened } \\
\text { Hardened }\end{array}\right.\end{array}$ & $\begin{array}{r}11,000 \\
12,000 \\
9,000 \\
10,000\end{array}$ & $\begin{array}{l}37,000 \\
38,000 \\
35,000 \\
35,000\end{array}$ & $\begin{array}{l}17.5 \\
19.6 \\
23.7 \\
20.5\end{array}$ & $\begin{array}{l}12,000,000 \\
12,000,000 \\
10,000,000 \\
11,000,000\end{array}$ & $\begin{array}{l}5 \\
6 \\
3 \\
4\end{array}$ & $\begin{array}{l}60 \\
60 \\
50 \\
55\end{array}$ & $\begin{array}{l}.62 \\
.63 \\
.70 \\
.64\end{array}$ \\
\hline
\end{tabular}


Values for a series of alloy $\mathrm{H}$ wires given the standard hardening heat treatment are included in Table 7 for the purpose of illustrating the effect of the rate of cooling. It will be noted that both the proportional limit and the ultimate strength are greatly increased by the slower cooling, while the elongation drops from 10.6 per cent for the quenched and 8.4 per cent for the air cooled to only 0.5 per cent. The other alloys tested were found to be affected in the same way, though to a smaller degree.

Alloy $\mathrm{G}$ was not susceptible to hardening by any of the heat treatments tried. This may be due in part to the low copper content. It will also be noted that the modulus of elasticity of alloy $\mathrm{G}$ is higher than that of any other alloy in this group. A possible explanation of this lies in the fact that this allow contains an appreciable amount of iridium and is low in copper. This may also account for its low elongation.

By referring to Table 8 it will be noted that alloy $\mathrm{I}$ is affected by heat treatment to a marked degree. Alloys $J$ and $K$ are affected to a smaller degree. The remaining alloys of this group are not affected appreciably. The modulus of elasticity of alloy L is high, possibly due to its iridium content. In the case of alloys of very low strength, particularly $\mathrm{Q}$ and $\mathrm{R}$, the proportional limit could not be determined with the highest degree of accuracy owing to the limited range of stresses over which observations could be made. The values reported are the best that could be obtained with the equipment available but probably are slightly higher than they should be. This would account for the low values for modulus of elasticity. The importance of these alloys, $\mathrm{Q}$ and $\mathrm{R}$, was not considered sufficient to warrant the construction of apparatus for determining these values with greater precision.

(3) Brinell Hardness.-The instrument ${ }^{10}$ used for making these determinations is a modification of the standard Brinell hardness tester and was designed especially for testing small samples. A photograph of the instrument is shown in Figure 20. The ball is hardened steel $1.6 \mathrm{~mm}\left(\frac{1}{16} \mathrm{inch}\right)$ in diameter, and for the wrought alloys a load of $6.4 \mathrm{~kg}$ (14.1 pounds) was used. This combination is equivalent to a $10 \mathrm{~mm}$ ball and $250 \mathrm{~kg}$ load. The samples used for this test were strips approximately 0.23 inch wide and 0.006 inch thick. While samples of these dimensions are too thin for the determination of hardness with the highest degree of accuracy, the values obtained bear a definite relation to the true hardness and are comparable. Tests of several alloys using supporting anvils varying in hardness from that of hardened steel to that of bronze indicated that this factor had no appreciable influence on the values

\footnotetext{
10 Goodale, S. L., and Banks, R. M., "Development of Brinell hardness tests on thin sheet brass,"
} Proc. A. S. T. M., 19 (pt. 2), p. 757; 1919. 


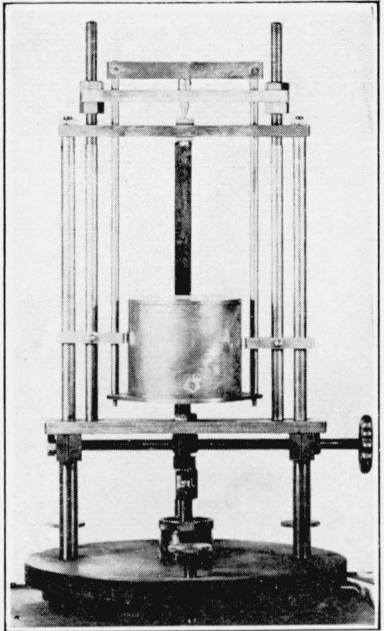

FIG. 20.-Instrument for determining Brinell hardness of small samples

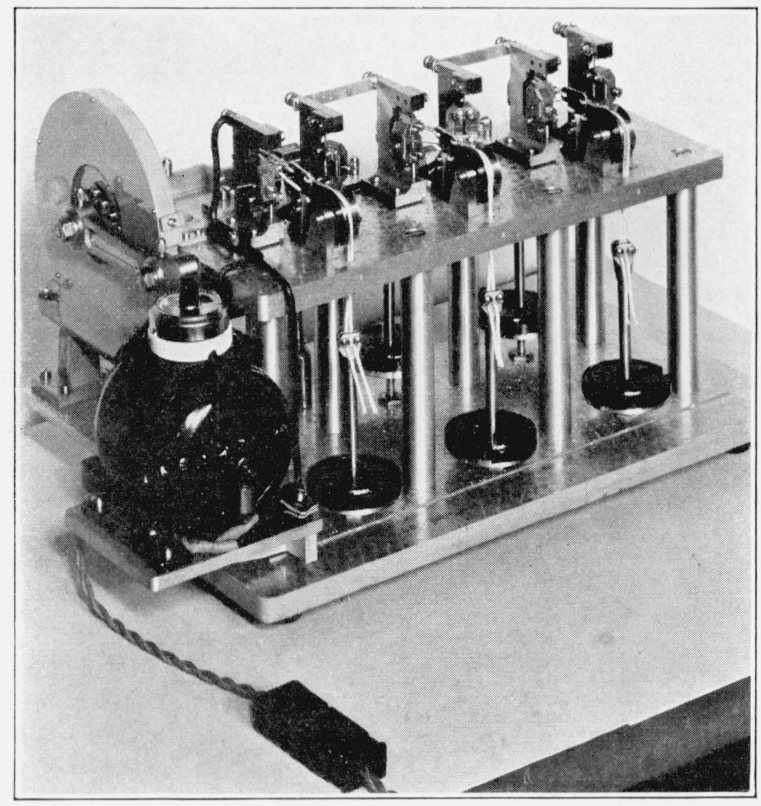

FIG. 21.-Dead-load flexure machine for making tests of the relative life of alloys subjected to repeated stresses 
obtained. The Brinell harness numbers of all strips tested, in both the softened and hardened states, are given in Table 8 . Hardness determinations were also made on all strips as purchased, as a matter of record. As these values are thought to be of little importance to the dentist, they are not included in this report.

The ratio, ultimate tensile strength in 1,000 lbs./in. ${ }^{2}$ divided by Brinell hardness number, is also given in Table 8. From these values the relation between these two properties for alloys of this group, excepting only alloy $\mathrm{P}$ hardened, may be written as $S=(0.65$ $\pm 0.05) H$, where $S$ is tensile strength in $1,000 \mathrm{lbs}$. $/ \mathrm{in} .^{2}$ and $H$ is Brinell hardness number.

(4) Life Tests (Repeated Stresses).- - It is well known to many dentists that clasps, both wrought and cast, orthodonthia spring wires, and other appliances that are subjected to repeated stresses, such as those induced by mastication or the removal and insertion of the appliance in the mouth, often give good service for a time but eventually fail, due to breakage, even when there is no evidence that the appliance has been subjected to abnormal usage or abuse. Such failures have been attributed to "crystallization" and numerous other causes, but are now generally recognized as being due to fatigue or the effect of stress applied a great number of times. It appeared desirable, therefore, to obtain some data on the relative resistance of the various dental gold alloys to these repeated stresses.

Although a great deal of data on the fatigue resistance of a number of ferrous and nonferrous alloys had been published, no report of such data on dental gold alloys was found in the literature. None of the machines commonly employed in determining fatigue resistance appeared to be entirely suitable for testing samples of the size used in dentistry. It was necessary, therefore, to design and construct a special machine for thisinvestigation. In designing this machine valuable advice and assistance was received from the staff of the bureau's laboratory of engineering mechanics and other members of the bureau's staff familiar with fatigue testing. A number of designs were suggested and rejected because of defects. A photograph of the machine built according to the design finally adopted is shown in Figure 21.

A brief description of the operation of this machine follows. The sample under test is supported in a horizontal position between one of the three pairs of upright holders shown at the top of the photograph. A yoke is placed over the sample midway of the holders, and cords fastened to either side of the yoke pass over pulleys and support weights. These weights are lifted alternately by means of a rocker arm driven by the motor shown at the left of the photograph. As the weight on one side is lifted the one on the other side is allowed to hang suspended from the sample under test. Thus the sample is subjected to a bending stress first in one direction and then in the 
other. The magnitude of the stress can be varied at will by adjusting the weights. The number of applications of stress is recorded by means of a revolution counter, and the operation is continued until the test specimen fails.

The fatigue resistance of a material is usually expressed as the maximum stress which a specimen will endure for any number of repetitions, or as the stress at which the specimen endures a definite number of alternations of stress. In order to determine these values it is necessary to test specimens at each of a number of stresses, a procedure which would require a great deal of time, especially with a low-speed machine, such as the one used in this investigation. For this reason it was decided to use as an index of the relative fatigue resistance, or life, of the dental gold alloys of this group the number of alternations of a definite stress endured by each alloy. Accordingly a load was selected that would cause failure of most of the alloys between 10,000 and 100,000 reversals.

The specimens used were round wires 0.035 inch in diameter, accurately sized by drawing through the diamond die previously mentioned. The length of the specimen between supports was 2 inches, and the load used was 14 ounces. With this combination the theoretical maximum fiber stress set up in the test specimen was calculated to be approximately $100,000 \mathrm{lbs}$. $/$ in. $^{2}$ The selection of a markedly different stress value will undoubtedly change slightly the relative arrangement or order of failure, but such changes as are necessary to produce an arrangement differing appreciably from that reported do not appear to be justified from service conditions.

At least three duplicate samples of each material were tested and the average value reported. The values obtained are given in Table 9. These indicate a marked variation in the life or length of service to be expected of the different materials. It will be noted that for all alloys, except alloy $\mathrm{G}$, tested in both the softened and hardened conditions, the life value is greatly increased by the hardening heat treatment. As the other mechanical properties of alloy $\mathrm{G}$ were not susceptible to improvement by heat treatment, it was not expected that such treatment would greatly affect its life value. In the case of alloy A, however, the useful life was increased fivefold. This furnishes a very striking example of the benefits to be derived from properly heat treating alloys of this character.

TABLE 9.-Results of flexure life tests: Number of reversals to cause failure ${ }^{1}$

\begin{tabular}{|c|c|c|c|c|c|c|c|c|}
\hline & \multicolumn{8}{|c|}{ Alloy } \\
\hline & A & B & $\mathrm{C}$ & D & $\mathrm{E}$ & F & G & H \\
\hline $\begin{array}{l}\text { Softened } \\
\text { Hardened...-. }\end{array}$ & $\begin{array}{l}15,000 \\
75,000\end{array}$ & $\begin{array}{r}4,000 \\
15,000\end{array}$ & $\begin{array}{l}23,500 \\
88,500\end{array}$ & 23,50 & 18,000 & 25,000 & $\begin{array}{l}19,000 \\
24,000\end{array}$ & $\begin{array}{l}41,000 \\
58,000\end{array}$ \\
\hline
\end{tabular}

1 Average of several tests given to nearest 500 . 


\section{CAST ALLOYS}

(a) CHEMICAL COMPOSITION

As a preliminary survey of the field, in order to determine something of the general nature and variations likely to be encountered in dental casting golds, chemical analyses were made of a number of selected alloys. The analyses were made by William H. Swanger, research associate, and Dr. R. Gilchrist, chemist, Bureau of Standards. The methods ${ }^{11}$ employed in analyzing these alloys were the same as those used in connection with the wrought alloys. The chemical compositions, together with the uses recommended for these alloys by their respective manufacturers, are given in Table 10. In many instances the properties of the alloys as stated by their manufacturers are also included.

Alloys XXVII, XXVIII, XXIX, XXX, S-III, S-IV, and S-V were made up by the cooperating laboratories as being representative of various grades of material as indicated in the table. In the case of the solders it should be noted that they are representative of the higher gold content solders employed for the purposes indicated. Of this group only one, alloy XXVIII, was analyzed. The analysis and batch formula of this alloy agreed within the limits of accuracy of the analysis. The compositions reported for this group of alloys are the batch formulas.

TABLE 10.-Chemical composition of casting golds (per cent by weight)

\begin{tabular}{|c|c|c|c|c|c|c|c|c|c|c|}
\hline Alloy & Gold & Silver & $\begin{array}{l}\text { Cop- } \\
\text { per }\end{array}$ & $\begin{array}{l}\text { Plati- } \\
\text { num }\end{array}$ & $\begin{array}{l}\text { Palla- } \\
\text { dium }\end{array}$ & $\begin{array}{l}\text { Nick- } \\
\text { el }\end{array}$ & Zine & $\begin{array}{l}\text { Irid- } \\
\text { ium }\end{array}$ & Tin & $\begin{array}{l}\text { Uses and claims as stated by } \\
\text { manufacturers }\end{array}$ \\
\hline I & 71.3 & 7.1 & 9.9 & 10.62 & & & 0.08 & 0.14 & 0.83 & $\begin{array}{l}\text { For casting clasps and bars; extra } \\
\text { hard; gold color; melting point, } \\
1,750^{\circ} \text { F }\end{array}$ \\
\hline II & 78.0 & 10.0 & 5.9 & 6.1 & & & & .1 & & $\begin{array}{l}\text { For hard inlays, abutments and } \\
\text { three-quarter crowns. }\end{array}$ \\
\hline IIII & 60.0 & 11.0 & 8.8 & 13.1 & 5. 94 & & .72 & .10 & .14 & $\begin{array}{l}\text { For cast clasps; melting point, } \\
1.960^{\circ} \mathrm{F} \text {, platinum color. }\end{array}$ \\
\hline IV & 71.4 & 6.0 & 15.6 & 2. 78 & & 1. 98 & 2. 38 & & & $\begin{array}{l}\text { For clasps, saddles, arches, and } \\
\text { bars; for casting clasps and sad- } \\
\text { dles in one piece; very tough, } \\
\text { strong, and springy; fusing }\end{array}$ \\
\hline $\mathrm{V}$ & 62.8 & 13.9 & 18.9 & & & 2. 57 & 1.92 & & & $\begin{array}{l}\text { For clasps, saddles, bars, etc.; } \\
\text { one-piece castings. }\end{array}$ \\
\hline VI & $\begin{array}{l}59.3 \\
59.8\end{array}$ & 8.1 & 12. 7 & 15.95 & 3.55 & & .08 & & & For cast clasps; 21 per cent plat. \\
\hline 1 VIII & $\begin{array}{l}59.8 \\
65.9\end{array}$ & $\begin{array}{r}13.5 \\
5.9\end{array}$ & $\begin{array}{l}\text { 13. } 6 \\
10.2\end{array}$ & $\begin{array}{r}5.22 \\
10.58\end{array}$ & $\begin{array}{l}7.10 \\
5.69\end{array}$ & & 1. 67 & .20 & & $\begin{array}{l}\text { For clasps; } 14 \text { per cent plat. } \\
\text { A cast-clasp alloy containing } \\
\text { gold, platinum, palladium, and } \\
\text { rhodium; high elasticity and } \\
\text { strength; melting point, } 2,105^{\circ}\end{array}$ \\
\hline IX & 64.9 & 12.5 & 10. 0 & 12. 23 & & & .03 & .14 & .1 & $\begin{array}{l}\text { For clasps, bars, crown posts, } \\
\text { bridge construction, soldered or } \\
\text { cast; tough and springy. }\end{array}$ \\
\hline $\mathrm{X}$ & 68.3 & 11.1 & 13.9 & 2.86 & 2. 89 & .93 & .05 & & & $\begin{array}{l}\text { For clasps, lingual and palatal } \\
\text { bars and saddles; gold color; }\end{array}$ \\
\hline $\mathrm{XI}$ & 64.4 & 7. 2 & 10.4 & 11.15 & 5. 74 & .16 & 1.07 & & & $\begin{array}{l}\text { Cast-clasp metal; unexcelled in } \\
\text { strength; high platinum per- }\end{array}$ \\
\hline $\mathrm{XII}$ & 65.4 & 5.4 & 11.8 & 10.80 & 5. 64 & .05 & 1. 09 & & & $\begin{array}{l}\text { Cast clasp metal; excellent for } \\
\text { white clasp work; rich in plat- } \\
\text { inum. }\end{array}$ \\
\hline
\end{tabular}

${ }_{1}$ Manganese present, but less than 0.01 per cent. Rhodium present, 0.56 per cent, about one-third of which appeared not to be alloyed with the rest of the metal.

11 See footnote 4, p. 869. 
TABLE 10.-Chemical composition of casting golds (per cent by weight)-Continued

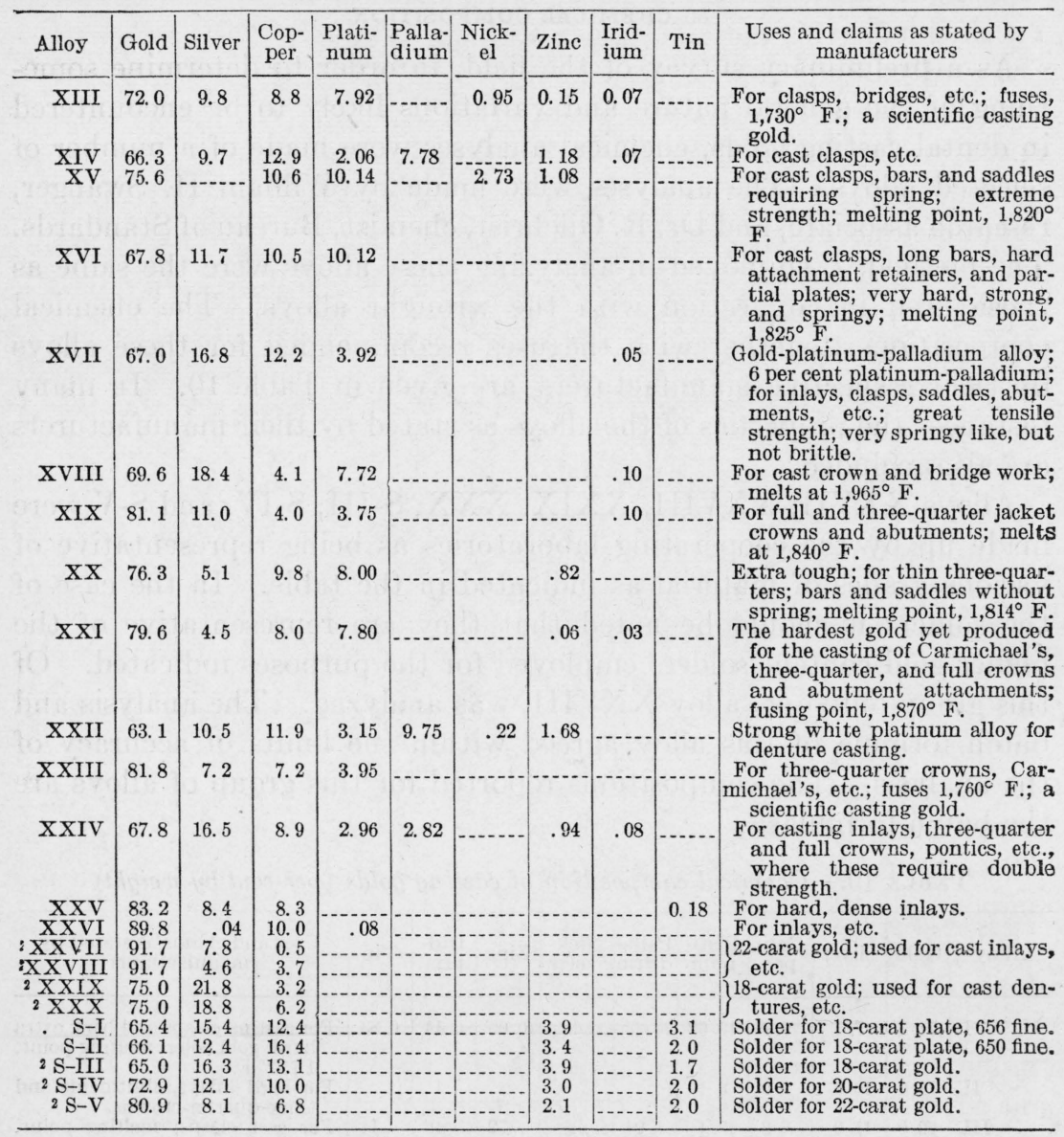

${ }^{2}$ Composition given is the batch formula.

By referring to Table 10 it will be noted that, as in the case of the wrought alloys, these materials contain small percentages of a large number of metals, as many as nine metals being found in a single alloy. Some of these are undoubtedly present as impurities in the major constituents. The formulas of most of these alloys are quite complex and appear to be largely empiric.

It is thought that the chemical compositions of this great variety of alloys, supplemented by complete tests of a few alloys representative of the various types, furnish a very good index of the general properties of the casting golds in use.

\section{(b) MELTING RANGES}

Although the "wire "method ${ }^{12}$ of determining fusion temperatures, used in the investigation of wrought alloys, furnishes an index of the 
maximum temperature at which these materials may be manipulated with safety, this method does not yield sufficient information in the case of casting golds and solders. For the most intelligent use of these materials it is necessary to know not only the maximum temperatures at which they are sufficiently rigid and cohesive to be soldered, bent, or otherwise manipulated with safety, but also the minimum temperatures at which they are sufficiently fluid to be cast or, in the case of solders, flowed. For this reason it was necessary to determine the melting ranges of the alloys of this group. The lower limit of the metling range, or the temperature at which fusion begins, is an index of the maximum temperature at which the alloy may be manipulated with safety, and the upper limit, or the temperature at which fusion is completed, is an index of the minimum temperature at which the alloy may be cast or flowed in the case of a solder.

In determining the metling ranges of these alloys the usual method of observing the changes in the rate of heating or cooling as the alloy is melted or allowed to freeze was employed. Two such determinations are illustrated in Figure 12. The melting ranges determined are given in Table 14, in which the mechanical properties also are summarized. By referring to this table it will be noted that the melting ranges of most of the alloys of this group are quite long, in some cases extending over $100^{\circ} \mathrm{C}$. or more. Alloy S-V, solder for 22-carat gold, furnishes a striking example of the significance and importance of this range.

Careful determinations of the metling range of this alloy showed that fusion of a small part of its constitutents begins at $745^{\circ} \mathrm{C} .\left(1,375^{\circ} \mathrm{F}\right.$.), although complete liquidation of the alloy does not occur until a much higher temperature is reached. Samples heated to approximately $750^{\circ} \mathrm{C}$. $\left(1,380^{\circ} \mathrm{F}\right.$.) appeared to be solid upon visual observation but were found to be extremely weak, falling to pieces when picked up with tongs. It is obvious that if this solder is used in the construction of an appliance which later must be soldered at a place near the first joint, care must be taken to use a solder for this operation which is flowed at a temperature below $745^{\circ} \mathrm{C}$. $\left(1,375^{\circ} \mathrm{F}\right.$.), or other suitable precautions must be taken in order to avoid possible injury to the first joint.

It will be noted that there is quite a large variation in the melting ranges of the various casting alloys examined. The upper limit of the ranges varies from $1,050^{\circ} \mathrm{C}$. $\left(1,920^{\circ} \mathrm{F}\right.$.) to $870^{\circ} \mathrm{C}$. $\left(1,600^{\circ} \mathrm{F}\right.$.) and the lower limit from $1,030^{\circ} \mathrm{C} .\left(1,885^{\circ} \mathrm{F}\right.$.) to $820^{\circ} \mathrm{C}$. $\left(1,510^{\circ} \mathrm{F}\right.$.) for alloys XXVII and V, respectively. The upper limits should be considered in selecting suitable equipment for melting these alloys preparatory to casting. The lower limits, as well as the metling: ranges of the solders themselves, should be considered in selecting: suitable solders for use in conjunction with the cast appliance. 
(c) MECHANICAL PROPERTIES

In the investigation of the mechanical properties of the cast gold alloys the properties determined were proportional limit, ultimate tensile strength, modulus of elasticity, percentage elongation, and Brinell hardness. The effects of heat treatment and of variations in the casting processes were also studied.

In determining these properties, especially the tensile properties, a number of difficulties were encountered. One of the most important of these was the preparation of suitable test specimens. These specimens should be castings of such size and produced under such conditions as to be analagous to dental castings in their properties. At the same time they must be large enough to permit sufficient accuracy in testing. As a preliminary to the development of a method of producing such samples it was necessary to determine as much as possible concerning the properties of dental castings and the variations in properties likely to be produced by variations in the casting process. Accordingly, a number of castings were made and examined to determine the effects of such variations.

In the dental literature mention has been made of the occurrence and deleterious effects of the segregation and burning out of certain constituents of casting golds. Tests were made to determine to what extent these effects are likely to occur in the ordinary dental casting process. A cylindrical casting $10 \mathrm{~mm}$ in diameter and about $20 \mathrm{~mm}$ long was made of Alloy III, an alloy relatively high in platinum and palladium. Chemical analyses were made of the outside and center of this casting to determine whether or not there was a difference in the compositions of these parts of the casting. As these analyses were made for comparison only, determinations of all the constituent metals were not made. The analyses are given in Table 11. No significant difference was found.

TABLe 11. ${ }^{1-S e g r e g a t i o n}$ in Alloy $I I^{2}$

\begin{tabular}{|c|c|c|c|c|c|c|c|c|c|c|}
\hline & \multicolumn{2}{|c|}{$10 \mathrm{~mm}$ casting } & \multicolumn{4}{|c|}{ Cast at moderate temperature ${ }^{3}$} & \multicolumn{4}{|c|}{ Cast at high temperature ${ }^{4}$} \\
\hline & \multirow{2}{*}{ Outside } & \multirow{2}{*}{ Inside } & \multicolumn{2}{|c|}{ Air pressure } & \multicolumn{2}{|c|}{ Centrifugal } & \multicolumn{2}{|c|}{ Air pressure } & \multicolumn{2}{|c|}{ Centrifugal } \\
\hline & & & Top & Bottom & Top & Bottom & Top & Bottom & Top & Bottom \\
\hline $\begin{array}{l}\mathrm{Au} \\
\mathrm{Ag} \\
\mathrm{Cu}\end{array}$ & $\begin{array}{r}59.9 \\
10.9 \\
8.8\end{array}$ & $\begin{array}{r}60.4 \\
10.9 \\
8.5\end{array}$ & $\begin{array}{l}59.9 \\
10.9\end{array}$ & $\begin{array}{l}59.9 \\
11.0\end{array}$ & $\begin{array}{l}59.8 \\
10.9\end{array}$ & $\begin{array}{l}60.1 \\
10.9\end{array}$ & $\begin{array}{l}60.3 \\
11.0\end{array}$ & $\begin{array}{l}60.4 \\
11.0\end{array}$ & $\begin{array}{r}60.4 \\
11.0 \\
8.6\end{array}$ & $\begin{array}{r}60.6 \\
11.1 \\
8.8\end{array}$ \\
\hline do & .76 & .78 & .72 & .76 & .77 & .67 & .56 & .56 & & \\
\hline Pd................ & 12.9 & 13.4 & & & & & & & $\begin{array}{r}1.9 \\
5.9\end{array}$ & $\begin{array}{r}12.3 \\
5.8\end{array}$ \\
\hline
\end{tabular}

1 Analyses were made by W. H. Swanger, research associate, Bureau of Standards.

2 Complete analyses were not made. The values reported are sufficient for purposes of comparison.

3 Throughout this report the term "moderate temperature" is used to designate a temperature slightly above the minimum at which castings could be made with the alloy in question. It is obvious that this temperature will vary for different alloys, depending upon their melting points, and, possibly to some

extent, on other factors.
"The term "high temperature" is used to designate a temperature markedly higher than the moderate temperature defined above. 
Two series of castings of Alloy III were then made with both an air pressure and a centrifugal casting machine. For one series the gold was heated to a moderate casting temperature with a hydrogen-air blowpipe. For the other series the gold was heated to much higher temperature with an oxygen-gas blowpipe. The castings were rods approximately $1 / 8$-inch in diameter by $1 \frac{1}{2}$ inches long and were made in investment molds at a temperature of about $250^{\circ} \mathrm{C} .\left(480^{\circ} \mathrm{F}\right.$.) to $300^{\circ} \mathrm{C}$. $\left(570^{\circ} \mathrm{F}\right.$.). Chemical analyses were made of the top or residue button and the bottom of each of these castings. These analyses also are given in Table 11. In no case was any significant difference between the composition of the top and that of the bottom of a casting found.

The freezing range of this alloy is very long, there being a difference of more than $160^{\circ} \mathrm{C}$. between the temperature at which freezing begins and that at which solidification is completed. This and the size of the castings and, in one series of castings, the high temperature of the gold are conditions much more favorable to segregation than those usually encountered in dental practice. Since no segregation was detected even under these conditions, it may be concluded that, in general, this effect is not likely to be serious in dental castings.

The extent to which the composition of this alloy, Alloy III, may be changed by the burning out of certain constituent metals during the casting process was determined by another series of tests. A section $3 / 4$ of an inch long was cut out of the center of a cast bar $3 / 8$ of an inch in diameter and 6 inches long. This center section was cut into three parts which were analyzed, one after being remelted with hydrogen and air and held at a moderate temperature for two minutes, one after being remelted with gas and oxygen and held at a very high temperature (approximately $1,600^{\circ} \mathrm{C}$., $2,900^{\circ} \mathrm{F}$.) for five minutes, and one without remelting. During the remeltings borax flux was used freely. The analyses are given in Table 12.

TABLE 12.1-Change in composition of Alloy III due to remelting

\begin{tabular}{|c|c|c|c|}
\hline & $\begin{array}{l}\text { Not re- } \\
\text { melted }\end{array}$ & $\begin{array}{l}\text { Remelted } \\
\text { at moder- } \\
\text { ate tem- } \\
\text { perature }\end{array}$ & $\begin{array}{l}\text { Remelted } \\
\text { at high } \\
\text { tempera- } \\
\text { ture }\end{array}$ \\
\hline $\begin{array}{l}\mathrm{Au} \\
\mathrm{Ag} \\
\mathrm{Cu} \\
\mathrm{Zn}\end{array}$ & $\begin{array}{r}60.5 \\
11.0 \\
8.5 \\
.64\end{array}$ & $\begin{array}{r}60.5 \\
11.0 \\
8.6 \\
.56\end{array}$ & $\begin{array}{r}60.8 \\
11.0 \\
8.6 \\
.32\end{array}$ \\
\hline
\end{tabular}

${ }^{1}$ Analyses were made by W. H. Swanger, research associate, Bureau of Standards.

The remelting and holding at a moderate temperature for two minutes is a more severe treatment than the gold would ordinarily receive if cast only once. It may be considered as equivalent to remelting and casting at least twice. Yet it will be noted from Table 
12 that no significant change in composition owing to this treatment was found. Heating to the excessively high temperature and holding this temperature for five minutes is very much more severe, both as to the temperature and the length of time this temperature was held than is likely to occur in ordinary dental practice. This treatment was so severe that during the entire five minutes small particles were flying off from the molten metal, and the total loss of metal was approximately one-half of the original weight. As will be seen from Table 12, the only change in composition of the alloy subjected to this treatment was the loss of about 50 per cent of the original zinc content.

In order that the conditions of test with respect to the grade of alloy used might be as severe as any likely to be encountered in practice, the tests were repeated using low-grade alloys (approximately 15-carat gold) containing a large percentage of base metals. These alloys were very similar to alloy $\mathrm{V}$, which was the lowest in precious metal content of the alloys analyzed. (See Table 10.) Since alloy V has been criticized as being too low in precious metals to be used in the mouth with safety it is thought that the low-grade alloys used in these tests represent the extreme in this respect. The results of these tests were very similar to those described for alloy III, except that at the very high temperatures the loss of base metals was slightly greater than for alloy III.

The conclusions to be drawn from these results may be stated briefly as follows: Gold alloys such as those tested in this investigation when remelted and cast with reasonable care are not expected to undergo any serious "unbalancing" or change in the proportions of their constituent metals, even if remelted and cast two or three times. This is true even of alloys so low in precious metal content as to be of doubtful value in the mouth. If due precautions are taken to prevent contamination from oxidation or the inclusion of foreign substances, such treatment should not seriously alter the mechanical properties of these alloys. If, however, the alloys are heated to excessively high temperatures loss of base metals is likely to occur.

In examining a number of castings of these alloys it was found that practically all of them were porous or pitted, though to varying degrees. Such porosity was sufficient to cause marked variations in the properties of different castings of the same alloy. In order to eliminate or reduce as much as possible variations due to this condition, a study of the causes of this porosity was undertaken. A number of articles on this subject are to be found in the dental literature. In most of these porosity is attributed to oxidation of the metal or to occluded gases. In order to verify these reports, and to obtain a clearer understanding of the prevailing conditions, it was decided to make an independent investigation. 


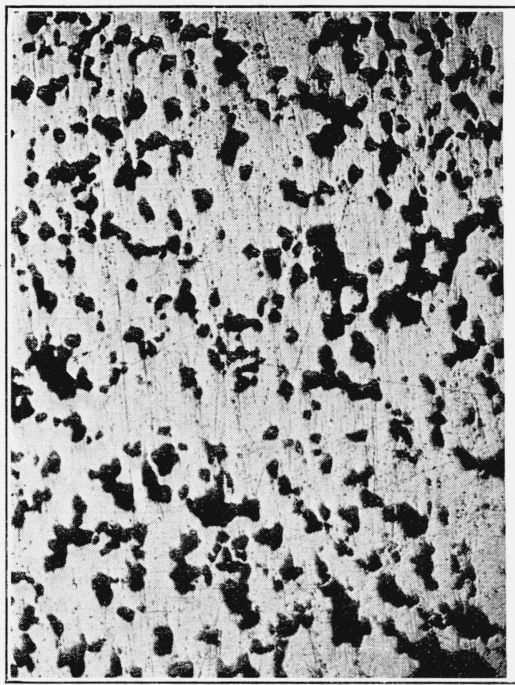

FIg. 22.- Section of a dental casting polished but not etched, $\times 90$

Shows type of porosity characteristic of certain casting golds. This appears to be due to localized shrinkage.

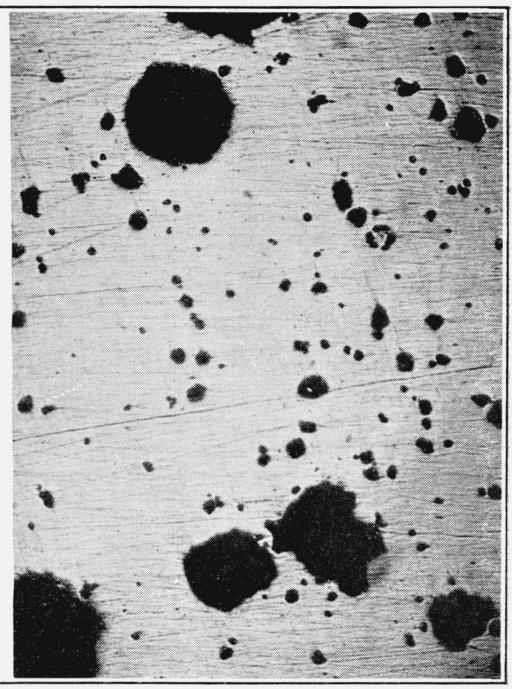

FIG. 23.-Section of a dental casting polished but not etched, $\times 90$

Shows a second type of porosity characteristic of some casting golds. This appears to be due to occluded gas.

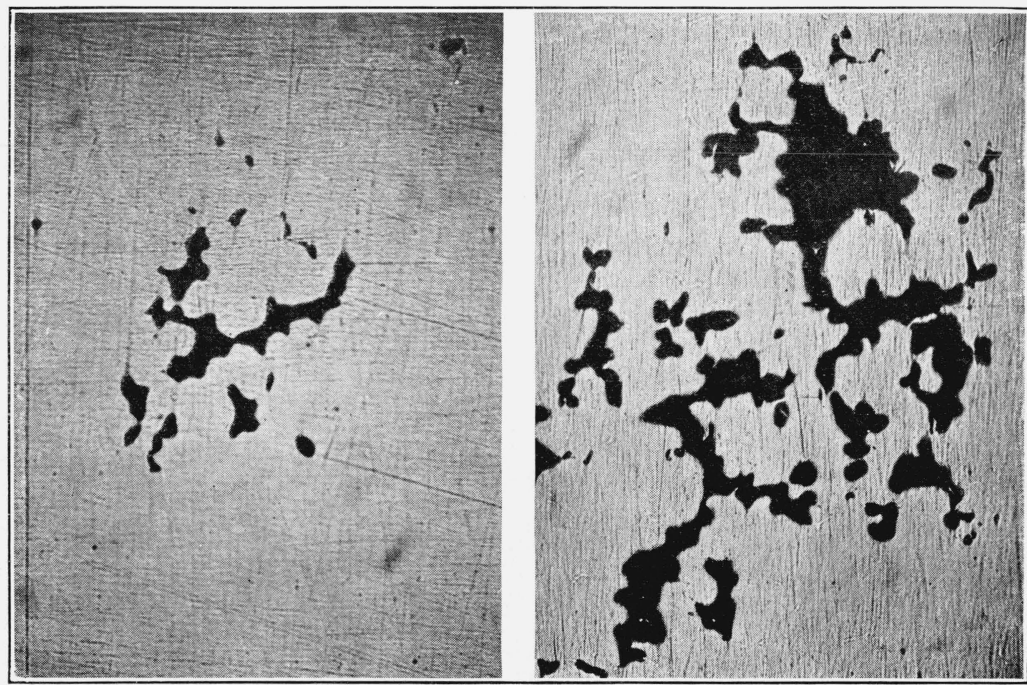

FIG. 24.-Section of same alloy as shown in Figure 22, after remelting invacuum. Polished but not etched, $\times 90$
Fig. 25.-Section of same alloy as shown in Figure 23, after remelting invacuum. Polished but not etched, $\times 90$ 
Accordingly, a large number of castings were made under systematically varied conditions. The composition of the metals used ranged from 24-carat gold and binary alloys of gold and various other metals to the complex alloys commonly employed in dentistry. The dimensions of the casting and sprue and the method of melting and casting were varied between wide limits. Sections of these castings were prepared and examined for porosity under the microscope.

All of the castings examined were porous to some extent, and in practically all cases the porosity could readily be classified as belonging to one of two apparently distinct types. These types are illustrated in Figures 22 and 23 and appear to be characteristic of certain alloys when melted and cast by any of the methods in common use in the dental laboratory. In Figure 22 the dark spots are voids around or between dendritès. The walls of these voids, when large enough to be seen, are bright and clean. No indication of any discoloration such as would be expected if metallic oxides were present was noted. It was observed, also, that this type of porosity occurs most frequently and is most pronounced in sections of the casting adjacent to the sprue. These characteristics of this type of porosity suggested that the voids were caused by localized shrinkage owing to different rates of cooling in different parts of the casting. In Figure 23 the round, dark spots are voids, the walls of which are also bright and clean. The appearance of these suggested that they were caused by or that their shape was influenced by occluded gas.

As a check on these observations castings of two alloys, which are characterized by these two types of porosity, respectively, were placed in graphite crucibles and packed in zirconia which formed a mold in which the casting could be remelted without losing its original shape. These castings were then remelted ${ }^{13}$ in a vacuum-induction furnace, held molten long enough for the elimination of any gas that might be present and allowed to freeze in vacuum. The porosity of these castings was then found to be as illustrated in Figures 24 and 25. The round voids shown in Figure 23 were completely eliminated. Voids similar to those shown in Figure 22 were found in both alloys. The porosity in the vacuum-fused alloys is caused very largely by localized shrinkage, and since this is very similar to the type of porosity shown in Figure22, which apparently is not caused by metallic oxides or occluded gas, it is concluded that this type of porosity is also caused by localized shrinkage. The elimination of the type of porosity shown in Figure 23 by vacuum fusion, which also eliminates any gas that might be present, tends to confirm the conclusion that this type of porosity is caused by occluded gas.

No evidences of serious porosity, caused by the inclusion of metallic oxides, were found when the usual precautions of melting with a

13 The remelting in vacuum was done by L. Jordan, of the division of metallurgy, Bureau of Standards. $5619^{\circ}-28-3$ 
reducing flame and using a protecting flux, such as fused borax or borax and charcoal, were taken. Determinations ${ }^{14}$ of the oxygen and hydrogen present in three alloys, XXIII, XIII, and III as supplied by their respective manufacturers, and in alloy III after being melted under various conditions, are of interest in this connection. The results of these determinations are given in Table 13. The samples tested as manufactured were purchased through a supply house in the usual manner and are believed to be representative of these alloys as supplied to the dental trade. Alloys XXIII and XIII were claimed by their maker to be manufactured by a special process which eliminates the possibility of contamination by oxidation, yet the percentage of oxygen found in these alloys is appreciably greater than that found in alloy III, which is claimed to be manufactured by the usual methods. The values for oxygen and hydrogen content of samples of alloy III melted under three different sets of conditions are given in the lower part of the Table 13, samples 4, 5, and 6 . Sample 4 was melted five times on a charcoal block in a hydrogen-air flame and sample 5 was melted once in an air-illuminating gas flame and cast in an investment mold. A flux consisting of powdered carbon and borax was used during the melting of both of these samples. Sample 6 was melted in a refractory crucible in a high-frequency induction furnace and was held completely molten for a period of 1 minute and 20 seconds. No flux or other protective medium was used. After the sample had cooled in the crucible the surface scale was removed by grinding before determining the gas content. In each case the sample used had previously been made gas free by vacuum fusion, hence the gases found were present due to melting under the conditions described.

TABLE 13.-Gas content of gold alloys

\begin{tabular}{|c|c|c|c|c|}
\hline $\begin{array}{l}\text { Sam- } \\
\text { ple } \\
\text { No. }\end{array}$ & Alloy & Treatment & $\begin{array}{c}\text { Oxygen } \\
\text { by weight }\end{array}$ & $\begin{array}{l}\text { Hydrogen } \\
\text { by weight }\end{array}$ \\
\hline $\begin{array}{l}1 \\
2 \\
3 \\
4\end{array}$ & $\begin{array}{l}\text { XXIII } \\
\text { XIII } \\
\text { III }\end{array}$ & $\begin{array}{l}\text { As manufactured- } \\
\text { do do }\end{array}$ & $\begin{array}{r}\text { Per cent } \\
0.0026 \\
.0025 \\
.0016\end{array}$ & $\begin{array}{r}\text { Per cent } \\
0.0003 \\
.0007 \\
.0006\end{array}$ \\
\hline 4 & III & $\begin{array}{l}\text { Originally gas-free metal melted five times in hydrogen-air flame } \\
\text { on charcoal block; borax-carbon flux used }\end{array}$ & .0090 & .0019 \\
\hline 0 & 111 & $\begin{array}{l}\text { Originally gas-free metal melted in air-illuminating gas flame, cast } \\
\text { in investment mold; borax-carbon flux used }\end{array}$ & & 0015 \\
\hline 6 & III & $\begin{array}{l}\text { Originally gas-free metal melted by induction in air without flux; } \\
\text { surface scale removed }\end{array}$ & .038 & .0008 \\
\hline
\end{tabular}

It will be noted that the oxygen content of each of these three samples was appreciably greater than that of the alloy as manufactured, indicating that if these alloys are seriously contaminated by oxygen, either in the form of metallic oxides or in some other form, such contamination is much more likely to occur during melting and casting

14 These determinations were made by L. Jordan, of the Bureau of Standards. For a description of the method used see B. S. Sci. Paper No. 514; 1925. 
by the usual dental laboratory methods than in the process of manufacture. The oxygen content of sample 6 , which was melted without the protection of a flux or of the products of combustion of a gas flame, was found to be more than twice as great as that of any other sample tested. This furnishes a general indication of the effectiveness of these protective media in preventing contamination of the alloy by oxygen. The oxygen content of sample 5, which received a treatment very similar to that received by the alloy in the usual melting and casting process, was found to be 0.015 per cent by weight. This seems to indicate that only a minor proportion of the porosity usually found in dental castings can be due to the inclusion of metallic oxides. If, as an extreme case, it is assumed that all of this oxygen was present in the form of cuprous oxide, $\mathrm{Cu}_{2} \mathrm{O}$, and that none of this oxide was in solution but all of it was present as inclusions, conditions that are not at all likely to occur, the volume of such inclusions would still be less than 0.5 per cent of that of the sample. It is concluded, therefore, that the porosity prevailing in most dental castings is due largely to localized shrinkage or to occluded gas, or to both.

As noted above, porosity was especially noticeable in sections of the casting adjacent to the sprue. This porosity has the effect of weakening the castings in these sections to a very marked degree. It was found that this could be largely eliminated by the use of a very short sprue of large diameter, the shorter the sprue and the larger the diameter the better. Where the use of such a sprue is inconvenient, it was found that the same result could be accomplished by providing within the mold a chamber somewhat thicker than the thickest part of the pattern and as near as possible to the pattern without actually touching it. This is easily done by attaching a ball of wax to the sprue before applying the investing material. On casting this chamber is filled with molten metal which, because of its size, remains liquid until after the casting has solidified, thus serving as a reservoir from which additional molten metal is supplied to the casting as it shrinks during solidification. This method of spruing resulted in the production of castings which were as sound near the sprue as elsewhere. The method can be applied to many of the usual types of dental castings and should prove of value in reducing the porosity of these.

In order to determine as much as possible concerning the properties of dental castings, a large number of these castings were subjected to such tests as could be applied. These castings were divided into three groups according to the type of dental appliance they represented; namely, clasps, inlays, and saddles or partial dentures. The patterns for the clasps were made by bending a strip of No. 20 gauge (0.032 inch) wax, 1 inch long by $1 / 8$ inch wide around a cylinder $3 / 8$ inch in diameter. The inlays were slightly tapered cylinders approximately $1 / 4$ inch in diameter and $1 / 8$ inch thick. The saddles were sheets 
$11 / 2$ inches long, $1 / 2$ inch wide, and No. 22 gauge ( 0.025 inch) thick with three round sections $\frac{3}{16}$ inch in diameter built up to $\frac{3}{32}$ inch in thickness. A number of each of these castings were made of each of five alloys selected from the so-called hard, medium, and soft groups. The methods of spruing, investing, and burning out of the molds were varied between wide limits. The temperature of the molds at the time of casting was varied from slightly above room temperature to about $650^{\circ} \mathrm{C}$. $\left(1,200^{\circ}\right.$ F.). Both air pressure and centrifugal casting machines were used.

The castings were given the desired heat treatment, sectioned, and tested for Brinell hardness. Microscopic examinations for internal porosity and characteristic structure were made also. Comparison of these data with corresponding data obtained from tensile specimens of various sizes and cast in various ways proved of great value in selecting a method of preparing satisfactory tensile specimens.

The values obtained for the Brinell hardness of these dental castings are summarized in Table 14. The different types of castings agreed very closely in hardness, the differences between types being no greater than those between duplicate samples of the same type. Since the micrographic data obtained are of value chiefly as a partial identification of the materials tested and as a further verification of the analogy between dental castings and the tensile samples used, these data also are presented and discussed at this time.

TABLE 14.-Mechanical properties and melting ranges of cast-gold alloys

\begin{tabular}{|c|c|c|c|c|c|c|c|c|c|}
\hline \multirow[b]{2}{*}{ Alloy } & \multirow[b]{2}{*}{ Heat treatment ${ }^{1}$} & \multicolumn{4}{|c|}{ Tensile properties } & \multicolumn{2}{|c|}{$\begin{array}{l}\text { Brinell } \\
\text { hardness } \\
\text { number }\end{array}$} & \multirow{2}{*}{\multicolumn{2}{|c|}{ Melting range }} \\
\hline & & $\begin{array}{l}\text { Propor- } \\
\text { tional } \\
\text { limit }\end{array}$ & $\begin{array}{c}\text { Ulti- } \\
\text { mate } \\
\text { strength }\end{array}$ & $\begin{array}{l}\text { Elon- } \\
\text { gation } \\
\text { in } 3 \\
\text { inches }\end{array}$ & $\begin{array}{l}\text { Modulus of } \\
\text { elasticity }{ }^{3}\end{array}$ & $\begin{array}{c}\text { Ten- } \\
\text { sile } \\
\text { speci- } \\
\text { mens }\end{array}$ & $\begin{array}{c}\text { Den- } \\
\text { tal } \\
\text { cast- } \\
\text { ings }\end{array}$ & & \\
\hline \multirow{9}{*}{$\begin{array}{r}24 \text {-carat } \\
\text { XXVI } \\
\text { XXVII } \\
\text { XXVII } \\
\text { XXIX } \\
\text { XXX } \\
\text { II }\end{array}$} & & \multirow{2}{*}{$\begin{array}{l}\text { Lbs./in. } \\
41,000\end{array}$} & \multirow{2}{*}{\begin{tabular}{c|c}
.$^{2}$ & Lbs./in. ${ }^{2}$ \\
16,500
\end{tabular}} & \multirow[t]{2}{*}{$\begin{array}{l}\text { Per } \\
\text { cent }\end{array}$} & \multirow{2}{*}{ Lbs./in..$^{2}$} & \multirow{7}{*}{$\begin{array}{l}27 \\
76 \\
32 \\
54 \\
56 \\
74\end{array}$} & & \multirow{5}{*}{$\begin{array}{r}{ }^{\circ} C . \\
1,063 \\
925-940 \\
030-1,050 \\
970-1,020\end{array}$} & \multirow{2}{*}{${ }^{\circ} \mathrm{F}$} \\
\hline & & & & & & & & & \\
\hline & & 17,500 & 48,000 & 31 & $11,000,000$ & & & & $1,700-1,725$ \\
\hline & & 3,000 & 21,500 & 25 & & & & & $1,885-1,920$ \\
\hline & & 11,000 & 34,500 & 20 & & & 52 & & $1,775-1,875$ \\
\hline & & 11,000 & 36,000 & 19 & 11,0 & & & $925-995$ & $1,700-1,825$ \\
\hline & & 18,000 & 45,500 & 18 & 12, & & & $895-980$ & $1,650-1,795$ \\
\hline & Sof & & 48,0 & 18 & & 90 & 82 & $940-1,025$ & $1,725-1,875$ \\
\hline & Has & 26 & 50,5 & 10 & & 98 & 94 & 025 & 1,875 \\
\hline I & Softe & 50,000 & 64,500 & 1 & 13,0 & 154 & 150 & $910-1,010$ & $1,665-1,850$ \\
\hline & $\mathrm{HaI}$ & 61,000 & 84,000 & & & 195 & 196 & $910-1,010$ & $1,665-1,850$ \\
\hline V & Sof & 46,000 & 70,000 & 10 & & 149 & 148 & $820-870$ & 1,600 \\
\hline & & 73,000 & 103,000 & 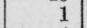 & 13,000 & 214 & 202 & $820-870$ & $1,510-1,600$ \\
\hline IV & Softe & 53,500 & 69,000 & 4 & 13,0 & 145 & 143 & $885-985$ & $1,620-1,805$ \\
\hline & Har & 94,500 & 108,500 & & 14, & 249 & 222 & $885-985$ & 1,62 \\
\hline $\mathrm{S}-\mathrm{V}$ & & 20,500 & 37,500 & 18 & $11,000,000$ & 78 & & $745-870$ & $1,375-1,595$ \\
\hline & $\begin{array}{l}\text { Softe } \\
\text { Hard }\end{array}$ & 24,000 & 36,000 & & $11,000,000$ & 103 & & $755-835$ & $1,390-1,535$ \\
\hline S-III & & 61,500 & 70,000 & 9 & & 180 & & $755-835$ & $1,390-1,535$ \\
\hline & & $\begin{array}{l}30,000 \\
77,000\end{array}$ & 92,000 & & $\begin{array}{l}12, \\
13\end{array}$ & 111 & & $\begin{array}{l}76: \\
76: \\
7\end{array}$ & 1,411 \\
\hline S-II & Soften & 29,500 & 44,500 & 12 & 11,0 & 103 & & $750-805$ & $1,385-1,480$ \\
\hline & & 77,500 & 83,500 & & $12,000,000$ & 193 & & $750-805$ & $1,385-1,480$ \\
\hline S-I & Sof & 27,000 & 42,500 & 14 & 11,0 & 111 & & & 1,37 \\
\hline & & 55,000 & 63,000 & & $12,000,000$ & 185 & & 745-785 & $1,375-1,445$ \\
\hline
\end{tabular}

1 In this table the heat treatments designated by "softened" and "hardened" consist of quenching in water from $700^{\circ} \mathrm{C}$. and cooling slowly from $450^{\circ} \mathrm{C}$., respectively. Those alloys for which no heat treatment is indicated were not appreciably affected by these treatments.

2 Where no value for elongation is given, the value obtained was less than 1 per cent.

3 Where modulus of elasticity is not given, this value was not determined.

4 Less than 1,000. 
B. S. Journal of Research, RP32

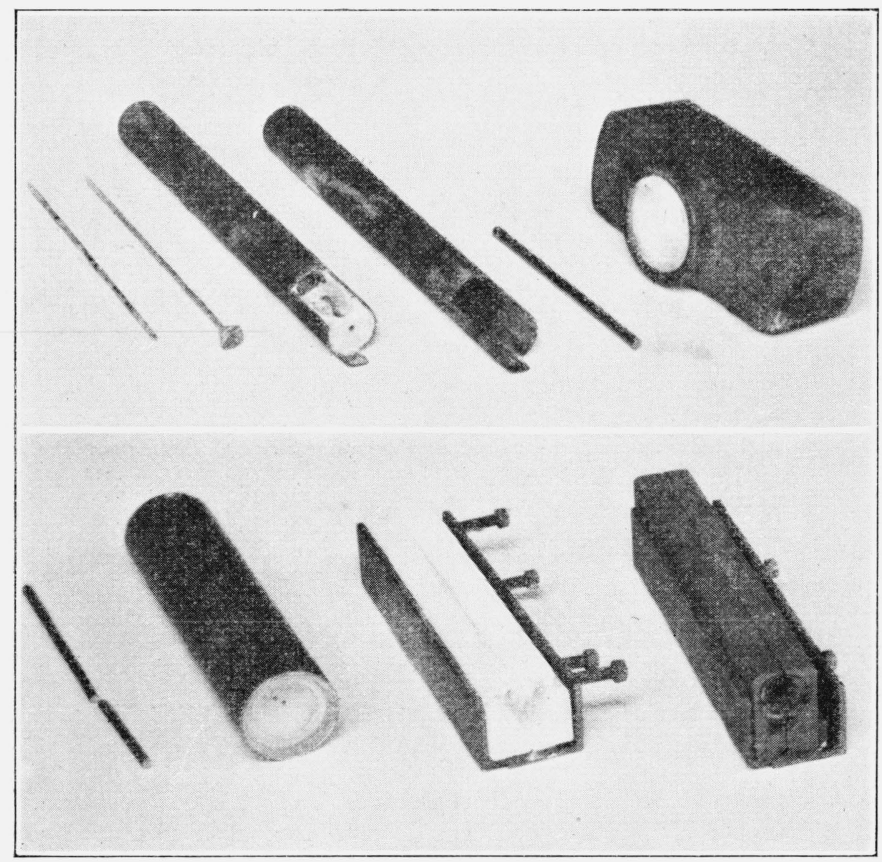

FIG. 26.-Types of molds used for casting test specimens, and some of the castings produced 
With this preliminary work completed, the development of a method of preparing satisfactory tensile specimens was undertaken. It was desired to use a specimen as small as would be consistent with the required accuracy of test, both for the reason that it was thought that the properties of small castings would more nearly agree with those of dental castings and because of the fact that the cost of the relatively large samples commonly employed in testing engineering materials would, in many instances, make them impracticable.

With these considerations in mind, castings of various shapes and sizes were made by a variety of methods and compared with the dental castings of the corresponding alloys. Some of these castings were made with the usual dental laboratory equipment, including both air pressure and centrifugal casting machines, using methods commonly employed in dental practice. Others were made by melting the metal in a suitable crucible and casting or pouring it into well-vented investment or hard carbon molds. Both flat strips and round rods were cast. In some instances it was found desirable to use special flasks adapted to the size and shape of the castings being made. A number of the types of molds employed and some of the castings produced are shown in Figure 26.

Comparisons of these castings with dental castings of corresponding alloys indicated that satisfactory tensile specimens could be cast with an air pressure or centrifugal casting machine or by pouring into suitable molds. Either flat strips or cylindrical rods up to oneeighth inch in diameter could be produced, which agreed very closely with the corresponding dental castings in Brinell hardness and microstructure. In general, the thin castings were freer from internal porosity than those of larger cross section. The tensile properties of a number of samples produced by the different methods described were determined and found to be in very good agreement. The variations between samples produced by the different methods were no greater than those between duplicate samples produced by the same method.

The method of casting into well-vented carbon molds was finally selected as being the most satisfactory for this investigation. This method has the advantage that variables in the casting process are more readily controlled, thus insuring greater uniformity from sample to sample and a lower percentage of casting failures. Of the castings produced by this method only about 5 per cent were discarded because of defects. The use of carbon rather than investment molds has the advantage that the carbon is more durable and less likely to warp.

In conformity with the general principle, recognized by the American Society for Testing Materials and leading engineers, that tensile specimens of circular cross section yield more consistent and reliable results than those of rectangular section, the cylindrical rod type of specimen was adopted. The samples used for most of these tests 
were approximately $1 / 8$ inch in diameter and $5 \frac{3}{4}$ inches long. Reference to the values for Brinell hardness given in Table 14 and to the micrographs of typical internal porosity and microstructure presented in Figures 27 to 31, inclusive, will show that the test specimens are very similar in these properties to the corresponding dental castings. When necessary, the rods were dressed down slightly with a fine file or emery paper to remove roughness or other minor irregularities of the surface. The diameter of individual rods was uniform from end to end to within approximately 0.002 inch.

The heat treatments given these alloys were similar to those developed for the wrought alloys and described in a previous section. After heat treatments were completed, a small section approximately $1 / 8$ inch long was cut from each end of the rod. These small samples were mounted in a matrix of sulphur, ground and polished and tested for Brinell hardness. The same samples were also used for the microscopic examinations for internal porosity and microstructure.

Micrographs showing the types of internal porosity found and the characteristic microstructure of the alloys tested, together with corresponding micrographs of the dental castings previously described, are presented in Figures 27 to 33, inclusive. No marked difference between the structure of any of these alloys in the softened condition and in the hardened condition was observed. In most instances the structure of the alloy in only one condition is shown. In comparing the micrographs of internal porosity it should be borne in mind that these micrographs are representative of the characteristic types of porosity observed rather than of the average condition of the entire casting. Since these defects usually are not uniformly distributed throughout the casting, it is difficult to obtain micrographs showing average conditions.

The Brinell hardness determinations were made with the same instrument used in the investigation of the wrought alloys and shown in Figure 20. For cast alloys having a hardness number greater than 50 a load of $12.8 \mathrm{~kg}$ (28.2 pounds) was used.

After the small samples for hardness tests and microscopic examination were cut from the rod the rest of the casting was used for the tensile tests. Most of these tests were made with a universal testing machine of 2,000 pounds capacity, in which the load was applied through four screws and measured by means of a beam and counterpoise. This machine was equipped with a self-aligning device, clamps, and an extensometer, which were designed and built especially for this investigation. A few of the tests on the alloys of very low strength were made with a machine of the pendulum type, having a capacity of 600 pounds.

In order to use as short a specimen as possible, short lugs of suitable shape were attached to the ends of the test rod by means of gold 
B. S. Journal of Research, RP32

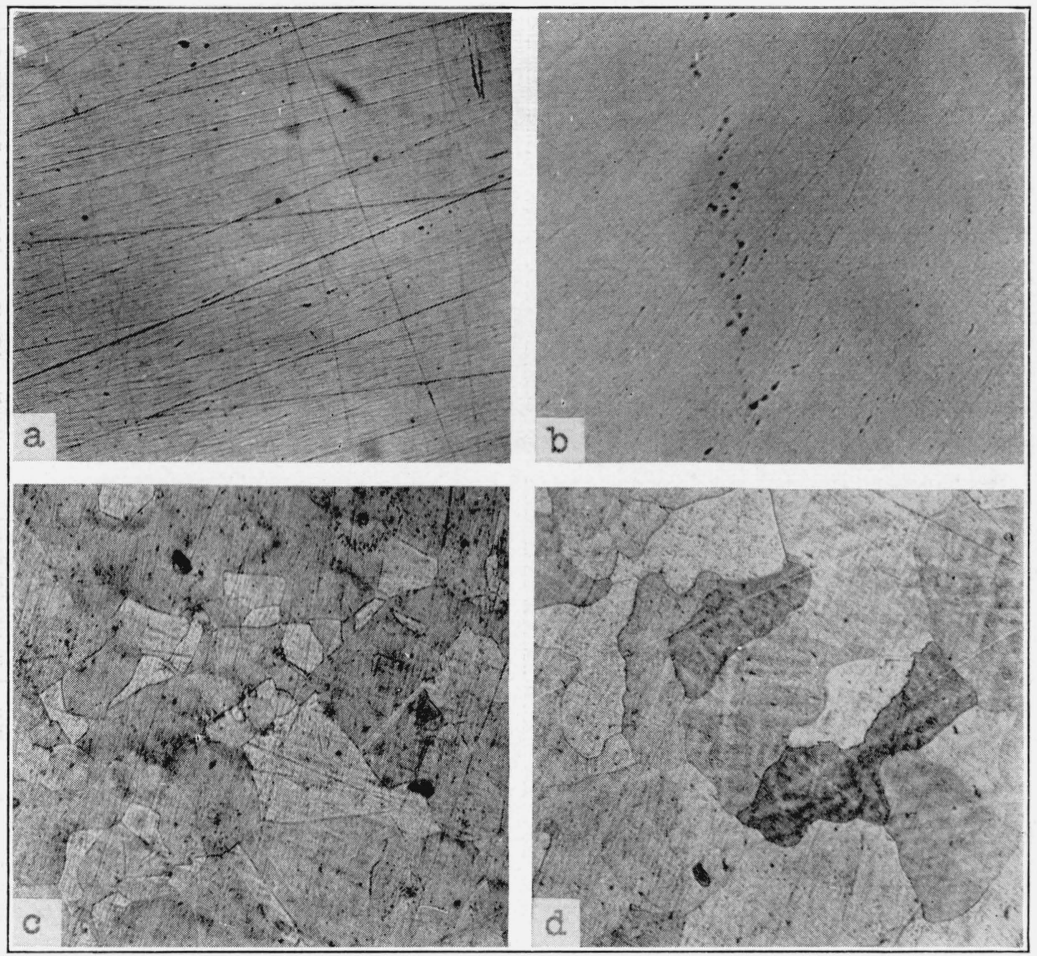

FIG. 27.-Micrographs of Alloy XXVIII showing agreement in characteristic structure of different types of castings

a, Porosity in dental casting, $\times 90 ; b$, Porosity in test specimen, $\times 90 ; c$, Microstructure of dental casting, etched with K C N, $\times 90 ; d$, Microstructure of test specimen, etched with $\mathrm{K} \mathrm{C} \mathrm{N}$, $\times 90$. 
B. S. Journal of Research, RP32

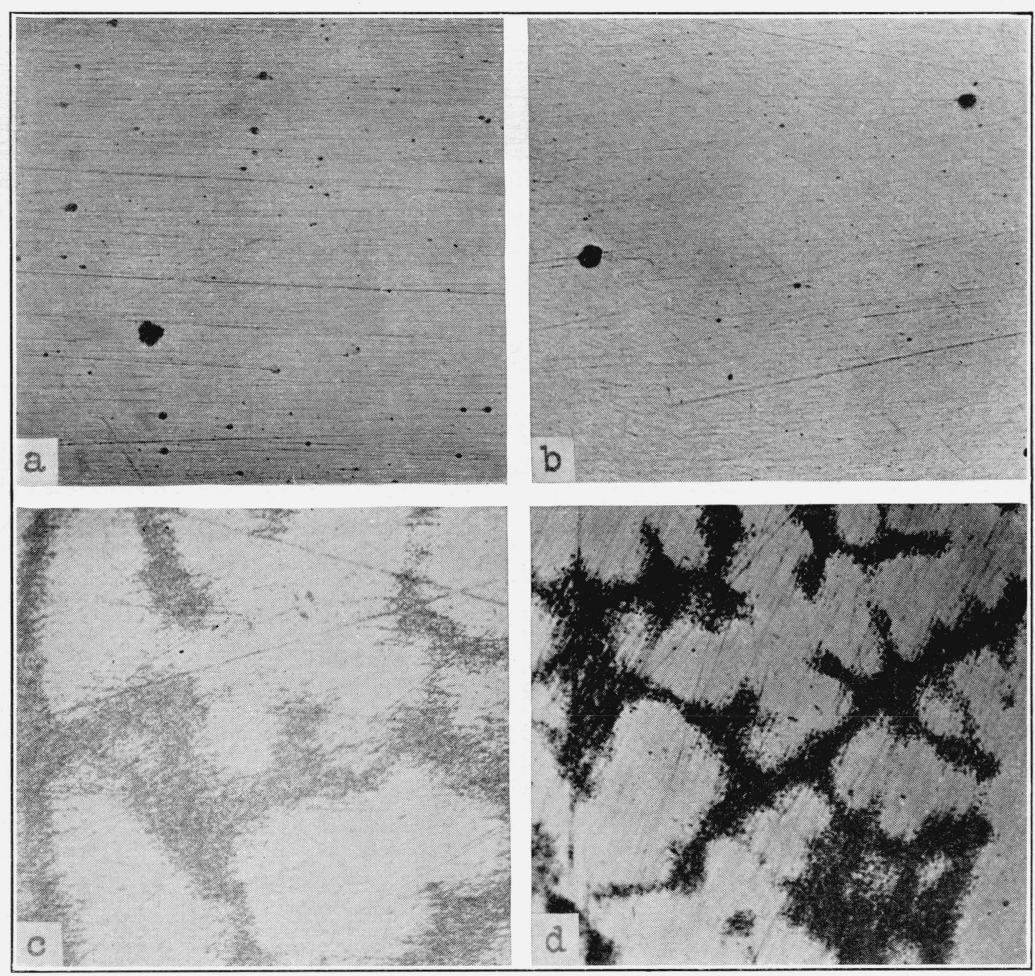

FIG. 28.-Micrographs of Alloy II showing agreement in characteristic structure of different types of castings

$a$, Porosity in dental castings, $\times 90 ; b$, Porosity in test specimens, $\times 90 ; c$, Microstructure of dental castings, etched with iodin, $\times 450$; $d$, Microstructure of test specimens, etched with iodin, $\times 450$. 
B. S. Journal of Research, RP32

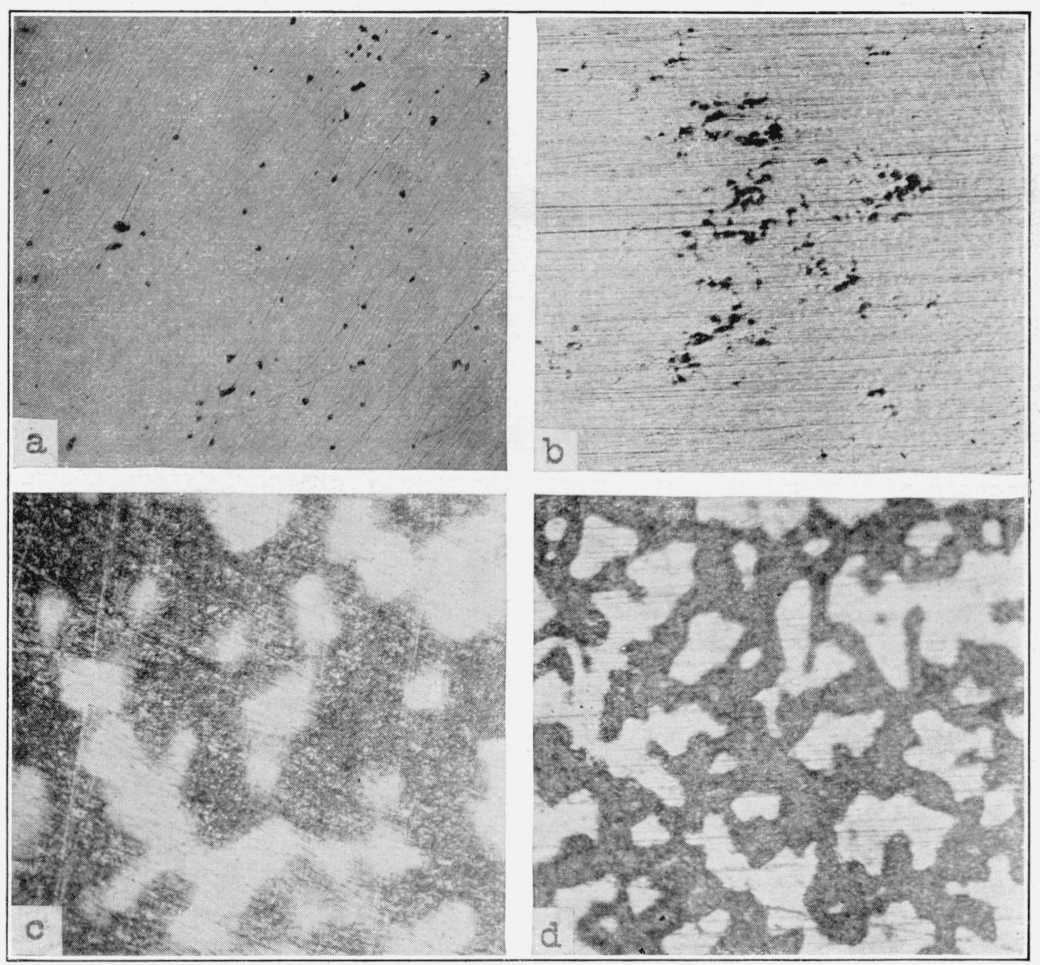

FIG. 29.-Micrographs of Alloy I showing agreement in characteristic structure of different types of castings

(a) Porosity in dental castings, $\times 90 ; b$, Porosity in test specimens, $\times 90$ (shows the center of a section near the sprue and is typical of shrinkage "pipes"); c, Microstructure of dental castings, etched with iodin, $\times 450 ; d$, Microstructure of test specimens, etched with iodin, $\times 450$. 
B. S. Journal of Research, RP32

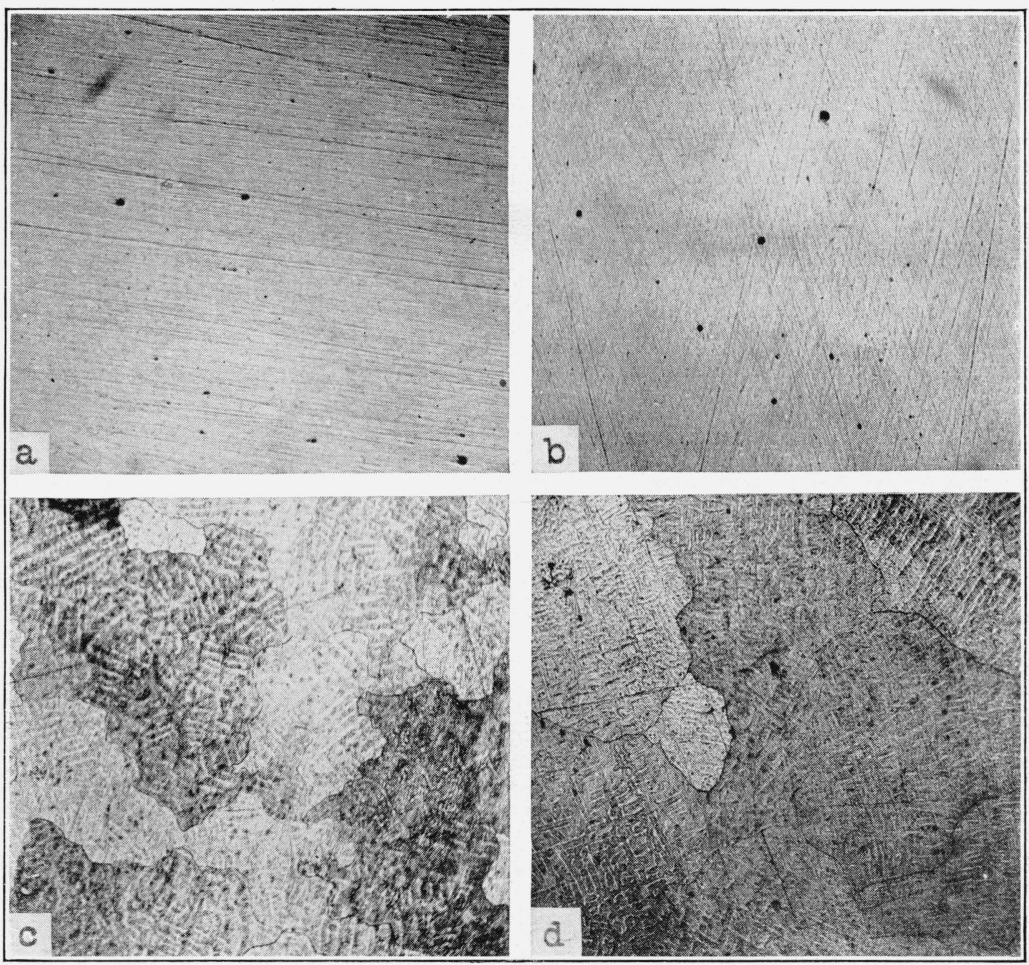

Fig. 30.-Micrographs of Alloy $V$ showing agreement in characteristic structure of different types of castings

$a$, Porosity in dental castings, $\times 90 ; b$, Porosity in test specimens, $\times 90 ; c$, Microstructure of dental castings, etched with $\mathrm{K} \mathrm{C} N, \times 90 ; d$, Microstructure of test specimens, etched with $\mathrm{K} \mathrm{C}$, $\times 90$. 
B. S. Journal of Research, RP32

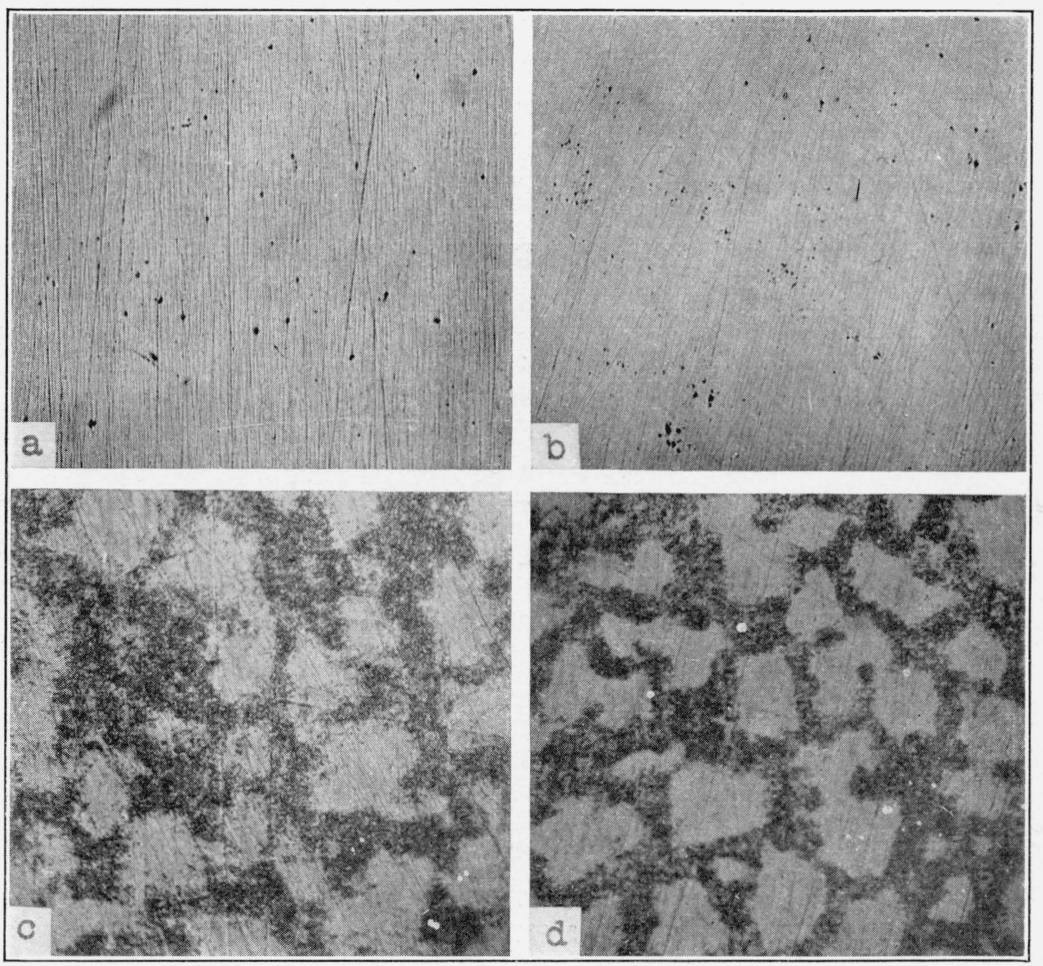

FIG. 31.-Micrographs of Alloy IV showing agreement in characteristic structure of different types of castings

$a$, Porosity in dental castings, $\times 90 ; b$, Porosity in test specimens, $\times 90 ; c$, Microstructure of dental castings, etched with iodin, $\times 450 ; d$, Microstructure of test specimens, etched with iodin, $\times 450$. 
B. S. Journal of Research, RP32
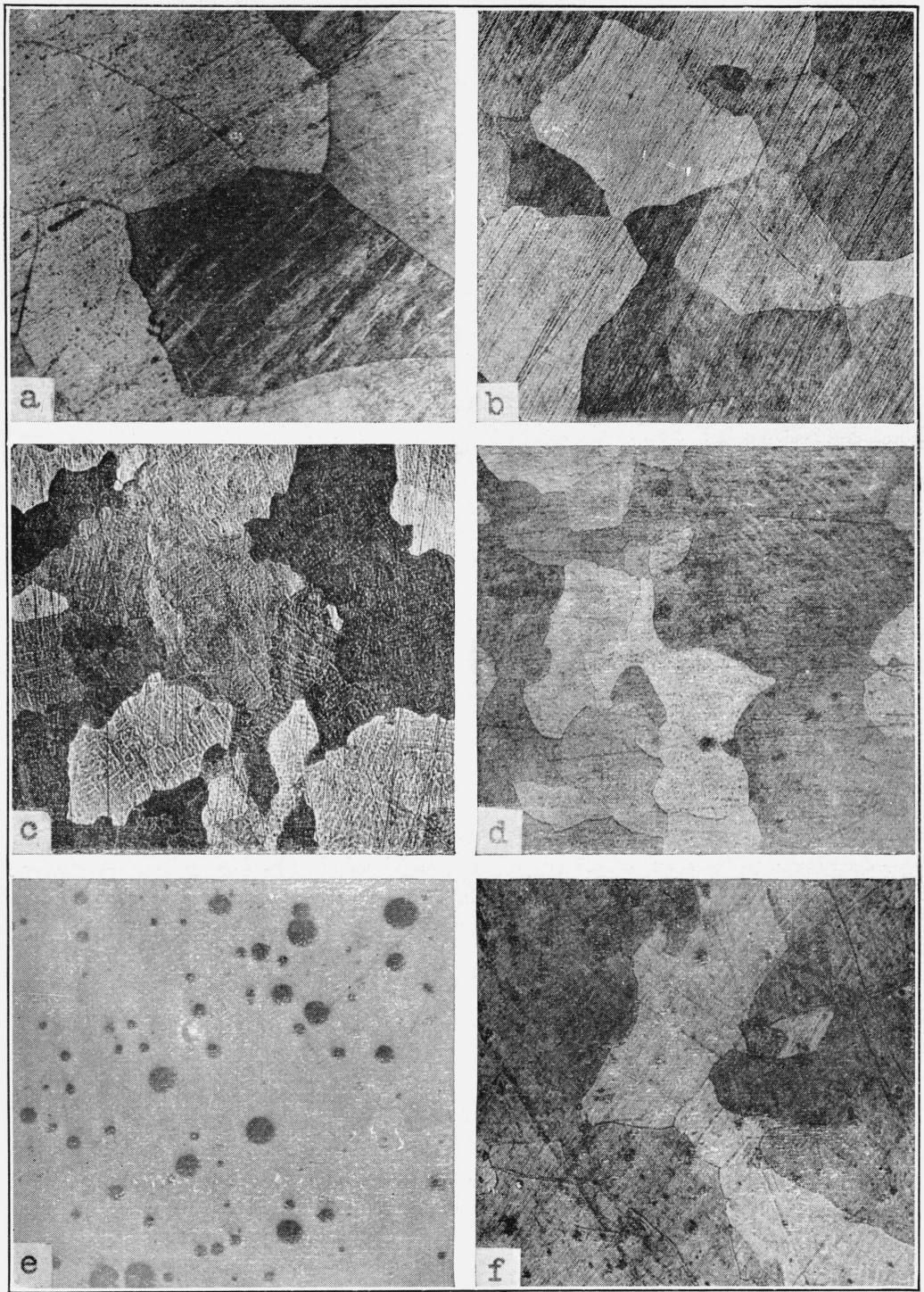

FIG. 32.-Microstructure characteristic of five dental golds tested, $\times 90$

$a$, 24-k gold, etched with aqua regia; $b$, Alloy XXVII etched with iodin; $c$, Alloy XXIX etched with iodin; $d$, Alloy XXVIII etched with chlorin water; $e$, Alloy XXVI not etched, showing characteristic type of porosity, apparently due to occluded gas; $f$, Alloy XXVI etched with aqua regia. 

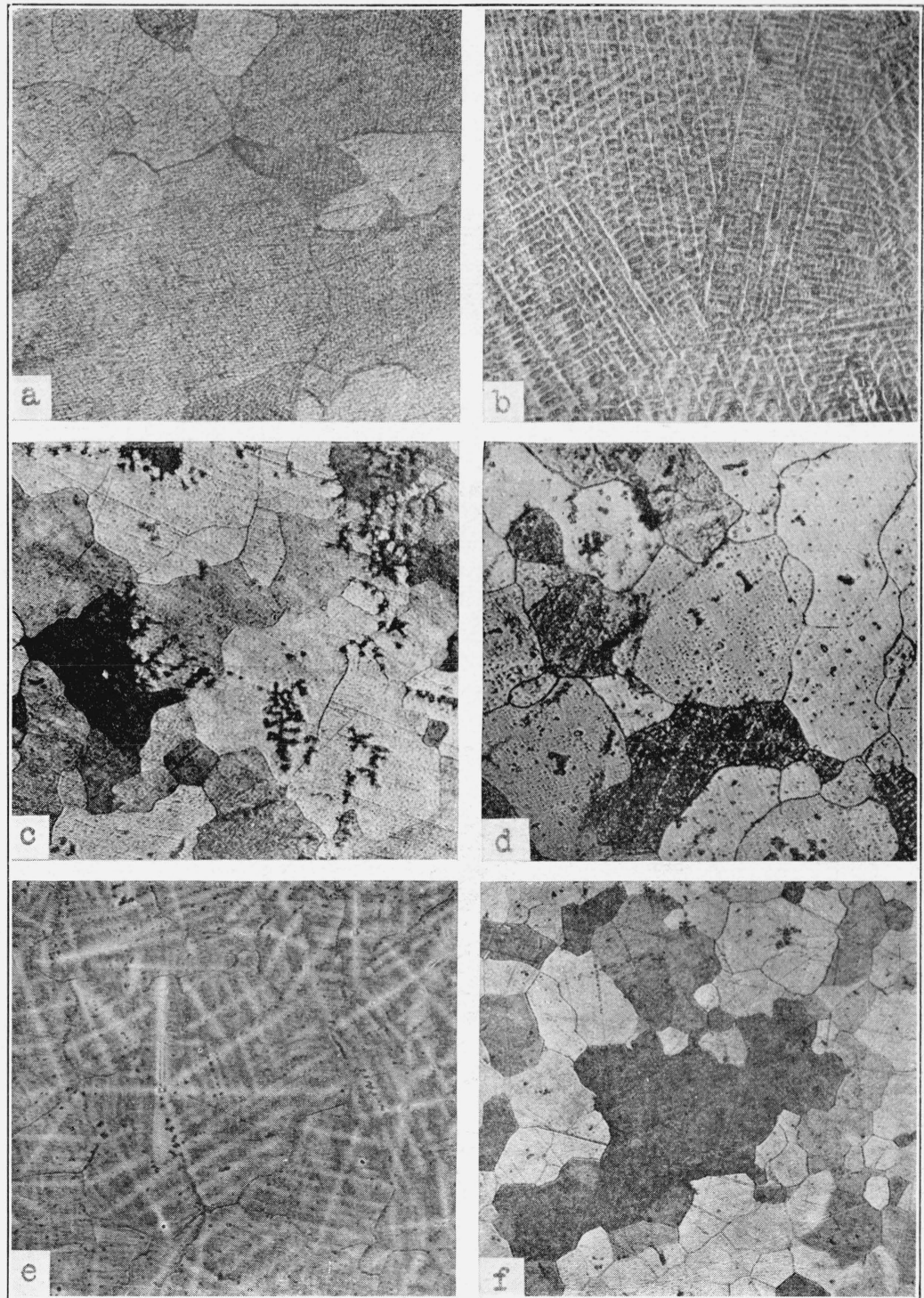

FIG. 33.-Microstructure characteristic of the gold solders tested $\times 90$

$a$, Alloy S-I, etched with chlorin water and $\mathrm{K} \mathrm{C} \mathrm{N;} b$, Alloy S-II etched with chlorin water and K C N; $c$, alloy S-IV, softened, etched with aqua regia; $d$, Alloy S-IV, hardened, etched with aqua regia; $e$, Alloy S-III etched with $\mathrm{K} \mathrm{C} \mathrm{N} ;$, Alloy $\mathrm{S}-\mathrm{V}$ etched with aqua regia. The dark dendritic patterns seen in $c$, are voids, probably caused by localized shrinkage. 
B. S. Journal of Research, RP32

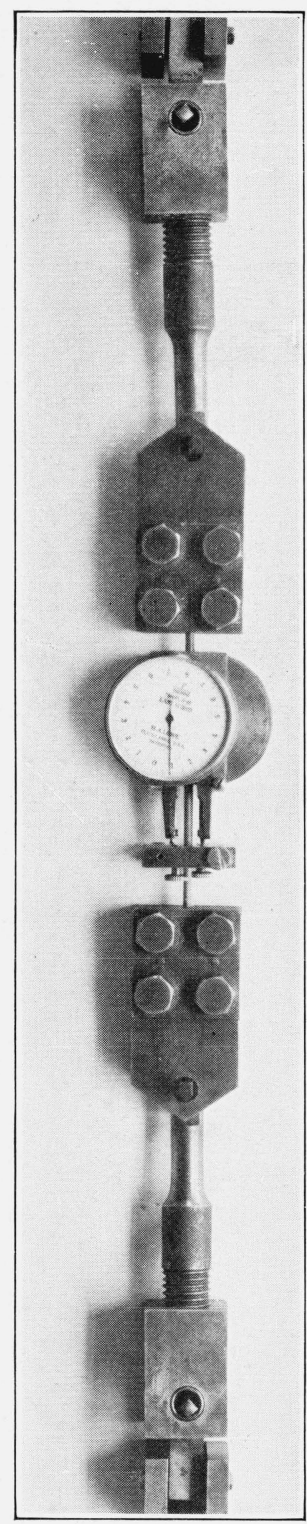

FIG. 34.-Self-aligning device, clamps, and extensometer used in tensile tests of castgold alloys 
solder. These lugs were then held in the clamps of the testing machine. Although this method was very satisfactory for some of the alloys, it was found that specimens of other alloys, especially those melting at relatively low temperatures, would almost invariably fail near the solder. This was true even when a silver solder melting at a comparatively low temperature was used. While such tests might prove of value in a study of the effects of soldering, and certainly do indicate that the strength of some of these materials is lowered by the soldering process, they are not suitable for determining the mechanical properties of the individual alloys. This method was therefore abandoned and it was necessary to use longer samples: The clamps finally adopted, together with the self-aligning device and the extensometer, are illustrated in Figure 34.

The self-aligning device consists of an arrangement whereby each end of the specimen is mounted on a system of two knife-edges, one at right angles to the other. This arrangement compensates for possible misalignment of the head of the testing machine.

The extensometer is similar in principle to the one used and described in connection with the study of wrought alloys and consists essentially of two dial micrometers mounted on opposite sides of the specimen. The micrometers measure the extension of that portion of the specimen lying between the two points of attachment, commonly called the gauge length. The effective gauge length of this extensometer is 2.85 inches. The micrometers are graduated in 0.0001 inch, and the error does not exceed 0.00002 inch.

In carrying out these tests the extensions, or deformations, corresponding to small load increments were observed and recorded until a stress well above the proportional limit or until the ultimate strength of the specimen was reached. In every case the specimen was loaded to rupture and the maximum load recorded as the ultimate strength. The loads and the corresponding deformations were then plotted to form the usual stress-strain diagrams. Proportional limit and modulus of elasticity were determined from these diagrams except in the case of materials having very low proportional limits, for which moduli were not determined. Typical stress-strain diagrams for a number of these alloys are shown in Figure 35. The elongation, or the ratio of the increase in length caused by tensile stress, to the original gauge length was measured after rupture of the sample. The gauge length used was 3 inches.

Of the 35 alloys - the compositions of which are given in Table 10-14 were selected for complete tests. This list includes alloys intended for a variety of uses. In some instances, where alloys intended for the same use were markedly different in composition two or more were selected from the same group. The mechanical properties of 24-carat gold were determined also. 
Determinations were made of the mechanical properties of at least three samples of each of these materials in each of the two conditions of heat treatment described. Where it was found that the different heat treatments produced no appreciable difference in the properties, only one series of values is reported. The values obtained for the various properties are presented in Table 14.

It is of interest to note that the relation between tensile strength and Brinell hardness, found to be nearly constant for the wrought

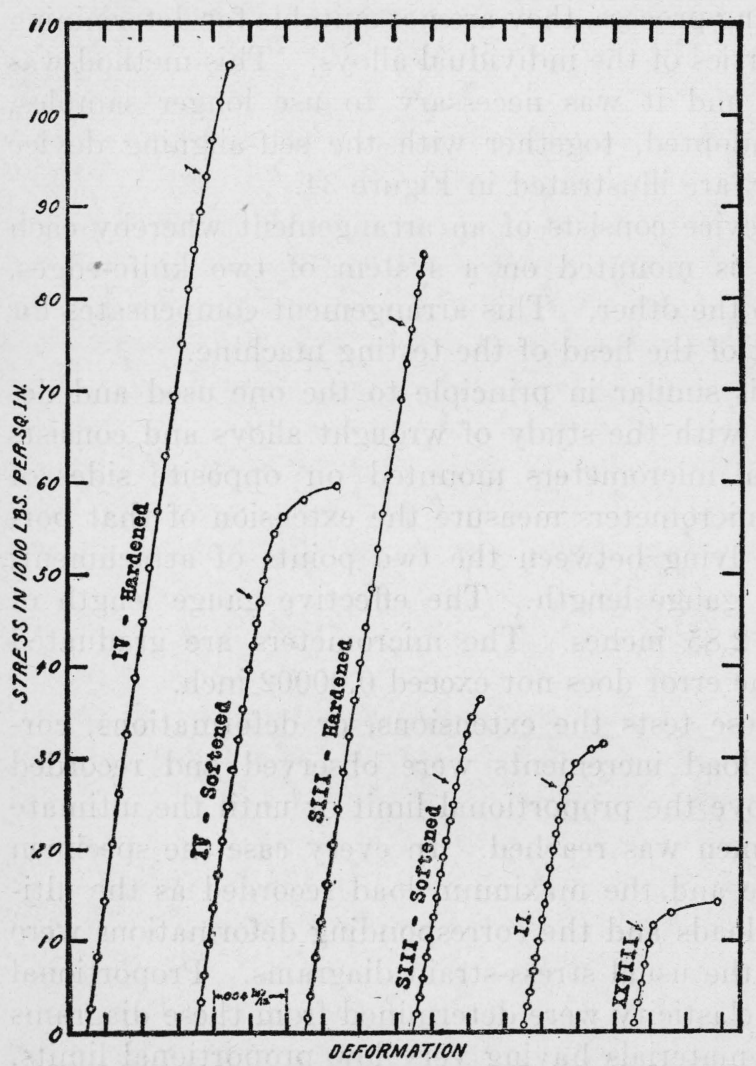

Fig. 35.-Stress-strain curves derived from tensile tests of cast gold alloys

Proportional limits are indicated by the arrows alloys, is quite variable for the cast materials in this group. This is probably due to the fact that the castings are less homogeneous than the wrought alloys.

An inspection of Table 14 will show wide variations in most of the properties determined. The values for proportionallimit range from less than 1,000 to nearly $95,-$ $000 \mathrm{lbs} . /$ in. $^{2}$, and the Brinell hardness numbers from 27 to 249 for 24-carat gold and Alloy IV, respectively. The elongations $\mathrm{range}$ from less than 1 per cent for several of the alloys to 34 per cent for 24-carat

gold. There are also marked differences in the melting ranges of the various alloys. Manifestly, there is a decided choice possible in selecting materials suitable for any specific purpose and definite values for the properties reported in this table are necessary for making the most efficient selection.

The following data on a few gold-foil fillings are included in this section for comparison with the cast-gold inlay. In securing these data six members of the dental profession, including recognized 
leaders in this field, were asked to cooperate in preparing test fillings. These cooperators were supplied with split steel molds or cavities one-eight inch square by three-sixteenths inch deep and with a quantity of gold foil, with the request that they fill the cavities, using as nearly as possible the technique employed by them in practice. The foil used was one of the well-known brands supplied to the profession, the same brand and grade being used throughout the tests. The fillings prepared by the cooperators were tested for density and Brinell hardness. They were also examined under the microscope for characteristic structure.

In determining the densities reported the volume of the test filling was calculated from micrometer measurements of its linear dimensions. The density was obtained by dividing the weight of the filling by this volume. For practical purposes the value for density obtained by this method may be considered as the weight of foil condensed into the cavity per unit volume of cavity. If there are irregularities in the surfaces of the fillings, due to imperfect adaptation to the cavity walls, this value was found to be slightly lower than that obtained by the usual method of weighing the sample in two media of different densities, such as air and water. Although density was determined by both methods, it is thought that in this instance the values obtained by the latter method are not so significant as those reported.

The fillings were sectioned, some perpendicularly to the direction of packing and others parallel to the direction of packing. Brinell hardness determinations were made at several points on each of these sections using the instrument previously described with a load of 6.4 $\mathrm{kg}$ (14.1 pounds). The values obtained for the density and Brinell hardness of the six fillings tested are given in Table 15. The Brinell hardness of three soft cast-inlay golds are also included in the table for ready comparison. Micrographs showing characteristic structure are presented in Figure 36.

TABLE 15.-Properties of foil fillings and soft inlay golds

\begin{tabular}{|c|c|c|c|c|}
\hline \multicolumn{3}{|c|}{ Foil fillings } & \multicolumn{2}{|l|}{ Cast-inlay golds } \\
\hline Sample No. & Density & $\begin{array}{c}\text { Brinell } \\
\text { hardness } \\
\text { number }\end{array}$ & Material & $\begin{array}{c}\text { Brinell } \\
\text { hardness } \\
\text { number }\end{array}$ \\
\hline & $\mathrm{g} / \mathrm{cm}^{3}{ }^{3}$ & 136 & 24-carat gold ${ }^{3}$-. & 27 \\
\hline - & $\begin{array}{l}17.3 \\
14.2\end{array}$ & $\begin{array}{r}50 \\
218 \\
21\end{array}$ & Alloy XXViI; 22 -carat gold ( 0.5 per cent copper). & 32 \\
\hline - & $\begin{array}{l}\text { 10. } \\
\text { 18. } \\
19.0\end{array}$ & $\begin{array}{l}01 \\
61 \\
60\end{array}$ & Alloy X X VIII; 22-carat gold ( 3.7 per cent copper) & 54 \\
\hline A verage & 17.1 & 46 & & \\
\hline
\end{tabular}

1 Brinell hardness of different spots varied from 22 to 46 .

2 Brinell hardness of different spots varied from 13 to 26 .

3 Density of 24-carat cast gold is $19.3 \mathrm{~g} / \mathrm{cm}^{3}$ (Smithsonian Physical Tables, 7th ed., p. 110). $5619^{\circ}-28-4$ 
By referring to Table 15 it will be noted that there are marked variations in the properties of the different fillings. The densities range from $14.2 \mathrm{~g}$ per cubic centimeter for sample No. 3 to $19.0 \mathrm{~g}$ per cubic centimeter for sample No. 6 , and the Brinell hardness numbers from 18 for sample No. 3 to 61 for sample No. 5 . It will also be noted that samples Nos. 1 and 3 are quite variable in hardness from place to place. The remaining samples were much more uniform.

The values obtained by averaging the six samples tested are 17.1 g. per cubic centimeter for density and 46 for Brinell hardness number. Using these values as a basis of comparison, it is seen that the gold-foil filling is markedly harder than an inlay cast of 24-carat gold. It is nearly as hard as an inlay cast of a 22-carat gold containing 3.7 per cent copper. The density is less than that of cast 24-carat gold.

(d) CASTING SHRINKAGE

The casting shrinkage of gold may be divided into three parts; namely, (1) the contraction of the liquid metal on cooling from the temperature at which it enters the mold to the freezing point, (2) the contraction of the metal on changing from the liquid to the solid state at constant temperature $\left(1,063^{\circ} \mathrm{C}\right.$., $1,945^{\circ} \mathrm{F}$. for pure gold), and (3) the contraction of the solid gold on cooling from the freezing point to room temperature.

A search of the literature failed to reveal any reliable value for part (1). Price, ${ }^{15}$ in his classical experiment, using a fused quartz mold, determined values for parts (2) and (3). These values he reported to be 1.46 per cent linear contraction due to change of state without change of temperature and 2.20 per cent linear contraction from the freezing point, $1,063^{\circ} \mathrm{C}$. $\left(1,945^{\circ} \mathrm{F}\right.$.) to $0^{\circ} \mathrm{C}$. $\left(32^{\circ} \mathrm{F}\right.$.). Price concludes that under favorable conditions all of the contraction of the gold, except that which occurs after the metal has solidified, is compensated for by the addition of liquid gold from the crucible.

It was thought advisable to verify this conclusion and determine the net casting shrinkage (or that which affects the dimensions of the casting) for some of the alloys of gold. The thermal contraction of the metal in the solid state was determined for 24-carat gold and some of its binary alloys. The apparatus ${ }^{16}$ used in making these determinations was that regularly used at this bureau for determining the thermal expansion of solids. A photograph of the instruments with a brief description is presented in Figure 37. The samples used were rods $30 \mathrm{~cm}$ long and approximately $1 \mathrm{~cm}$ in diameter. The temperature range for these tests was from the maximum temperature at which the sample was sufficiently rigid to maintain its shape without sagging, to room temperature. From the values determined in this

\footnotetext{
15 Price, W. A. Dental Cosmos, p. 265; March. 1911.

${ }^{16}$ For a detailed description of this apparatus see Souder and Hidnert, B. S. Sci. Paper No. 524, 21, p. 1; 1926.
} 
B. S. Journal of Research, RP32

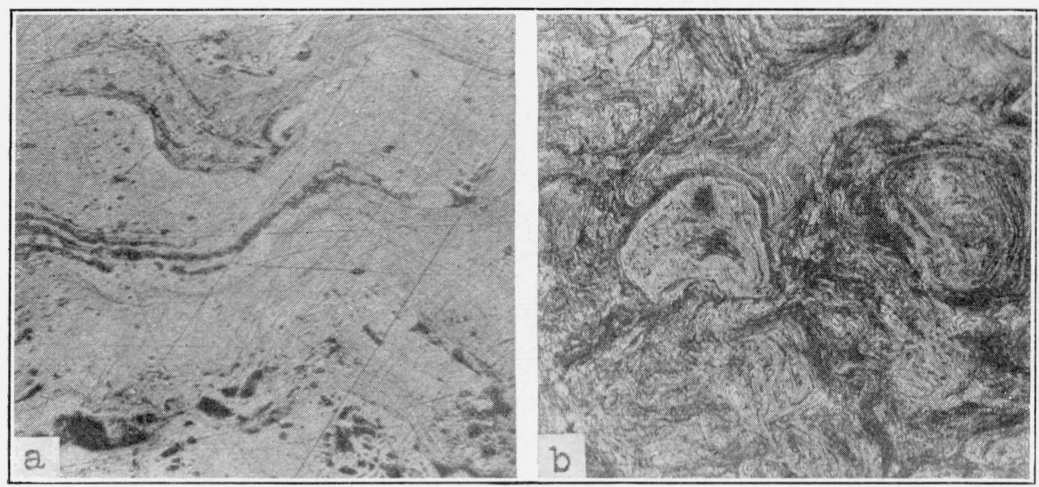

FIG. 36.-Micrographs of gold-foil fillings, etched with aqua regia, $\times 90$

$a$, Section parallel to the direction of packing; $b$, section perpendicular to the direction of packing. Note the laminated structure and voids due to incomplete condensation.

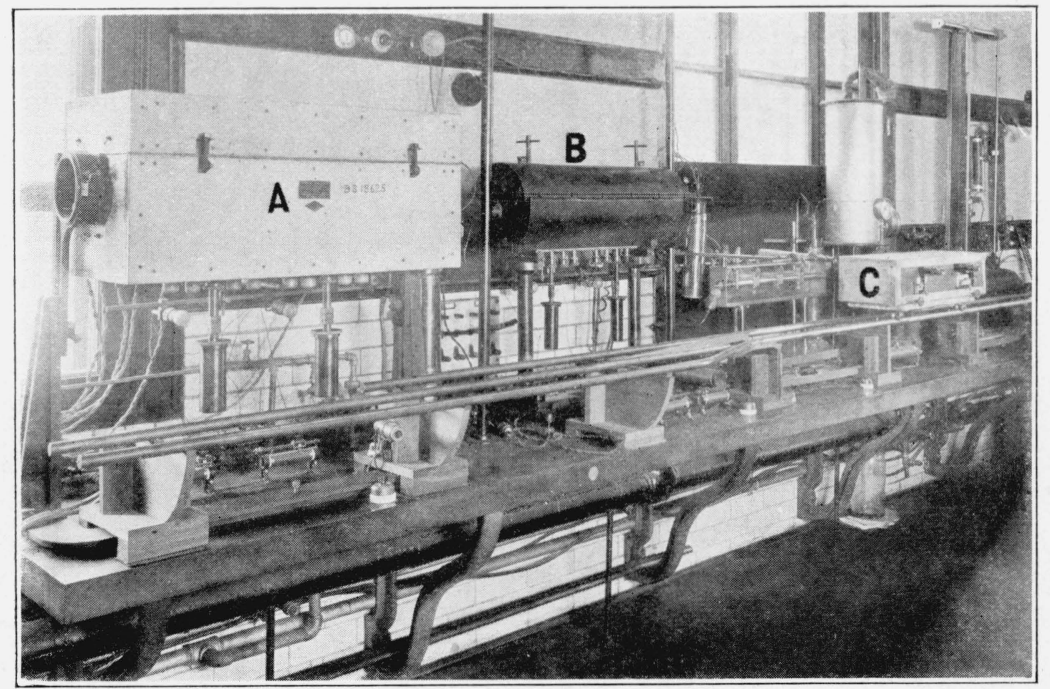

FIG. 37.-A pparatus for determining the thermal expansion of solids

Electric furnaces for heating the samples are shown at $A$ and $B$. The sample is placed in the furnace in a horizontal position and may be supported throughout its length. Very fine wires are passed over the ends of the sample and allowed to hang down through the tubes in the bottom of the furnace and are viewed through slots in the tube. Length changes, which are transmitted to the wires, are measured with micrometer microscopes mounted on a movable carriage shown at $C$. The furnace temperature is measured with thermocouples and a potentiometer. 
B. S. Journal of Research, RP32

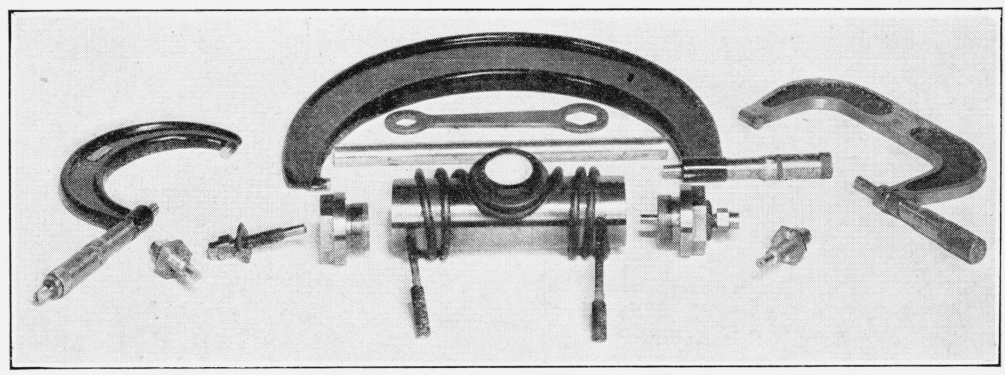

FIG. 38.-Apparatus for determining the net casting shrinkage of golds

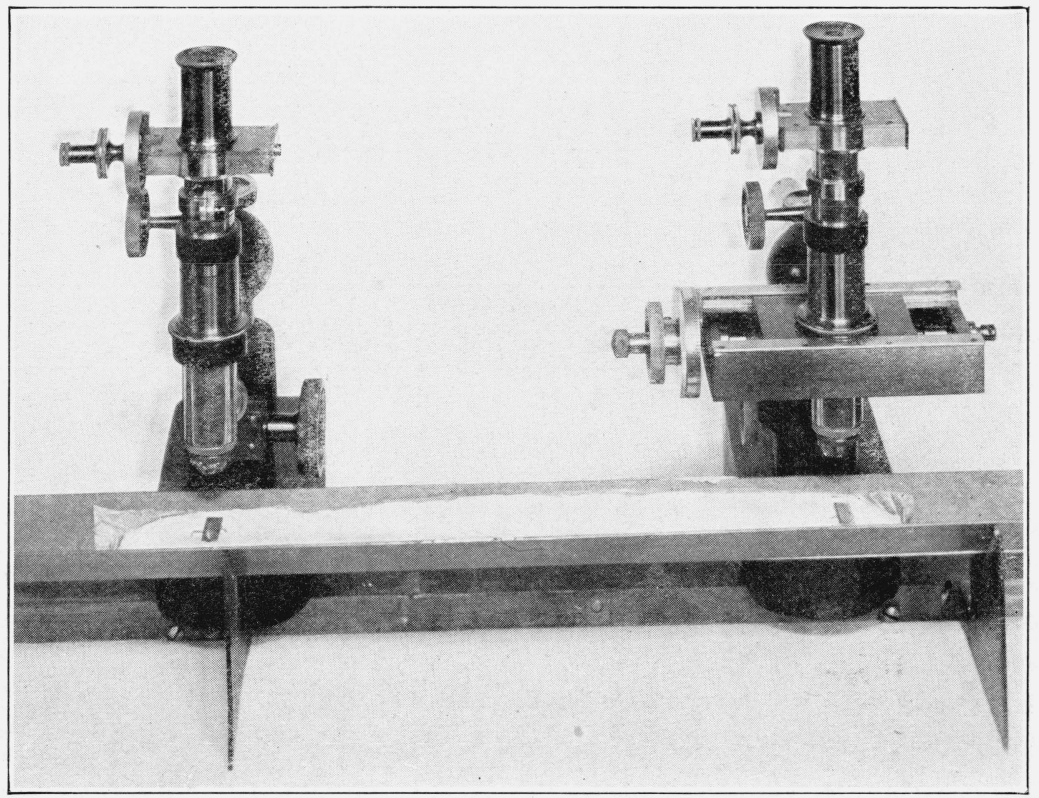

Fig. 45.-Apparatus for measuring setting changes of investments 
manner the total contraction from the melting point to room temperature was calculated by extrapolation. The values are given in Table 16. The apparatus used for measuring the net casting shrinkage is shown in Figure 38. The test procedure was as follows: The large caps were screwed tightly into the ends of the flask and the small hollow plugs screwed into the caps and locked in position with lock nuts. A metal rod, inserted through and supported by the hollow plugs, served as the pattern. The sprue was attached to the pattern with wax, the crucible former placed in position and the flask filled with investment. After the investment had set the crucible former, sprue, and pattern rod were removed. The hollow plugs were replaced with the solid plugs, thus forming a mold, the length of which is determined solely by the distance between the inside faces of the solid plugs. The flask was then placed in an oven and "burned out" at the desired temperature. The casting was made with an air-pressure machine in the ordinary manner.

TABLE 16.-Thermal contraction of golds

\begin{tabular}{|c|c|c|c|c|c|}
\hline & Material & $\begin{array}{l}\text { Maximum } \\
\text { temper- } \\
\text { ature of } \\
\text { test }\end{array}$ & $\begin{array}{l}\text { Observed } \\
\text { contraction } \\
\text { from maxi- } \\
\text { mum tem- } \\
\text { perature } \\
\text { to } 25^{\circ} \mathrm{C} \text {. }\end{array}$ & $\begin{array}{l}\text { Melting } \\
\text { point }^{1}\end{array}$ & $\begin{array}{l}\text { Computed } \\
\text { contraction } \\
\text { from melt- } \\
\text { ing point } \\
\text { to } 25^{\circ} \mathrm{C} \text {. }\end{array}$ \\
\hline $\begin{array}{l}24 \mathrm{carat} \\
90 \mathrm{Au}, 10 \mathrm{Ag} \\
90 \mathrm{Au}, 10 \mathrm{Cu} \\
90 \mathrm{Au}, 10 \mathrm{Ni}\end{array}$ & - & $\begin{array}{r}\circ C . \\
1,014 \\
973 \\
860 \\
886\end{array}$ & $\begin{array}{r}\text { Per cent } \\
1.71 \\
1.79 \\
1.48 \\
1.55\end{array}$ & $\begin{array}{r}\circ C . \\
1,063 \\
1,046 \\
926 \\
935\end{array}$ & $\begin{array}{r}\text { Per cent } \\
1.76 \\
2.03 \\
1.62 \\
1.91\end{array}$ \\
\hline
\end{tabular}

1 In this table, "melting point" is used to designate that temperature at which solidification is completed.

The metal parts of the apparatus are of an oxidation-resisting steel, the coefficient of thermal expansion of which is known. The temperatures of various parts of the flask were measured with small thermocouples and a potentiometer. The length, at room temperature, of each of the solid plugs was accurately determined. The distance between the outside faces of the solid plugs was measured with a micrometer. From these values the distance between the inside faces of the solid plugs, or the length of the mold, was computed.

After the casting had cooled to room temperature it was removed from the mold and its length measured with a micrometer. The difference between the length of the casting and the length of the mold is the net shrinkage of the casting. The castings were approximately $3 \frac{1}{4}$ inches long and 0.12 inch in diameter.

The temperature of the molds in which the castings were made was varied from approximately $300^{\circ} \mathrm{C}$. $\left(570^{\circ} \mathrm{F}\right.$.) to slightly above room temperature. The temperature of the metal was varied from the lowest at which a casting could be made to the maximum temper- 
ature obtainable with a good blowpipe, using hydrogen and compressed air. The casting pressure was varied from 5 to $20 \mathrm{lbs}$./in. ${ }^{2}$

A complete series of tests were made for one alloy, alloy XXVI $(90 \mathrm{Au}, 10 \mathrm{Cu})$. The values obtained are given in Table 17. A few tests by this method on other alloys and rougher measurements of the shrinkage of a large number of castings made for tensile test specimens indicated that no large variations from these values, due to variations in composition of the alloy, are to be expected for gold alloys within the range of composition commonly employed in dentistry.

It will be noted that the variations in the casting conditions had little, if any, effect, and that in every case the effective shrinkage is less than that of the solid metal from the melting point to room temperature. The average of the values for net casting shrinkage given in Table 17 is 1.25 per cent, whereas the contraction of the solid metal is 1.62 per cent.

TABLE 17.-Casting shrinkage of a gold-copper alloy (90 au, $10 \mathrm{cu}$ )

\begin{tabular}{|c|c|c|c|}
\hline Temperature of mold (approximate) & Casting temperature of gold & $\begin{array}{l}\text { Casting } \\
\text { pressure }\end{array}$ & $\begin{array}{l}\text { Net cast- } \\
\text { ing } \\
\text { shrinkage }\end{array}$ \\
\hline 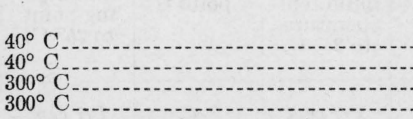 & $\begin{array}{l}\text { Moderate } \\
\text { High do }\end{array}$ & \begin{tabular}{r|} 
Lbs./in..$^{2}$ \\
20 \\
10 \\
10 \\
10
\end{tabular} & $\begin{array}{r}\text { Per cent } \\
1.24 \\
1.24 \\
1.26 \\
1.28\end{array}$ \\
\hline
\end{tabular}

Two possible explanations of this difference are suggested: (1) There may be sufficient friction or interlocking between the casting and the walls of the mold to hold and stretch the casting while it is cooling through that range of temperature within which the metal is very soft or weak, thus preventing the full normal shrinkage, and (2) the compensation of part of the total shrinkage of the solid metal may be dependent upon a difference in the rates of cooling of different parts of the casting. If part of the metal in the mold solidifies and cools to some temperature below the melting point before the metal in the sprue freezes, the shrinkage due to the cooling of this solid metal may be compensated by the addition of metal from the crucible.

The shrinkage of the liquid metal before the sprue freezes obviously would be compensated by the addition of metal from the crucible if the casting pressure were maintained. If a crust of solid metal has formed around the entire outside surface of the casting before the central part of the casting freezes, the shrinkage of this central portion as it cools to the freezing point may produce voids or porosity previously referred to as localized shrinkage in the casting. Such localized shrinkage would not affect the outside dimensions of the casting. 
In the case of shorter, bulkier castings the stretching force of the mold might not have so great an effect. The addition of more metal from the crucible would be less effective because of the relatively faster rate of freezing of the metal in the sprue. The shrinkage of such castings would probably be slightly greater than the values reported.

The effect of the casting temperature on the shrinkage of an alloy of 95 per cent aluminum and 5 per cent copper was determined in a different manner on larger castings. Molds were made of molding sand by ordinary foundry methods, using a pattern approximately $35 \mathrm{~cm}$ long by $1 \mathrm{~cm}$ square. Small steel plates were placed at each end of the mold to provide smooth end surfaces against which to cast. The distance between the end plates was measured with a scale divided to $0.5 \mathrm{~mm}$. The metal was melted according to regular foundry practice, except that the temperature was carried much higher than usual. The temperature of the metal in the ladle was measured with a thermocouple. Some of the molds were poured with metal at $1,030^{\circ} \mathrm{C}$. $\left(1,885^{\circ} \mathrm{F}\right.$.) and the remaining molds were poured when the metal had cooled to $725^{\circ}$ C. $\left(1,335^{\circ}\right.$ F.). After cooling the length of the castings was measured.

The average shrinkage of the castings poured at $1,030^{\circ} \mathrm{C} .\left(1,885^{\circ}\right.$ F.) was 1.61 per cent and of those poured at $725^{\circ} \mathrm{C}$. $\left(1,335^{\circ} \mathrm{F}\right.$.) 1.64 per cent. This indicates that the casting temperature has very little effect on the shrinkage and serves as a check on the method described above.

\section{SELECTION OF DENTAL GOLD ALLOYS}

In the foregoing sections various properties of dental gold alloys have been defined, and the significance of these properties in relation to the behavior of the alloys in service has been pointed out. From the data presented it is evident that the selection of a suitable alloy for a given use can be made on the basis of these physical properties. The principles of such a method of selection are embodied in the tentative specifications ${ }^{17}$ for dental gold alloys now being used in purchasing these materials for use by the various Government departments. These specifications were formulated by the Bureau of Standards in cooperation with the other Government departments concerned. In them definite minimum or maximum values are specified for such properties as proportional limit, tensile strength, percentage elongation, Brinell hardness, fusion temperature, and others. The values specified are based upon a combination of the results of an investigation of the properties of the available materials and of a theoretical consideration of the properties required to meet the demands of service. As the values for the various properties required

17 Souder, Wilmer, "Summary of reports on dental alloys"; J. A. D. A.; A pril, 1928. 
in the present specifications are tentative and are being revised as improvements are suggested, they are not included here. The principles of this method of selecting dental gold alloys, as outlined, are sufficient to illustrate a practical application of the data developed in this investigation. The perfection and general adoption of such a method would undoubtedly eliminate much of the waste incident to the use of unsatisfactory materials.

\section{ACCESSORY MATERIALS USED IN THE DENTAL CASTING PROCESS}

In order to determine the possible causes of dimensional inaccuracies of cast gold appliances other than the inaccuracies due to the casting shrinkage of the gold alloys, an investigation was made of the properties of the waxes used for making the pattern and the investments used for making the molds for these castings. It was thought that such an investigation might result in the development of methods of manipulating these materials that would not only avoid the introduction of further inaccuracies, but also compensate for the shrinkage of the cast gold alloys.

\section{PATTERN WAXES}

In the usual dental casting process the pattern for the casting is made by building up the appliance in pattern wax. The wax is warmed to a temperature at which it becomes soft and plastic, usually 40 to $50^{\circ} \mathrm{C}$. (104 to $122^{\circ} \mathrm{F}$.), depending upon its composition, and is adapted to the tooth or model in that condition. In order to determine the dimensional changes caused by the cooling of the pattern after being adapted, thermal expansion tests were made on five inlay pattern waxes. Four of these waxes, Nos. 1, 2, 3, and 4, were purchased on the open market and are believed to be representative of those in general use. Wax No. 5 was made up as an experimental material and contains 25 per cent carnauba, 60 per cent paraffin $\left(55^{\circ}\right.$ C. melting point), 10 per cent ceresin, and 5 per cent refined beeswax with a very small amount of oil soluble coloring matter. This wax at ordinary room temperature is sufficiently hard to withstand the necessary handling without being distorted and can be carved without chipping or flaking. It becomes soft and plastic at temperatures between 45 and $50^{\circ}$ C. ( 113 to $122^{\circ} \mathrm{F}$.), and can be almost completely eliminated from the investment mold by heating to $250^{\circ} \mathrm{C}$. $\left(480^{\circ} \mathrm{F}\right.$.) or higher temperatures. This material was used in making many of the experimental castings. The apparatus used in making the thermal-expansion tests was that previously described and illustrated in Figure 37. The samples used were approximately $300 \mathrm{~mm}$ long and $5 \mathrm{~mm}$ in diameter. The length changes due to changes in temperature are represented graphically in Figures 39 to 43 
and are summarized in Table 18. Values for the thermal expansion of an impression compound, used for taking impressions of the teeth and other parts of the mouth, are also included in the table and are represented graphically in Figure 44.

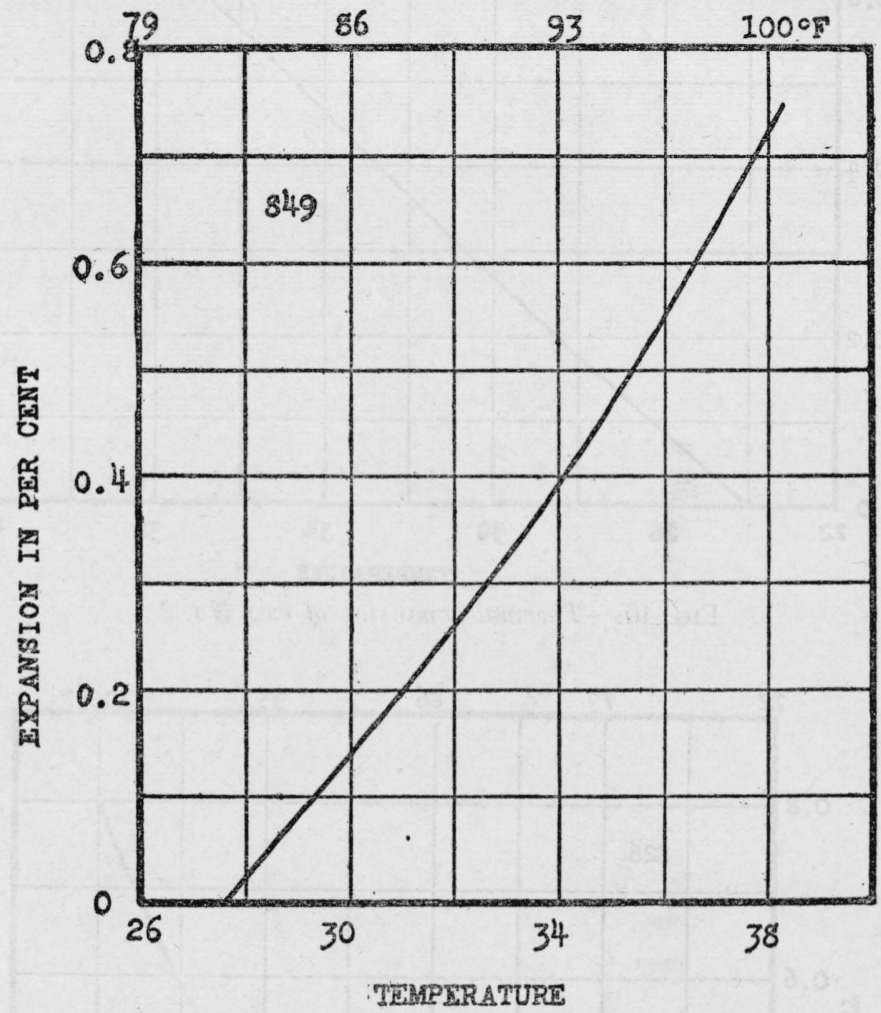

Fig. 39.-Thermal expansion of wax No. 1

TABLE 18.-Thermal expansion of five inlay waxes and one impression compound

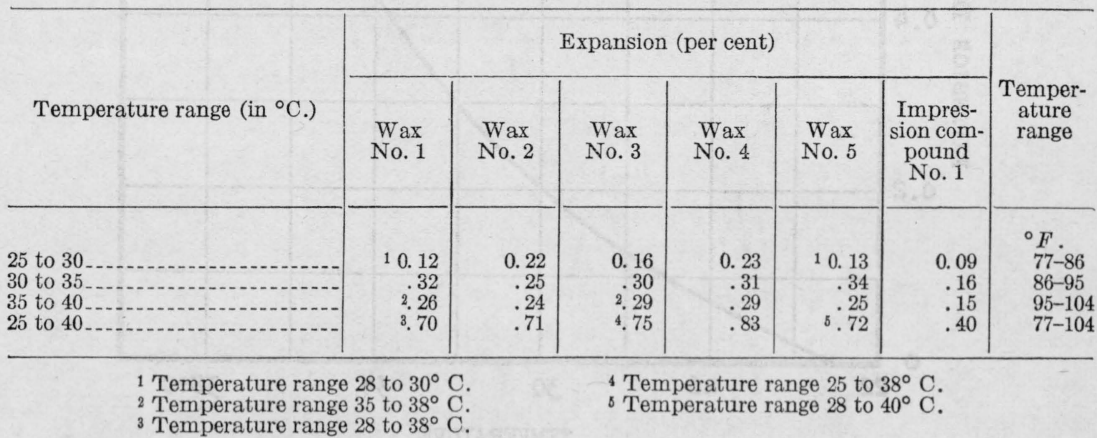

By referring to the values given in Table 18 it will be seen that if a pattern made of any of these inlay waxes is made to fit the cavity or 


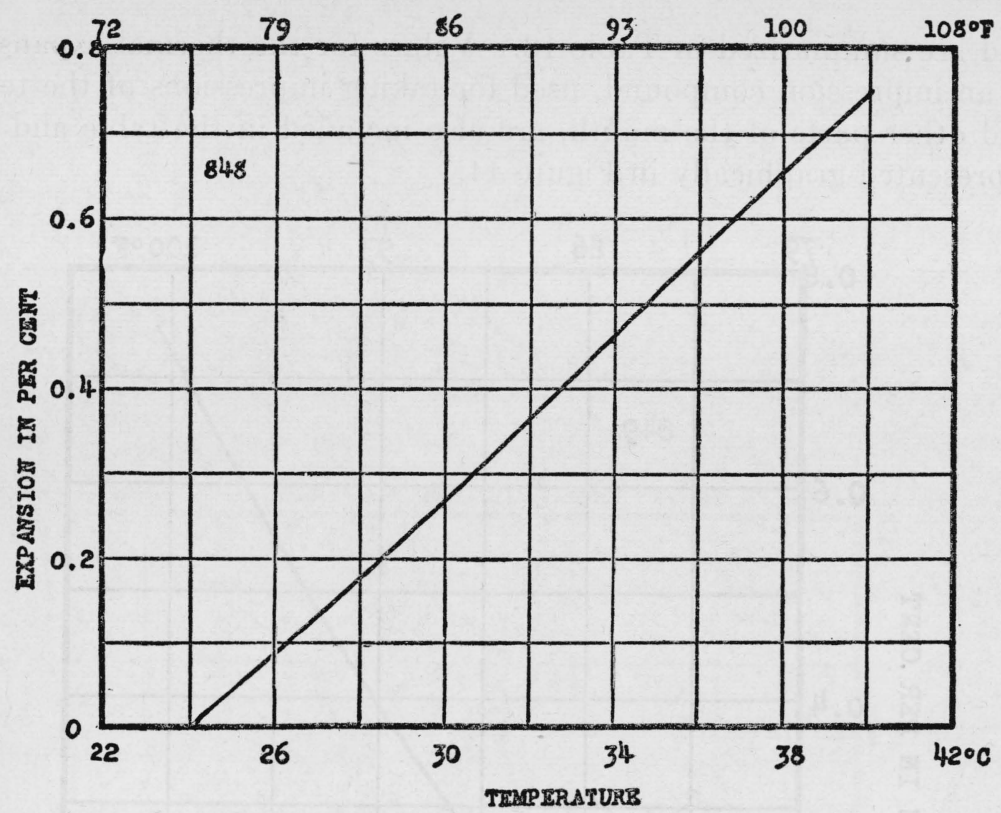

FIG. 40.-Thermal expansion of wax No. 2

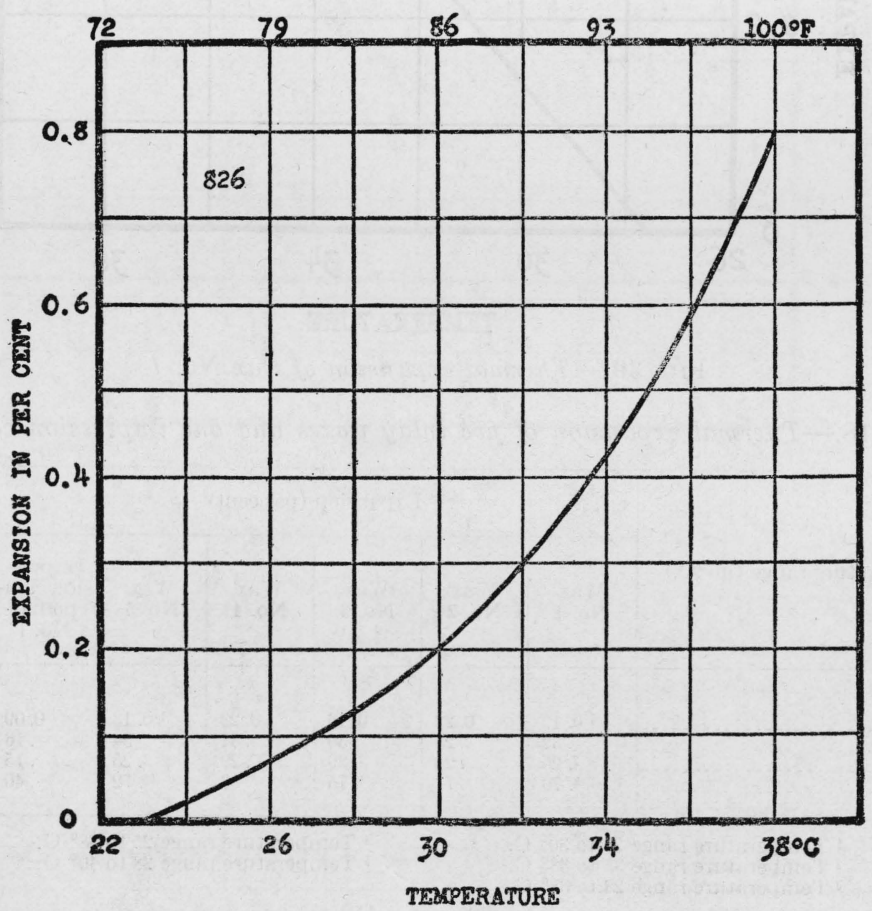

Fig. 41.-Thermal expansion of wax No. 3 
model at $40^{\circ} \mathrm{C}$. $\left(104^{\circ} \mathrm{F}\right.$.) and allowed to cool to $25^{\circ} \mathrm{C}$. $\left(77^{\circ} \mathrm{F}\right.$.), the pattern will be too small by about 0.7 to 0.8 per cent, depending upon the wax used. These values also indicate the degree to which the shrinkage of the cast gold alloys may be compensated for by expanding the wax pattern as suggested by Dr. C. S. Van Horn ${ }^{18}$ in 1910 . If the wax pattern is held in position under pressure and chilled and made to fit at $25^{\circ} \mathrm{C}$. $\left(77^{\circ} \mathrm{F}\right.$.) for example, it can be expanded from 0.7 to 0.8 per cent by reheating to $40^{\circ} \mathrm{C}$. $\left(104^{\circ} \mathrm{F}\right.$.).

It has been pointed out by Van Horn, Price, ${ }^{19}$ and others that if a wax pattern is heated a distortion or warpage due to the release of

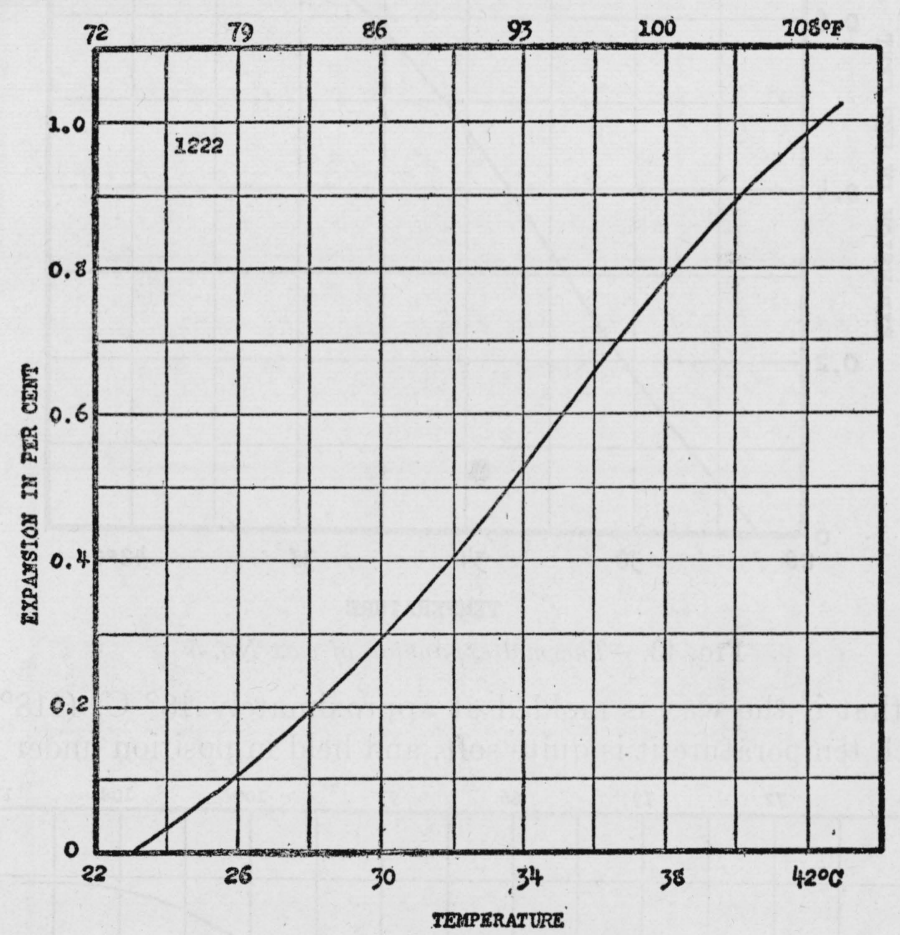

FIG. 42-Thermal expansion of wax No. 4

internal stresses is likely to result. Tests were made to verify this, and it was found that under certain conditions very serious distortions took place, but that by properly controlling conditions the effect could be so reduced as to be of no practical importance. These tests indicated that, in general, the softer a wax is when worked or the higher the temperature at which it is worked the higher will be the temperature to which it may be reheated without seriously distorting.

\footnotetext{
${ }^{18}$ Van Horn, C. S., "Castings; a review and commentary, including a technique"; Dental Cosmos, p. 873; August, 1910.

${ }_{19}$ Price, Weston A., "The laws determining the behavior of gold in fusing and casting"; Dental Cosmos, p. 265; March, 1912 .
} 
The length of time the wax is held at a given temperature on reheating also affects the amount of distortion. In general, the longer the time the greater the distortion will be. In the case of wax No. 5 it was

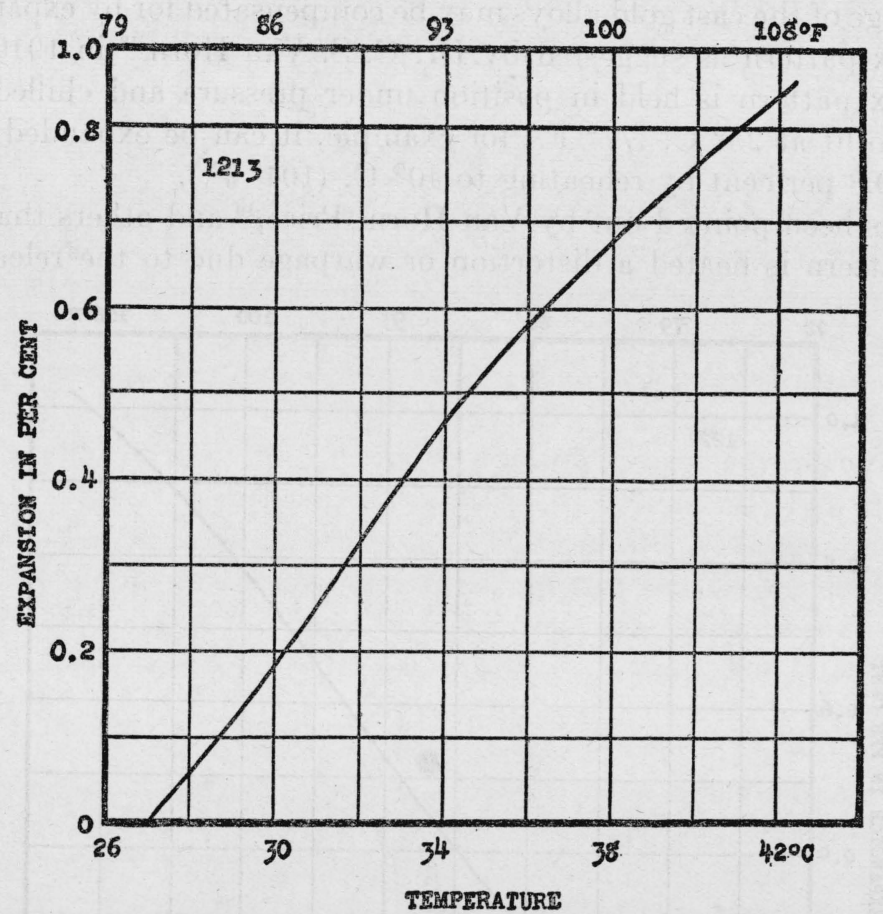

Fig. 43.-Thermal expansion of wax No. 5

found that if the wax is molded at approximately $48^{\circ} \mathrm{C}$. $\left(118^{\circ} \mathrm{F}\right.$.), at which temperature it is quite soft, and held in position under pres-

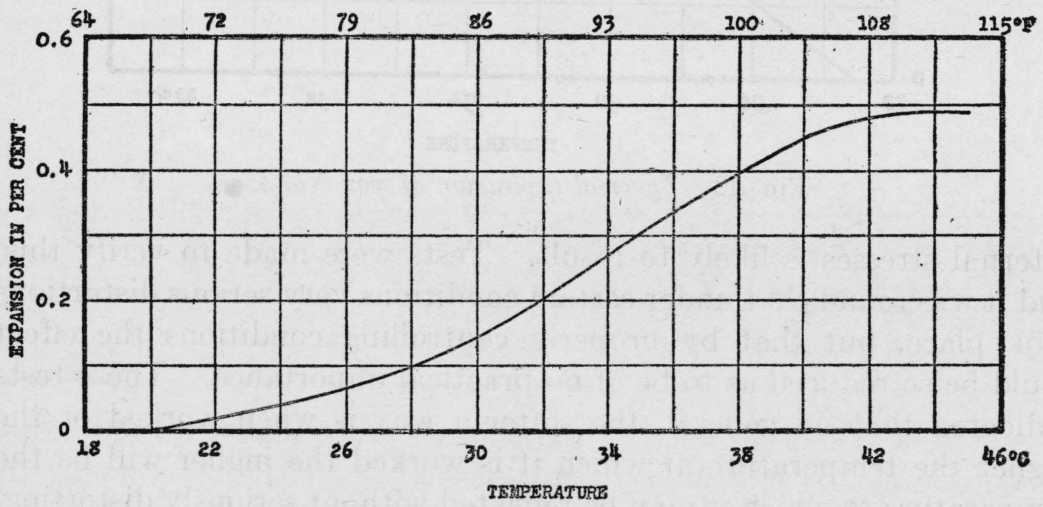

Fig. 44.-Thermal expansion of impression compound No. 1

sure while it is being chilled it may be reheated to $40^{\circ} \mathrm{C}$. $\left(104^{\circ} \mathrm{F}\right.$.) and held at that temperature for 45 minutes or longer without appreciable distortion. 
By holding the pattern in position under pressure and chilling and, when necessary, adding small quantities of wax where required the pattern may be made to fit at $27^{\circ} \mathrm{C}$. $\left(81^{\circ} \mathrm{F}\right.$.) or even lower temperatures. If the pattern is made of wax No. 5 , heating it from $27^{\circ} \mathrm{C}$. $\left(81^{\circ} \mathrm{F}\right.$.) to $40^{\circ} \mathrm{C}$. $\left(104^{\circ} \mathrm{F}\right.$.) will result in an expansion of 0.76 per cent, which can be used to compensate for part of the shrinkage of the cast gold alloy.

\section{INVESTMENTS}

Most of the investments or materials used for making the molds for dental castings consist chiefly of plaster of Paris and silica, although small quantities of other materials are often added as modifiers. The molds are made by mixing the investment powder and water to the desired consistency and pouring the mixture around the wax pattern. The investment sets or hardens because of the reaction between the water and the plaster of Paris and is then heated to drive off the excess moisture and to eliminate the wax pattern. Dimensional changes of the mold caused by the setting reaction or by heating may affect the dimensions of the casting. Other properties of the mold to which inaccuracies of the casting may be attributed are insufficient strength to withstand the pressure of the molten metal as it enters the mold, resulting in a distorted casting; insufficient porosity to permit the escape of the air or other gases in the mold, resulting in an incomplete casting; and roughness of the surface of the casting. These properties were determined for a number of investments and the effects of variations in the manipulative procedure were studied.

Eleven investments and two artificial stone compounds selected as representative of those in general use were purchased for test. The approximate composition of these as determined by chemical analysis ${ }^{20}$ are given in Table 19.

TABLE 19.-Approximate composition of investments and artificial stone compounds

\begin{tabular}{|c|c|c|c|c|c|c|c|c|c|c|c|}
\hline & \multicolumn{11}{|c|}{ Percentage by weight } \\
\hline & $\begin{array}{c}\text { No. } \\
3\end{array}$ & No. & No. & No. & $\underset{9}{\text { No. }}$ & $\begin{array}{c}\text { No. } \\
10\end{array}$ & $\begin{array}{c}\text { No. } \\
11\end{array}$ & $\begin{array}{c}\text { No. } \\
13\end{array}$ & No. & $\begin{array}{c}\text { No. } \\
18\end{array}$ & $\begin{array}{c}\text { No. } \\
19\end{array}$ \\
\hline $\begin{array}{l}\text { Caicined gypsum }\left(\mathrm{CaSO}_{4} 1 / 2 \mathrm{H}_{2} \mathrm{O}\right)_{-} \\
\text {Anhydrite }\left(\mathrm{CaSO}_{4}\right)\end{array}$ & 56 & 37 & 31 & 30 & 27 & 24 & 19 & $\begin{array}{l}19 \\
77\end{array}$ & $\begin{array}{l}24 \\
74\end{array}$ & 26 & 39 \\
\hline Siliceous matter (mainly silica) ... & 41 & 59 & 67 & 68 & 72 & 73 & 80 & 2 & (1) - & 72 & 58 \\
\hline Boric acid. & (n-n & & & - & 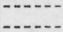 & (n) & (n) & & 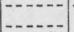 & 1 & $\overline{2}$ \\
\hline Coloring matter and impurities... & 3 & 1 & 2 & 2 & 1 & & 1 & $\overline{2}$ & 2 & 1 & 1 \\
\hline
\end{tabular}

$\Lambda$ number of experimental investments were made up and tested to determine the effects of the fineness of the silica, of varying the proportions of plaster of Paris and silica, and of the addition of small quantities of other materials.

\footnotetext{
${ }^{20}$ The author is indebted to T. P. Sager and R. B. Rudy, of the Bureau of Standards, for analyzing these materials,
} 
(a) DIMENSIONAL CHANGES CAUSED BY SETTING

A photograph of the instrument used for determining the dimensional changes of investments owing to crystallization or setting is shown in Figure 45. The instrument consists of a V-shaped support for the investment and two micrometer microscopes attached to a common base. The investment is mixed and poured into the Vshaped support which is lined with waxed paper to prevent the investment from adhering to its walls. Two small metal plates, on which are ruled reference lines, are placed in position, one at each end of the sample. These plates are provided with short projections which are embedded in the investment and prevent motion of the plates relative to the sample. Any length change of the sample results in a corresponding change in the distance between the reference lines and is measured with the micrometer microscope. The length of the samples used was $30 \mathrm{~cm}$, and the length changes were determined with an accuracy of 0.005 per cent of the total length. In some cases the increase in temperature, due to the setting reaction, was measured by means of a mercurial thermometer placed on the sample and covered with cotton wool. The values obtained are given in Table 20.

TABLE 20.-Setting changes of investments

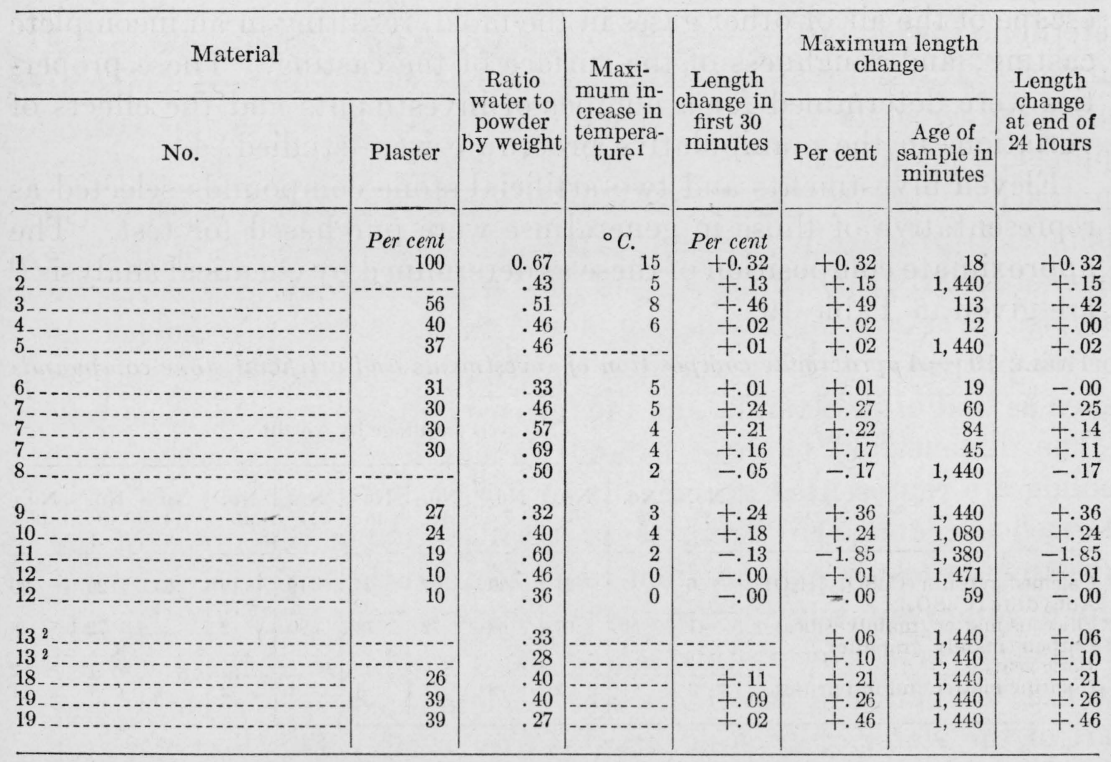

1 As measured with a thermometer on the surface of the sample. Temperature inside the sample was probably very slightly higher.

2 Artificial stone compound.

It will be noted that most of the materials tested expanded on setting, the amounts of expansion ranging up to 0.5 per cent. In general, the expansion increases as the plaster content increases, 
though this is not always true. Increasing the proportion of water decreases the expansion in most cases. It will be noted that investment No. 11 contracted 1.85 per cent on setting. This may be due in part to the high water ratio necessary because of the extreme fineness of the powder and in part to the low plaster content. The expansion of the two artificial stone compounds is seen to be comparatively small.

The rise in temperature on setting varied from $0^{\circ}$ to $15^{\circ} \mathrm{C}$. For the usual casting investment the rise in temperature is about $5^{\circ} \mathrm{C}$. While this is sufficient to cause an appreciable expansion of the wax pattern, this effect was not observed in practice. This may be due to the fact that the evolution of heat occurs simultaneously with the setting of the investment, and that the expansion of the investment during setting is very nearly equal to that of the wax caused by the increase in temperature.

(b) DIMENSIONAL CHANGES CAUSED BY HEATING

The samples used for determining the dimensional changes of investments caused by changes in temperature were $30 \mathrm{~cm}$ long and similar to those used for determining setting changes. The apparatus used was the same as that shown in Figure 37. In some cases an additional thermocouple was embedded in the sample in order to determine the lag of the temperature of the sample behind that of the furnace. It was found that in these tests when the furnace temperature was increased the temperature of the center of the sample lagged appreciably until the free water was driven off and then rapidly approached that of the furnace, after which the two temperatures changed at practically the same rate. The slower the rate of heating the more nearly the temperature of the furnace represented that of the sample. The rate of heating employed in these tests was such that for the purposes of this report the temperature of the furnace may be taken as that of the sample, and the furnace temperatures are reported.

The dimensional changes caused by heating and by subsequent cooling are represented graphically in Figures 46 to 62 and are summarized in Table 21. From these it will be noted that most of the investments tested expand from room temperature up to a temperature of approximately $125^{\circ}$ to $150^{\circ} \mathrm{C}$. $\left(255^{\circ}\right.$ to $300^{\circ} \mathrm{F}$.). (If the rate of heating were slower, this temperature would be slightly lower.) At this temperature the free water is eliminated very rapidly, and part of the water of crystallization is driven off. This loss of water of crystallization is accompanied by a shrinkage, the magnitude of which is largely dependent on the percentage of plaster present. In the case of investment No. 1, 100 per cent plaster (fig. 46), this shrinkage is very. large and continues as the temperature is raised to $560^{\circ}$ C. $\left(1,040^{\circ} \mathrm{F}\right.$.) (the maximum temperature reached in this test). 
In the case of the investments containing 10 to 60 per cent plaster this first shrinkage is relatively small and takes place over a short temperature range. So far as the dimensions of the mold are concerned, it is of little importance. As the temperature is increased a second expansion takes place up to a temperature of $250^{\circ}$ to $350^{\circ} \mathrm{C}$. $\left(480^{\circ}\right.$ to $660^{\circ} \mathrm{F}$.), when a second shrinkage begins. In most cases this second shrinkage is much greater than the first and takes place over

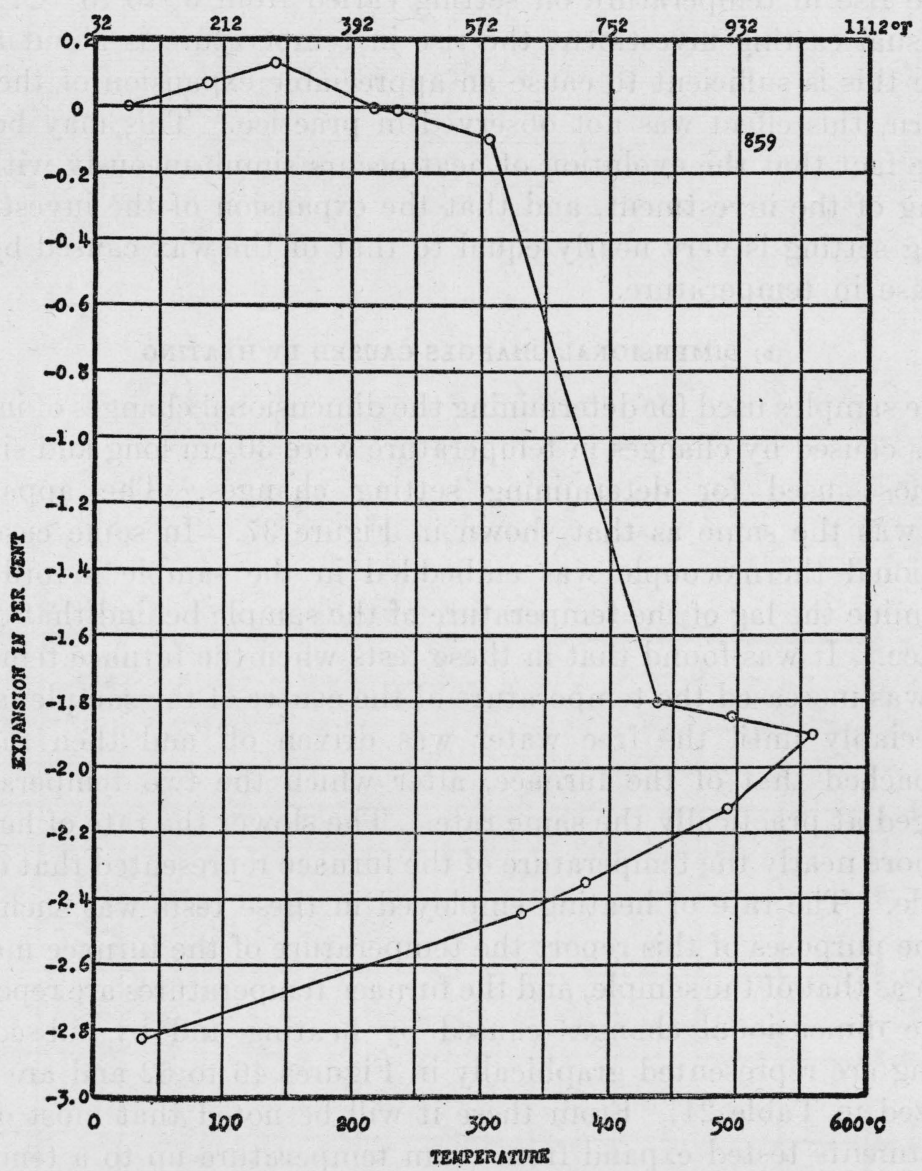

FIG. 46.-Thermal expansion of investment No. 1

a much larger temperature range. It is probably due to the loss of the remaining water of crystallization. At about $400^{\circ}$ to $450^{\circ} \mathrm{C}$. $\left(750^{\circ}\right.$ to $840^{\circ} \mathrm{F}$.) a third expansion begins and continues up to approximately $600^{\circ} \mathrm{C} .\left(1,110^{\circ} \mathrm{F}\right.$.). Above $600^{\circ} \mathrm{C} .\left(1,110^{\circ} \mathrm{F}\right.$.) an increase in temperature causes very little change in length for most of the investments tested. Usually there is a very slight shrinkage, though in most cases this is so small that it is negligible. 
TABLE 21.-Dimensional changes with temperature

\begin{tabular}{|c|c|c|c|c|c|c|c|c|c|}
\hline & \multicolumn{2}{|l|}{ Material } & \multicolumn{2}{|c|}{ First contraction } & \multicolumn{2}{|c|}{ Second contraction } & \multirow{2}{*}{$\begin{array}{c}\text { Maxi- } \\
\text { mum } \\
\text { tempera- } \\
\text { ture of } \\
\text { test }\end{array}$} & \multirow{2}{*}{$\begin{array}{l}\text { Length } \\
\text { change } \\
\text { to maxi- } \\
\text { mum } \\
\text { tempera- } \\
\text { ture }\end{array}$} & \multirow{2}{*}{$\begin{array}{l}\text { Length } \\
\text { change } \\
\text { after } \\
\text { cooling }\end{array}$} \\
\hline & No. & Plaster & $\begin{array}{l}\text { Temper- } \\
\text { ature } \\
\text { range }\end{array}$ & $\begin{array}{l}\text { Length } \\
\text { change }\end{array}$ & $\begin{array}{c}\text { Temper- } \\
\text { ature } \\
\text { range }\end{array}$ & & & & \\
\hline & & $\begin{array}{c}\text { Per cent } \\
100 \\
56 \\
40 \\
37\end{array}$ & $\begin{array}{c}{ }^{\circ} C . \\
140-560 \\
140-165 \\
175-200 \\
150-195 \\
140-180\end{array}$ & $\begin{array}{c}\text { Per cent } \\
+0.13-1.90 \\
+.13-+.03 \\
+.15-.11 \\
+.14-.11 \\
+.14-.13\end{array}$ & $\begin{array}{l}305-435 \\
300-470\end{array}$ & $\begin{array}{r}+0.09-0.52 \\
+.14-.64 \\
+\quad .18-.43 \\
+\quad .22-.09\end{array}$ & $\begin{array}{r}{ }^{\circ} C . \\
560 \\
503 \\
511 \\
501 \\
511\end{array}$ & $\begin{array}{c}\text { Per cent } \\
1-1.90 \\
2-.47 \\
2-.61 \\
2-.35 \\
2-.02\end{array}$ & $\begin{array}{r}\text { Per cent } \\
-2.82 \\
-1.26 \\
-1.41 \\
-1.11 \\
-.78\end{array}$ \\
\hline & & $\begin{array}{c}31 \\
30 \\
30 \\
-27\end{array}$ & & $\begin{array}{r}+.11-.07 \\
+.15-.14 \\
+.15-.12 \\
+.13-.12 \\
+.16-.16\end{array}$ & & $\begin{array}{l}+.20-.15 \\
+.22-.06 \\
+.25-.02 \\
+.26-.02 \\
+.27-.09\end{array}$ & $\begin{array}{l}510 \\
623 \\
650 \\
500 \\
800\end{array}$ & $\begin{array}{l}2-.03 \\
1+.42 \\
1+.49 \\
2+.18 \\
+.70\end{array}$ & $\begin{array}{l}-.84 \\
-.79 \\
-.75 \\
-.62 \\
-.61\end{array}$ \\
\hline & & $\begin{array}{l}24 \\
19 \\
10\end{array}$ & $\begin{array}{r}140-170 \\
105-155 \\
92-96 \\
125-230\end{array}$ & $\begin{array}{r}+.14-.13 \\
+.01-.01 \\
+.09-.07 \\
+.09-.05\end{array}$ & & $\begin{array}{l}+.23-.02 \\
+.26-.20 \\
+.29+.23 \\
+.02-.17\end{array}$ & $\begin{array}{l}512 \\
602 \\
499 \\
370\end{array}$ & $\begin{array}{l}2+.18 \\
2+.82 \\
2+.48 \\
1-.17\end{array}$ & $\begin{array}{l}-.64 \\
-.42 \\
-.16 \\
-.74\end{array}$ \\
\hline 9 & & $\begin{array}{r}26 \\
39 \\
30\end{array}$ & $\begin{array}{l}135-180 \\
165-180 \\
175-235 \\
195-215\end{array}$ & $\begin{array}{l}+.16-.00 \\
+.20-.13 \\
+.20-.15 \\
+.15-.14\end{array}$ & $\begin{array}{c}235-505 \\
320-405 \\
-335-445\end{array}$ & $\begin{array}{r}+.02-1.92 \\
+.28-.19 \\
+.22-.02\end{array}$ & $\begin{array}{l}505 \\
828 \\
675 \\
720\end{array}$ & $\begin{array}{r}1-1.92 \\
1+.87 \\
1+.89 \\
1+.40\end{array}$ & $\begin{array}{l}-2.65 \\
=.56 \\
=.47 \\
-.91\end{array}$ \\
\hline
\end{tabular}

1 Contracting at maximum temperature of test.

2 Expanding at maximum temperature of test.

3 Proprietary investments.

4 Mixed with 25 per cent less than normal amount of water.

$s$ Artificial stone compound.

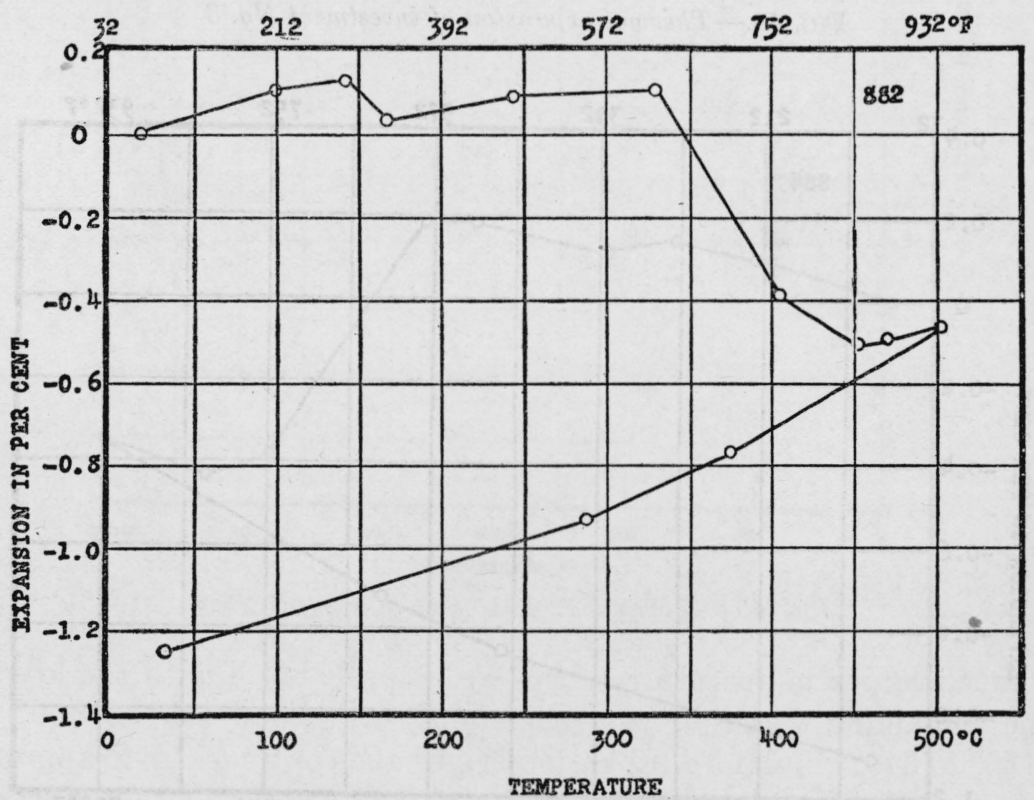

FIG. 47.-Thermal expansion of investment No. 2

All of the investments tested contract very markedly when allowed to cool after being heated to temperatures above $125^{\circ} \mathrm{C}$. $\left(225^{\circ} \mathrm{F}.\right)$. Investments held at any constant temperature, except 


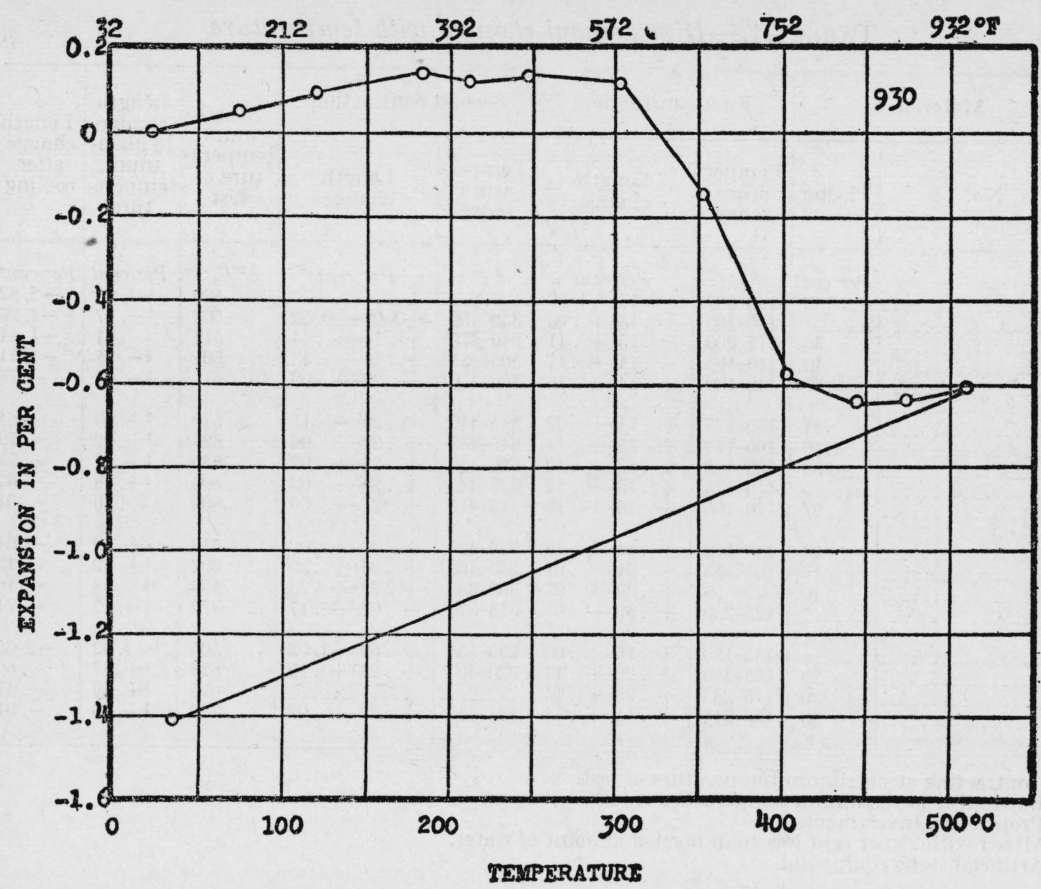

Fig. 48.-Thermal expansion of investment No. 3

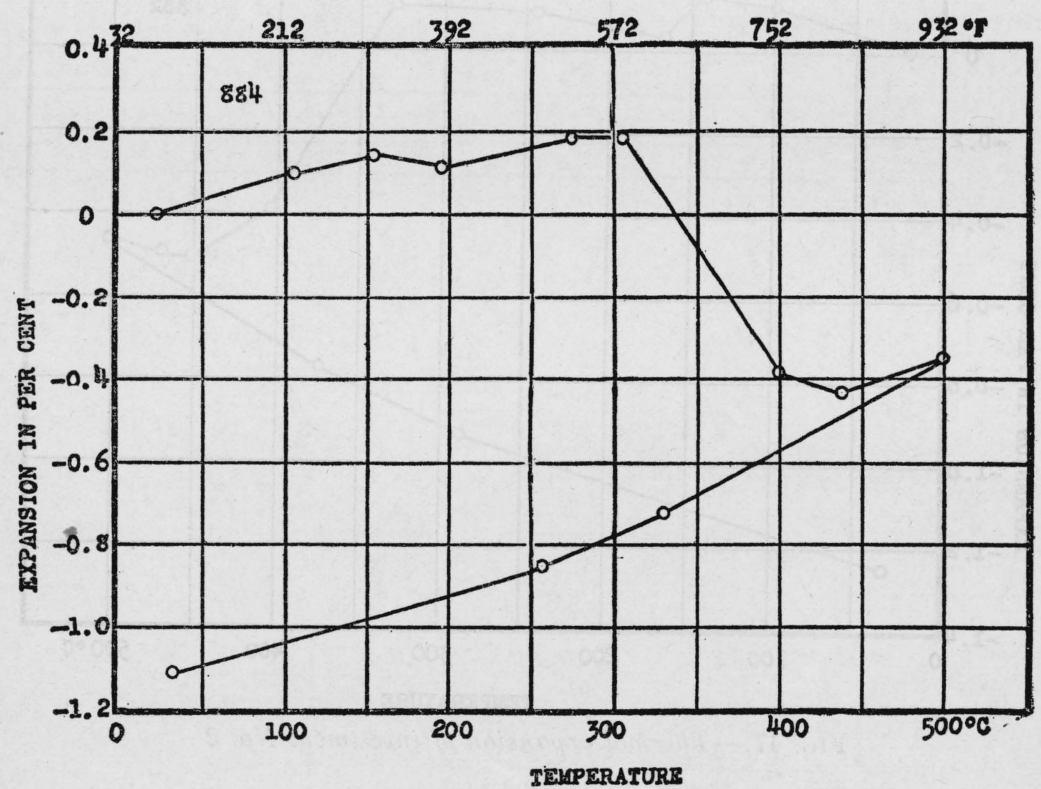

FIG. 49.-Thermal expansion of investment No. 4 
within the two contraction ranges indicated, did not shrink, even when held for several hours.

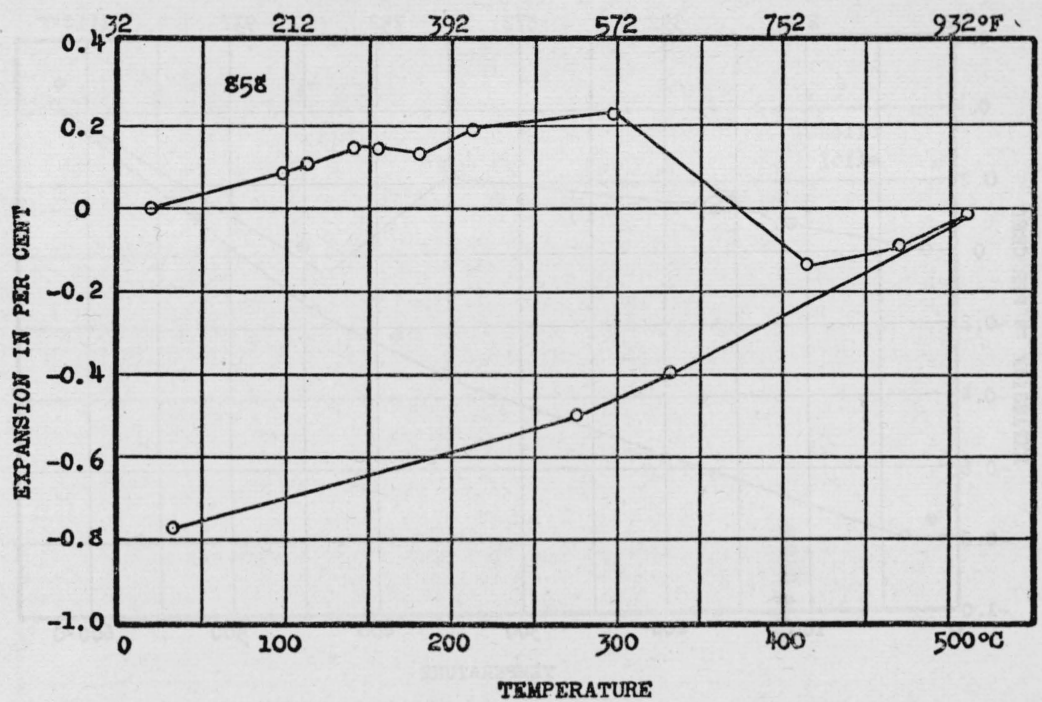

FIG. 50.-Thermal expansion of investment No. 5

In Figure 51 are shown the results of two thermal expansion tests on the same sample of investment No. 6. In the first test the sample was heated to approximately $500^{\circ} \mathrm{C}$. $\left(930^{\circ} \mathrm{F}\right.$.) and allowed to cool to room temperature. The sample was then heated to slightly

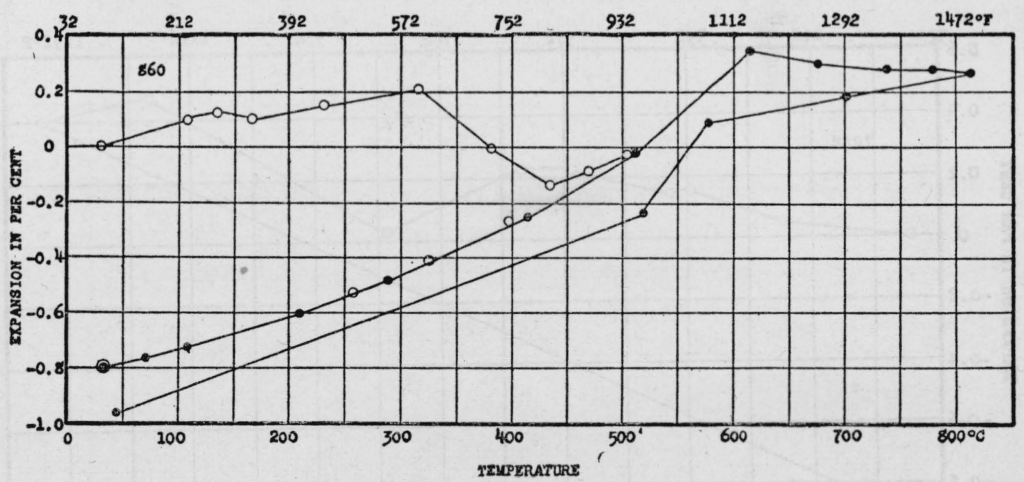

FIG. 51.-Thermal expansion of investment No. 6

The light circles represent the observations during the first test, when the sample was heated to approximately $500^{\circ} \mathrm{C}$. and allowed to cool to room temperature. The dark circles represent the observations on a second heating and cooling

above $800^{\circ}$ C. $\left(1,475^{\circ}\right.$ F.) and again allowed to cool to room temperature. After cooling to room temperature following the first heating to $500^{\circ} \mathrm{C}$. $\left(930^{\circ} \mathrm{F}\right.$.) the investment was 0.8 per cent shorter 
than its original length. It will be noted that the first cooling curve very nearly coincides with the second heating curve up to the maxi-

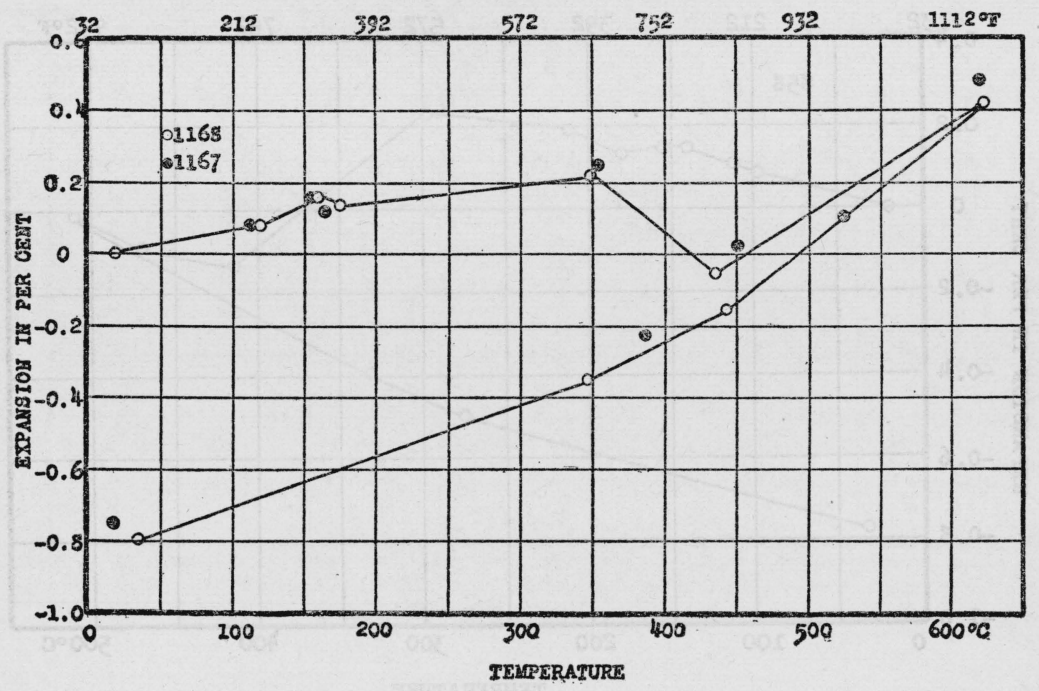

Fig. 52.-Thermal expansion of investment No. 7

The light circles represent the expansion of a sample made of $100 \mathrm{~g}$ of powder and $46 \mathrm{ml}$ of water, and the dark circles that of a sample made of $100 \mathrm{~g}$ of powder and $35 \mathrm{ml}$ of water

mum temperature of the first heating. This indicates that the shrinkage caused by cooling from $500^{\circ} \mathrm{C}$. $\left(930^{\circ} \mathrm{F}\right.$.) may be corrected by reheating to that temperature. If, however, the investment is

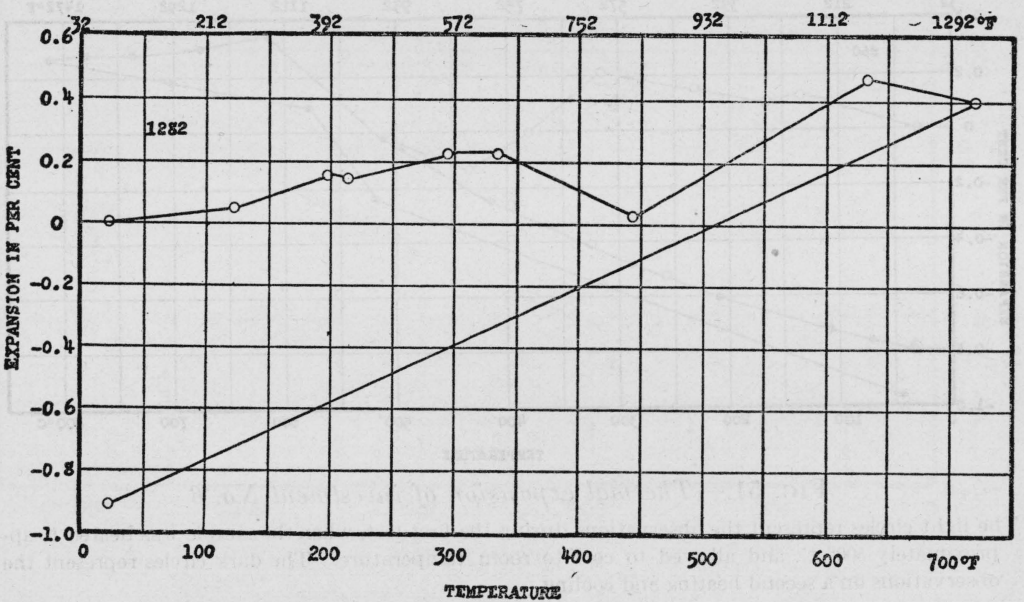

Fig. 53.-Thermal expansion of investment No. 20

allowed to cool from $500^{\circ} \mathrm{C}$. $\left(930^{\circ} \mathrm{F}\right.$.) and is then reheated to a temperature lower than $500^{\circ}$ C. $\left(930^{\circ}\right.$ F.) - for example, $300^{\circ} \mathrm{C}$. 
$\left(570^{\circ}\right.$ F.) - it will be appreciably shorter than it was when first heated to that temperature.

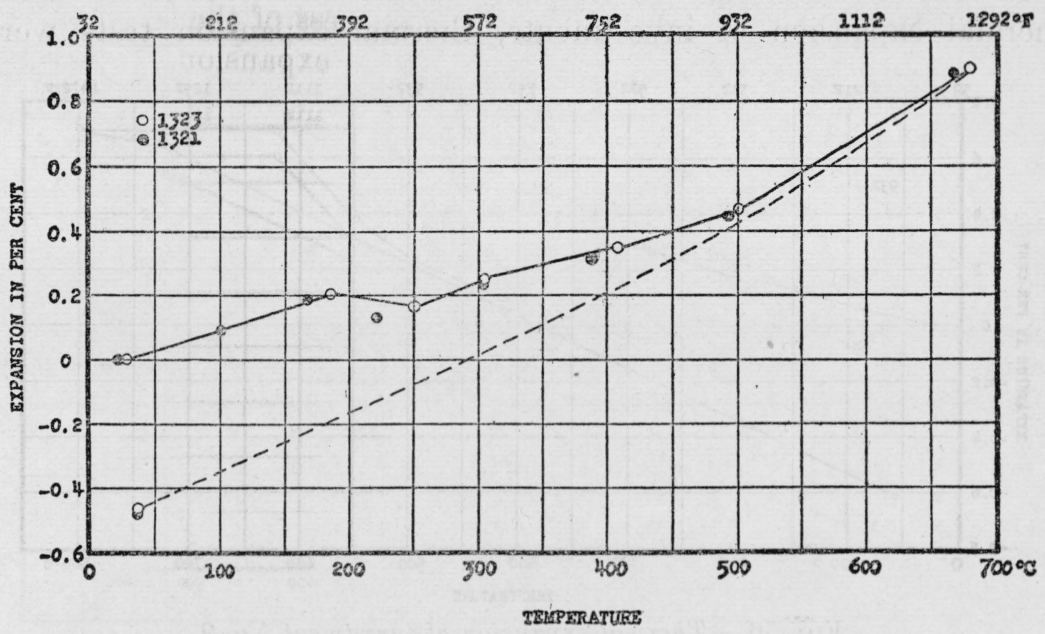

Fig. 54.-Thermal expansion of investment No. 19

The light circles represent the expansion of a sample made of $100 \mathrm{~g}$ of powder and $32 \mathrm{ml}$ of water, and the dark circles that of a sample made of $100 \mathrm{~g}$ of powder and $43 \mathrm{ml}$ of water

In Figure 52 are shown the results of tests on two samples of investment No. 7, one made of $100 \mathrm{~g}$ of powder to $46 \mathrm{ml}$ of water and the other of $100 \mathrm{~g}$ of powder to $35 \mathrm{ml}$ of water, and in Figure 54

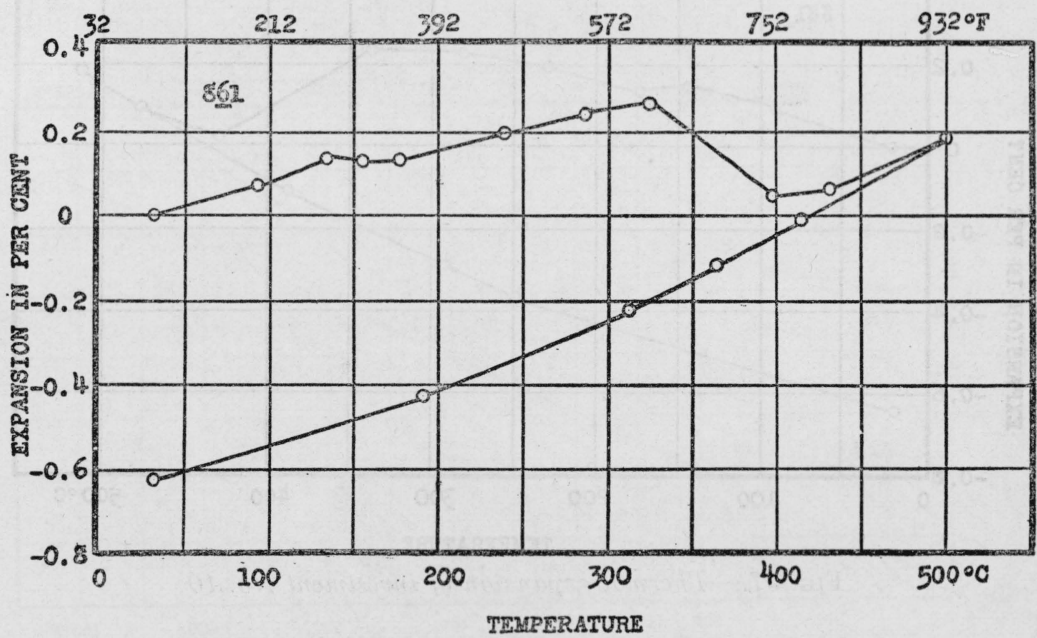

Fig. 55.-Thermal expansion of investment No. 8

are shown the results of tests on two samples of investment No. 19, one made of $100 \mathrm{~g}$ of powder to $43 \mathrm{ml}$ of water and the other of 100 $\mathrm{g}$ of powder to $32 \mathrm{ml}$ of water. It will be noted that these varia- 
tions in the amount of water used had no significant effect on the thermal expansion of these investments.

In order to determine the effect of the fineness of the silica on the thermal expansion of investments, thermal expansion tests were

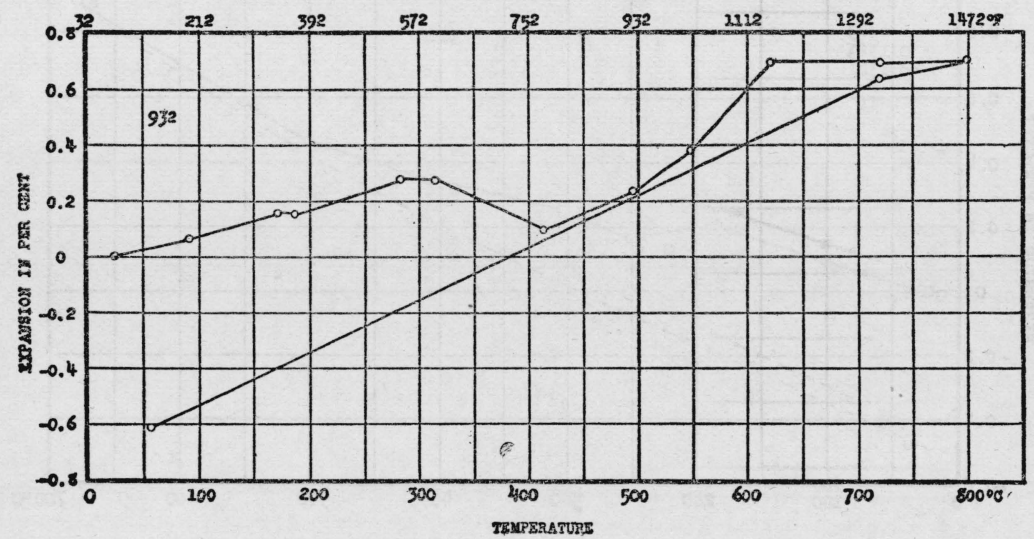

FIG. 56.-Thermal expansion of investment No. 9

made on an experimental investment, No. 20, consisting of 30 per cent of plaster of Paris and 70 per cent of a coarse silica. The plaster in this investment is of the same grade as that in investment No. 7 , which consists of approximately 30 per cent of plaster and

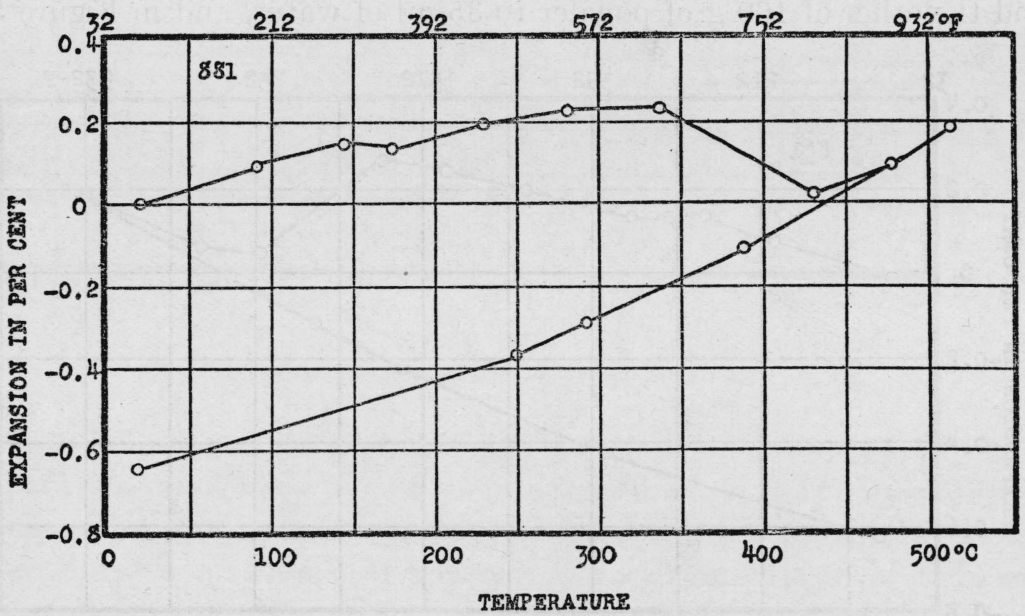

Fig. 57.-Thermal expansion of investment No. 10

70 per cent of a fine silica. The fineness ${ }^{21}$ of the silica used in these two investments is given in Table 22. The thermal expansion of investment No. 7 is represented grapbically in Figure 52 and that of

${ }^{21}$ The author is indebted to John Tucker, jr., of the Bureau of Standards, for determining the fineness of these materials, 
investment No. 20 in Figure 53. A comparison of these graphs indicates that the fineness of the silica has very little effect on the thermal expansion of investments of this nature.

TABLE 22.-Fineness of silica in investments Nos. 7 and 20

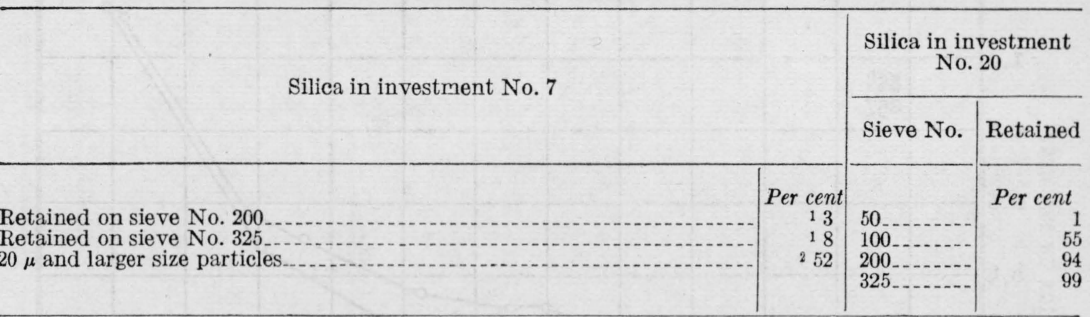

1 As determined by wet sieving.

2 As determined by air current elutriation. The value is approximately equivalent to the percentage of the material that would be retained on a No. 1000 sieve.

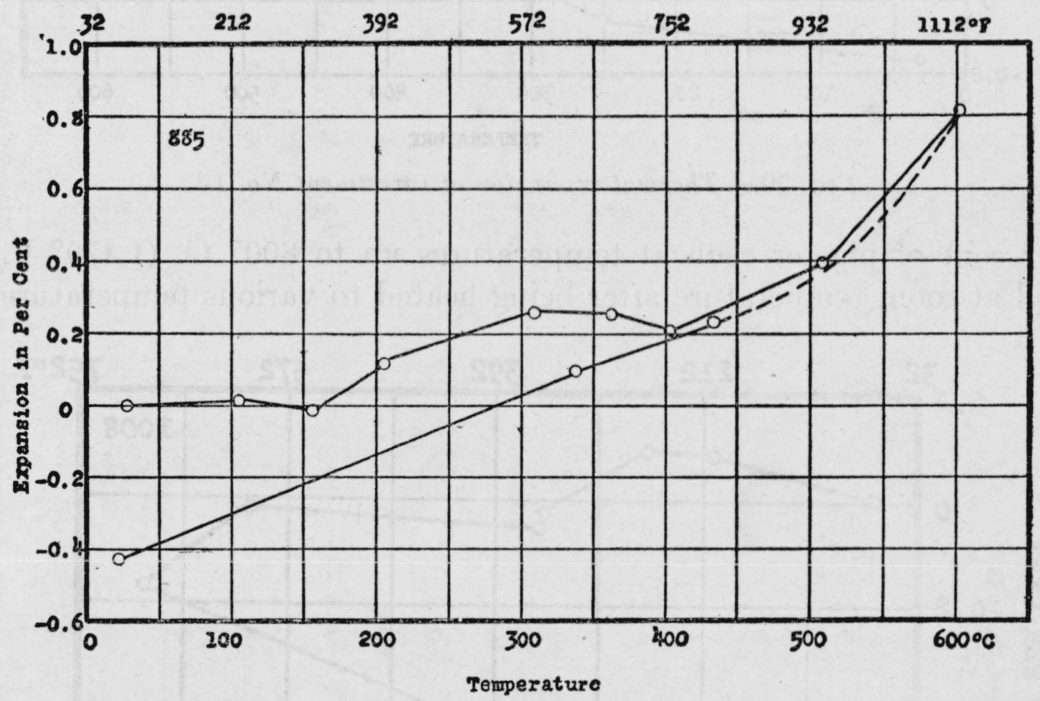

Fig. 58.-Thermal expansion of investment No. 11

From a study of the values for the thermal expansion of the investments tested it is obvious that if it is desired to compensate for part of the shrinkage of the cast gold alloys by casting into an expanded mold it is important to avoid heating the mold to a temperature within the contraction range, and to cast into the mold before it is allowed to cool. While the values vary for the different investments, in general an expansion of about 0.2 to 0.3 per cent may be obtained by heating the mold to approximately $300^{\circ} \mathrm{C}$. $\left(570^{\circ} \mathrm{F}\right.$.). Heating to approximately $600^{\circ} \mathrm{C}$. $\left(1,110^{\circ} \mathrm{F}\right.$.) will cause dimensional changes ranging from an expansion of more than 1 per cent to a contraction of more than 0.5 per cent, depending upon the investment used. 
(c) COMPRESSIVE STRENGTH

Determinations were made of the compressive strength of a plaster of Paris and of two inlay casting investments containing about 30

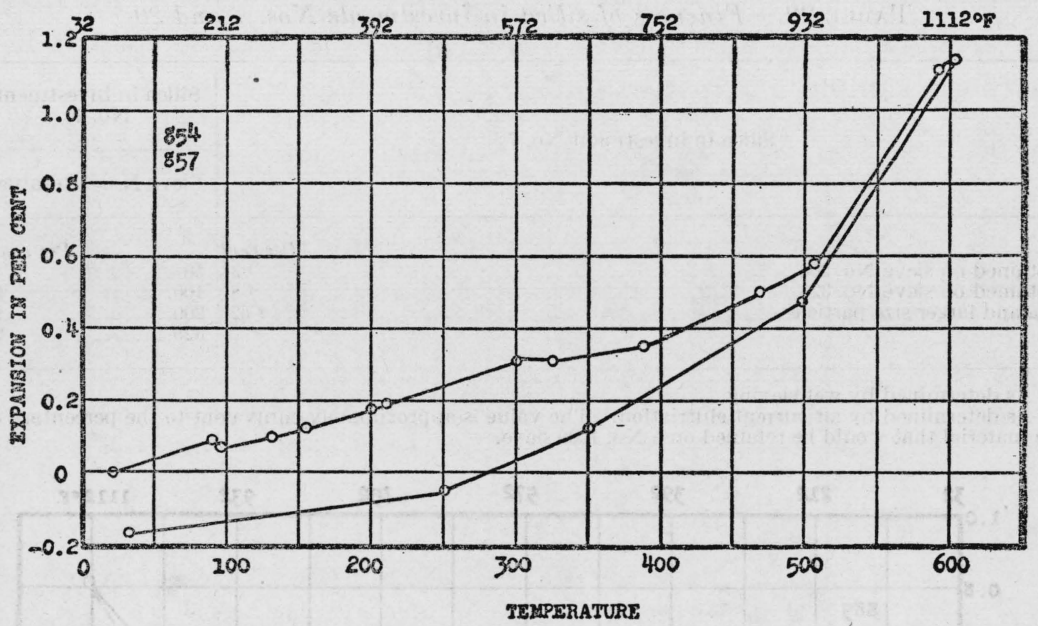

FIG. 59.-Thermal expansion of investment No. 12

per cent of plaster each at temperatures up to $800^{\circ} \mathrm{C}$. $\left(1,470^{\circ} \mathrm{F}\right.$.) and at room temperature after being heated to various temperatures

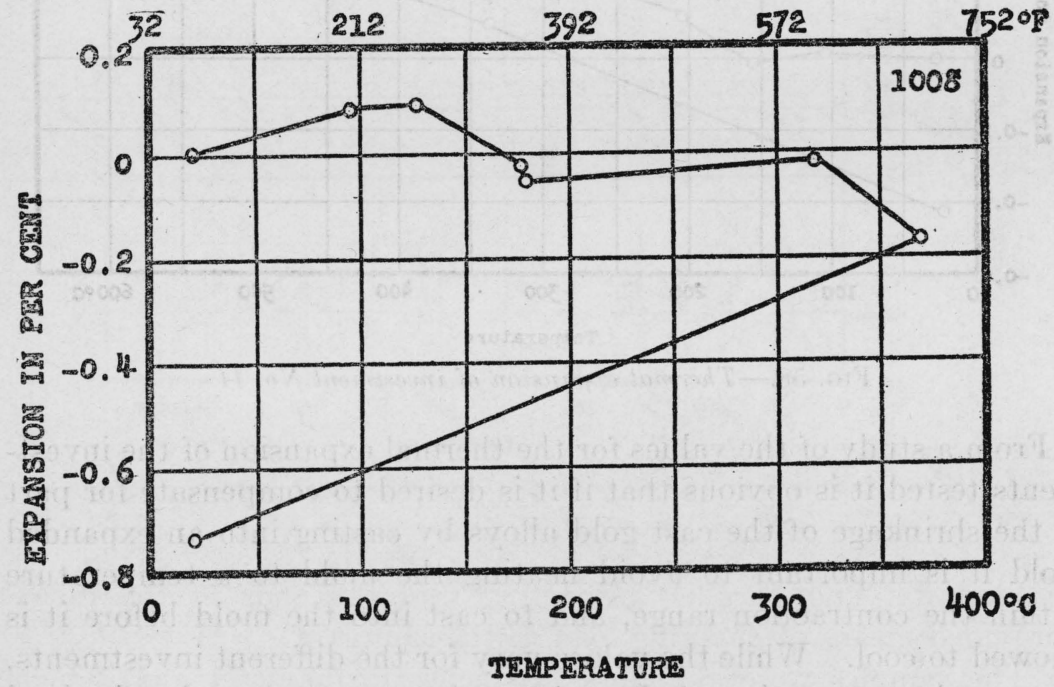

Fig. 60.-Thermal expansion of investment No. 13

(Artificial stone compound)

and allowed to cool. A universal testing machine of 2,000 pounds' capacity was used. The load was applied through four screws and 
measured by means of a beam and counterpoise. The additional apparatus used in making tests on samples at elevated temperatures is shown in Figure 63. The heating device was a chromel wound, vertical tube electric furnace with rheostats or a voltage regulator for controlling the temperature. The temperature was measured with a thermocouple and petentiometer. Two steel cylinders with ends

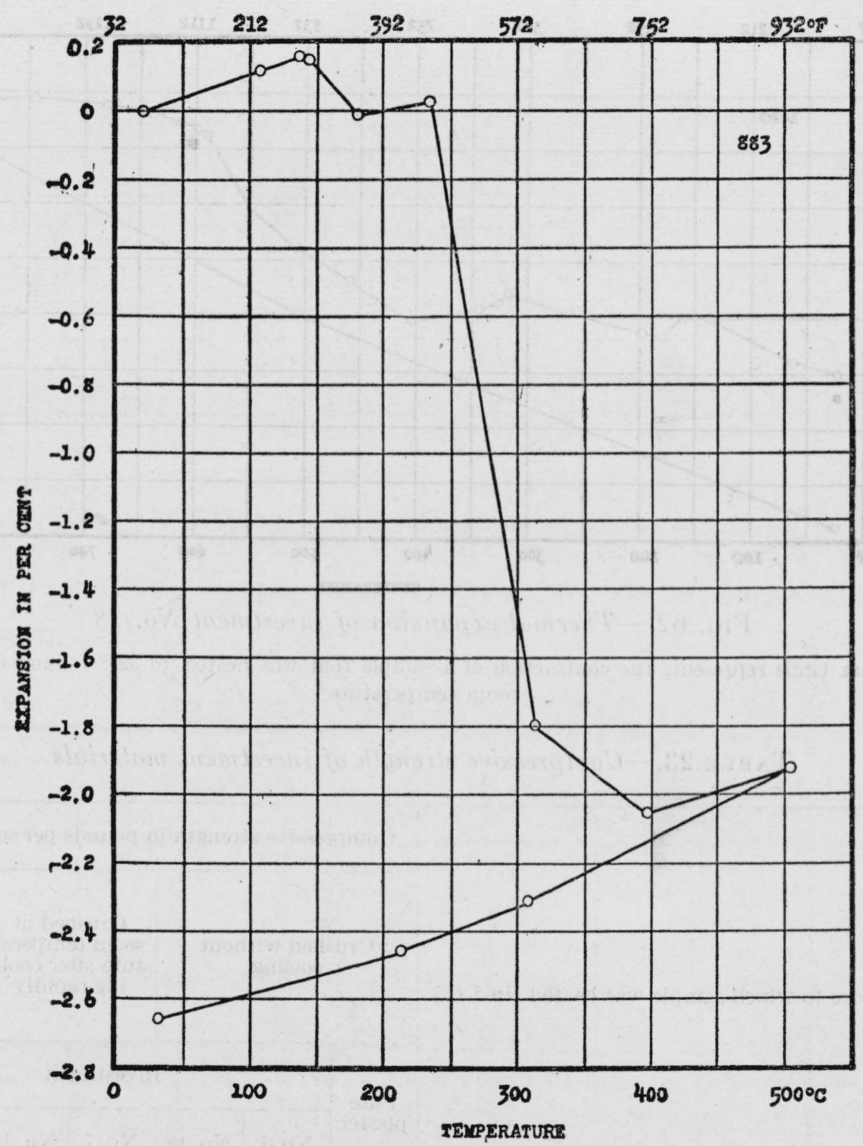

FIG. 61.-Thermal expansion of investment No. 14

(Artificial stone compound)

ground flat and parallel, projecting into the ends of the furnace provided means of applying load to the sample.

The samples were cylinders 1.3 inches in diameter and 2 inches long. They were prepared with parallel faces in the mold shown in Figure 64. The type of fracture obtained, also illustrated in Figure 64 , indicates that the loading was axial.

The values obtained are given in Table 23 . In all cases the values given are the average of several tests. The values for two of the ma- 
terials in the green state - that is, before heating - are included for comparison. Except when otherwise stated the proportions used were 46 parts water to 100 parts powder, by weight, for investment Nos. 7 and 18 and 67 parts water to $100 \cdot$ parts powder for the pure plaster. The powder and water were mixed in a mechanical spatulator.

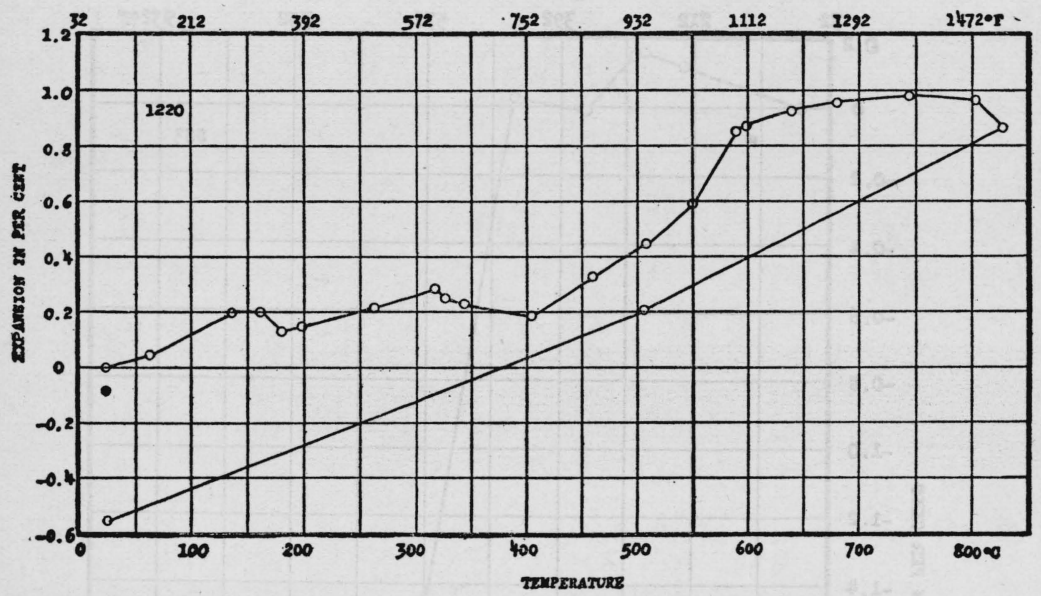

FIg. 62.-Thermal expansion of investment No. 18

The dark circle represents the contraction of a sample that was heated to $325^{\circ} \mathrm{C}$. and cooled to room temperature

TABLE 23.-Compressive strength of investment materials

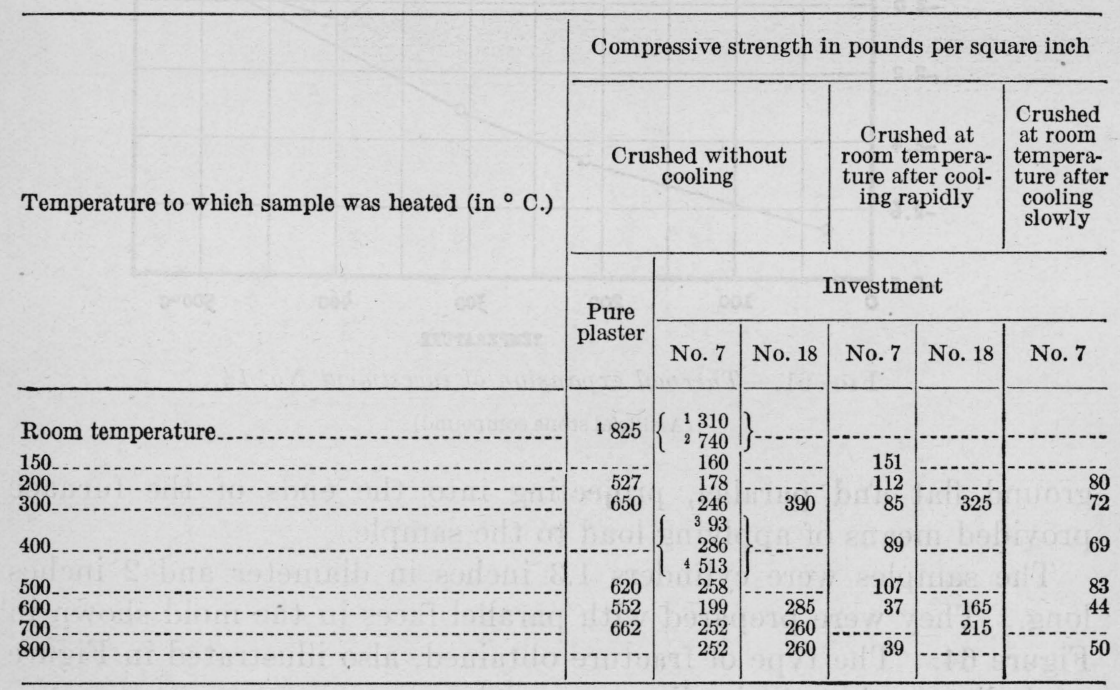

1 Crushed 3 hours after mixing.

2 Crushed 6 days after mixing.

3 Mixed with 25 per cent more than normal amount of water.

- Mixed with 25 per cent less than normal amount of water. 


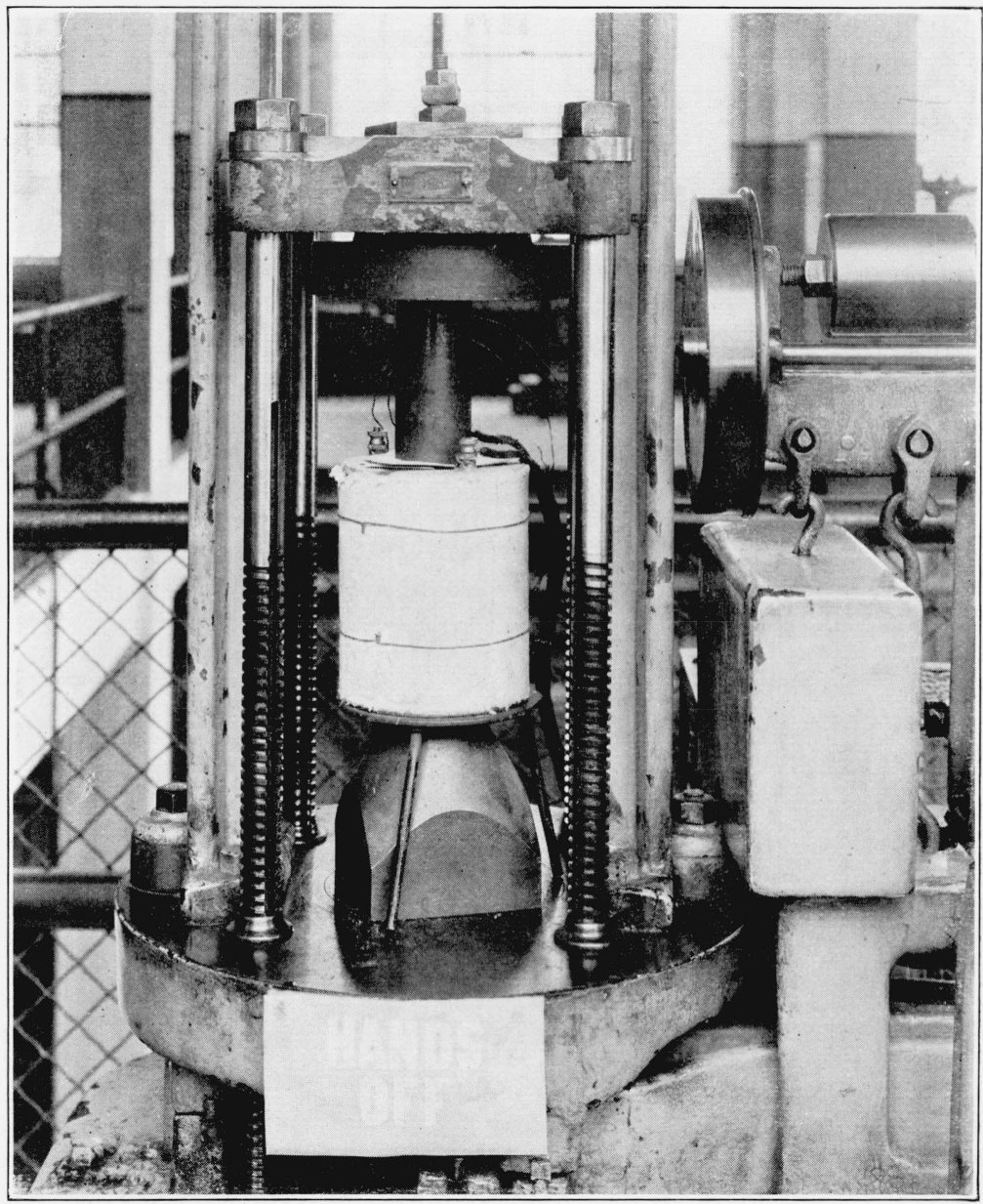

FIG. 63.-Apparatus for determining compressive strength of investments at elevated temperatures 
B. S. Journal of Research, RP32

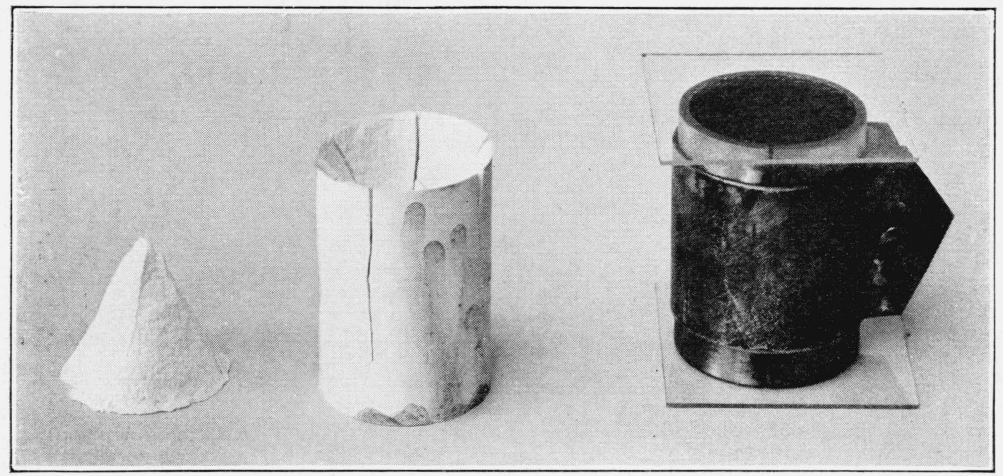

FIG. 64.-At the right is shown the type of mold in which the samples for determining compressive strength of investments were made. At the left is a crushed sample showing the type of fracture obtained

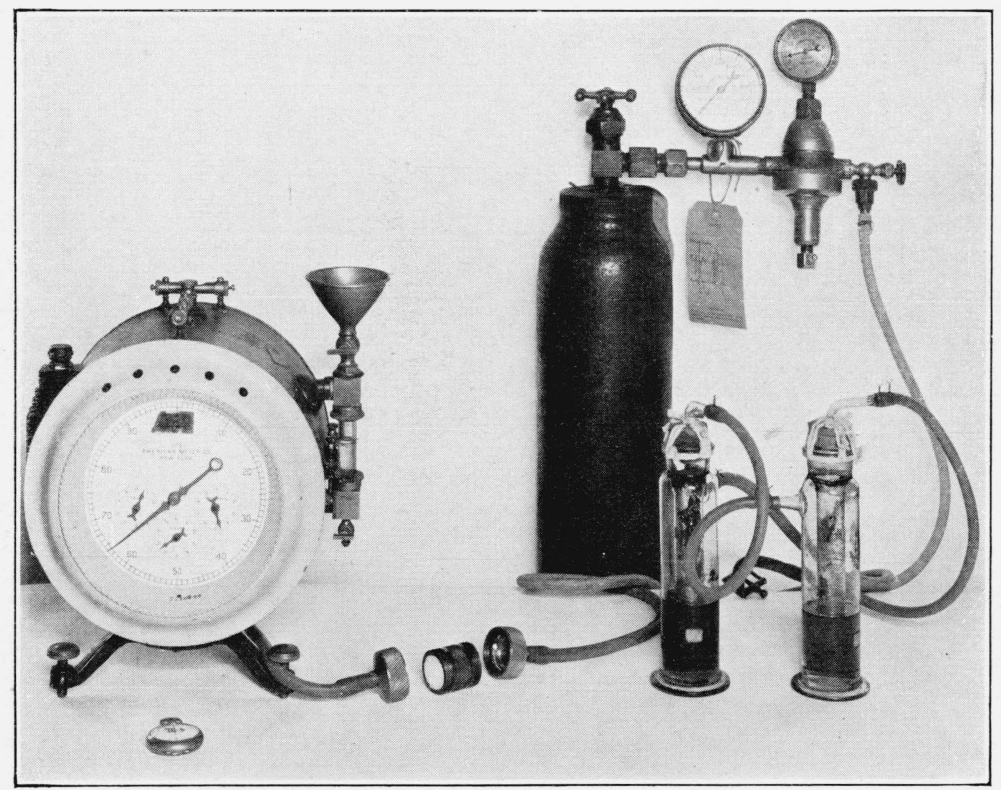

FIG. 65.-A Aparatus for determining relative porosity of investments

The rate of flow of air at a given pressure through an investment plug in the tapered ring is measured with the gas flow meter and stop watch. 
It will be noted that the strength of investment No. 7 (approximate composition 30 per cent plaster-70 per cent silica) drops from about $300 \mathrm{lbs}$./in. ${ }^{2}$ for the green material, three hours old, to 160 lbs./in. ${ }^{2}$ when heated to $150^{\circ} \mathrm{C}$. $\left(300^{\circ} \mathrm{F}\right.$.) and crushed hot. As the temperature is raised up to $400^{\circ}$ or $500^{\circ} \mathrm{C}$. $\left(750^{\circ}\right.$ or $930^{\circ} \mathrm{F}$.) the strength increases. At $600^{\circ} \mathrm{C} .\left(1,110^{\circ} \mathrm{F}\right.$.) the strength dropped to about $200 \mathrm{lbs}$./in. ${ }^{2}$, but at $700^{\circ} \mathrm{C} .\left(1,290^{\circ} \mathrm{F}\right.$.) and $800^{\circ} \mathrm{C}$. $\left(1,470^{\circ} \mathrm{F}\right.$. $)$ was again near the maximum, which is only slightly below the strength of the green material, three hours old. If this investment is allowed to cool to room temperature after being heated to the various temperatures indicated, the decrease in strength is very marked. It was thought that this decrease in strength might be due to cracking caused by too rapid cooling, but tests on samples allowed to cool slowly in the furnace over a period of several hours showed that the slow rate of cooling caused a still greater loss of strength.

Investment No. 18 is somewhat stronger than investment No. 7, especially at $300^{\circ} \mathrm{C}$. $\left(570^{\circ} \mathrm{F}\right.$.), and the loss of strength in cooling is not so marked.

The behavior of pure plaster or plaster without any added silica was similar to that of investment No. 7. The strength dropped from $825 \mathrm{lbs}$./in. ${ }^{2}$ for the green material, three hours old, to $527 \mathrm{lbs}$./in. ${ }^{2}$ when heated to $200^{\circ} \mathrm{C}$. $\left(390^{\circ} \mathrm{F}\right.$.). The strength increased slightly at the higher temperatures until, at $600^{\circ} \mathrm{C} .\left(1,110^{\circ} \mathrm{F}\right.$.), there was a marked loss in strength. At $700^{\circ} \mathrm{C}$. $\left(1,290^{\circ} \mathrm{F}\right.$.) the strength rose to $662 \mathrm{lbs} . /$ in. $^{2}$, which was the maximum value obtained for plaster crushed hot. When samples of pure plaster were cooled from $500^{\circ} \mathrm{C}$. $\left(930^{\circ}\right.$ F.) or higher, they invariably cracked and fell to pieces.

The effect of varying the proportion of water used with investment No. 7 is shown in the table. When the amount of water was increased 25 per cent, the strength at $400^{\circ} \mathrm{C}$. $\left(750^{\circ} \mathrm{F}\right.$.) dropped from 286 to $93 \mathrm{lbs}$./in. ${ }^{2}$ Decreasing the amount of water 25 per cent increased the strength to $513 \mathrm{lbs}$./in. ${ }^{2}$

From the results of these tests it may be stated that when the usual inlay casting investment, consisting of about 30 per cent of plaster and 70 per cent of silica, is heated to drive off the moisture and eliminate the wax pattern the loss of strength is comparatively small. If, however, the investment is allowed to cool, the mold becomes very weak and is likely to be distorted by the impact or pressure of the molten gold as it enters the mold.

\section{(d) POROSITY OF INVESTMENTS}

In casting into investment molds by any of the methods in common use it is necessary to provide some means of escape for the air in the mold in order that the space may be completely filled by the entering metal. While in some cases this may be satisfactorily 
accomplished by properly venting the mold, in general the porosity of the investing material must be relied on wholly or in part. For this reason the relative porosities of various types of investment were determined.

The apparatus developed for making these measurements is illustrated in Figure 65. The determination depends upon measuring the rate of flow of air under a given pressure through a given size plug of the material under test. The procedure is as follows: The investment to be tested is poured into the tapered ring shown in the photograph, allowed to set, and given the desired burning-out treatment. The investment plug is then removed from the ring and coated with a thin film of collodion, except on the ends. The inside of the ring is smeared with heavy grease and the plug replaced. The film of grease prevents leakage of air between the plug and the ring, and the collodion prevents the grease from penetrating into the plug. Air at the desired pressure is applied through the cap with hose connection, and the flow through the plug during a definite time interval is measured by means of a gas-flow meter and a stop watch. The average diameter of the plug is $30 \mathrm{~mm}$ and the length $36 \mathrm{~mm}$. The values obtained for a few materials are given in Table 24 .

TABLE 24.-Porosity of investments

\begin{tabular}{|c|c|c|c|c|c|}
\hline \multicolumn{2}{|c|}{ Material } & \multirow{2}{*}{$\begin{array}{c}\text { Ratio } \\
\text { water } \\
\text { to } \\
\text { powder } \\
\text { by } \\
\text { weight }\end{array}$} & \multirow[b]{2}{*}{ Drying-out treatment } & \multicolumn{2}{|c|}{$\begin{array}{l}\text { Flow of air in } \\
\text { ten-thousandths } \\
\text { cubic feet per } \\
\text { minute }\end{array}$} \\
\hline No. & Plaster & & & \begin{tabular}{|l|} 
At 10 \\
pounds \\
per \\
square \\
inch
\end{tabular} & $\begin{array}{l}\text { At 20 } \\
\text { pounds } \\
\text { per } \\
\text { square } \\
\text { inch }\end{array}$ \\
\hline 3 & $\begin{array}{c}\text { Per cent } \\
56\end{array}$ & 0.52 & Held at $250^{\circ} \mathrm{C}$. for $11 / 2$ hours.- & 21 & 47 \\
\hline 4 & 40 & .43 & $\left\{\begin{array}{l}\text { Heated slowly to } 220^{\circ} \\
\text { Held } 220^{\circ}-240^{\circ} \mathrm{C} \text {. for } 3 \text { hours }\end{array}\right.$ & 35 & 84 \\
\hline 7 & 30 & .46 & Held at $250^{\circ} \mathrm{C}$. for $1 \frac{1}{2}$ hours & 52 & 120 \\
\hline $\begin{array}{r}7 \\
115\end{array}$ & 40 & $\begin{array}{l}.49 \\
.52\end{array}$ & do & $\begin{array}{l}73 \\
83\end{array}$ & $\begin{array}{l}164 \\
191\end{array}$ \\
\hline 16 & 50 & .54 & .... do & 73 & \\
\hline & 60 & .52 & & & 121 \\
\hline 19 & $\begin{array}{l}26 \\
39\end{array}$ & $\begin{array}{r}.46 \\
.43\end{array}$ &..- do & $\begin{array}{l}75 \\
49\end{array}$ & $\begin{array}{l}187 \\
114\end{array}$ \\
\hline 19 & 39 & .30 & -....do do & 25 & \\
\hline
\end{tabular}

1 Investment containing 5 per cent of cornstarch.

It was found that, in general, the porosity decreases as the plaster content increases and also as the proportion of water used decreases. Since decreasing the proportion of water increases the strength of the investment, it was thought that it might be possible to improve the usual investments by adding a small amount of some material which would increase the porosity, thus permitting the use of a smaller 
B. S. Journal of Research, RP32

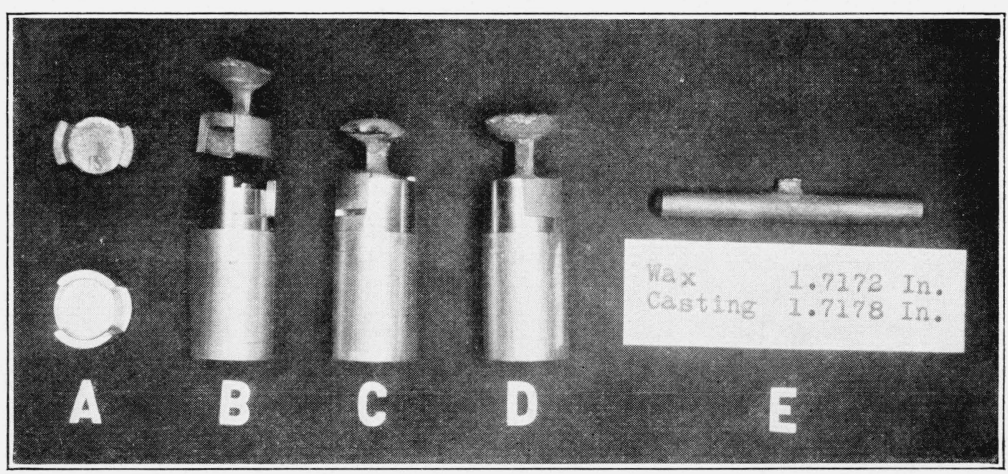

Fig. 67.- Steel model and gold castings

$A$, Top view of model; $B$, Side view of model and casting; $C$, Showing lack of dimensional accuracy in a casting made according to a popular technic; $D$, Showing a casting made by the methods described; $E$, Showing the dimensional accuracy of castings made by these methods. 
amount of water or a higher plaster content. Various materials, such as wood flour, waxes, resins, sugar, starch, and others, were suggested for this purpose. A number of these have been tried and found unsatisfactory for various reasons.

In preliminary tests cornstarch seemed to be a promising material for this purpose. As will be seen from the values given in Table 25 the rate of flow of air through investment No. 17, containing 60 per cent of plaster, 35 per cent of silica, and 5 per cent of cornstarch, was more than double that through investment No. 3, containing 56 per cent plaster, the proportion of water used being $52 \mathrm{ml}$ to $100 \mathrm{~g}$ of powder for each investment. However, it was found that investments containing starch are very little, if any, more porous than investments on the market, such as Nos. 18 and 19. For this reason and because the investments containing starch give off a very disagreeable odor and smoke when heated, the general use of these materials is not recommended.

\section{(e) SURFACE ROUGHNESS}

In examining a large number of castings made under varying conditions it was found that in practically every case there were a number of small nodules of gold projecting from the surface of the castings. In a few cases, these were very small and could be seen only with the aid of a microscope, but even these small nodules are sufficient to prevent an inlay from properly seating. Preliminary tests indicated that these projecting nodules are due mainly to small air bubbles in the investment, which came in contact with the pattern during the investing process, and that they might be eliminated or at least reduced in number and size by proper mixing and investing methods. Accordingly, various methods of mixing the powder and water and of applying the investment to the wax pattern were investigated. Patterns of a convenient size and shape were invested, the investment being mixed and applied in various ways. After the investment had been dried out and the pattern eliminated the mold was cut open and the investment surfaces which had been in contact with the pattern were examined under a binocular microscope. In this way the relative number and size of the air bubbles in the surfaces were easily detected.

It was found that by carefully applying the investment to the pattern with a small stiff sable or badger hair brush the air bubbles in the surface of the mold could be materially reduced, but were not completely eliminated if bubbles were present in the investment as mixed. The results of numerous tests indicate that air bubbles can be largely eliminated by very thoroughly mixing the water and powder. It was found that this could be accomplished much more consistently and conveniently with a stiff metal blade mechanical mixer of good design than with the usual plaster bowl and spatula. 
Another method suggested was that of mixing the investment in vacuum, and the experimental apparatus illustrated in Figure 66 was developed for this purpose. The powder is placed in the container and evacuated. The necessary amount of water is admitted and the mixing accomplished by shaking the container. If a number of balls of some dense material, such as steel, are placed in the container as shown in the drawing, a thorough mixing can be effected very quickly and easily. The results obtained with this apparatus indicate that it is exceptionally effective in eliminating air bubbles from the investment. However, this method of mixing is practicable only when a vacuum pump is available.

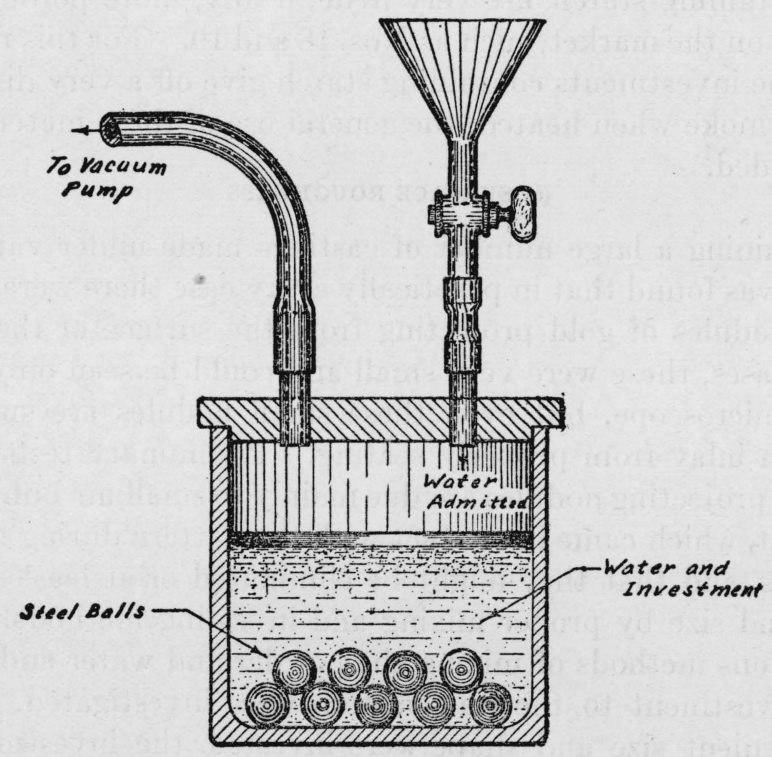

FIG. 66.-Apparatus for mixing investment in vacuum

Another form of surface defect often observed was a type of roughness which appeared to be due to an excess of water collecting on the surface of the pattern during or immediately after investing. It was found that by carefully painting the pattern with a thin coat of investment and then sprinkling this coating with dry investment powder, the excess water was absorbed and the roughness largely eliminated..$^{22}$ As a further proof that this type of roughness is caused by the presence of excess water, a hypodermic needle was used to deposit small drops of water on the surfaces of patterns invested and sprinkled with dry powder as described, and in every case the roughness reappeared.

${ }_{22}$ Reported in B. S. Tech. News Bul. No. 116, December, 1926. 


\section{CASTING TO DIMENSION}

In order to verify the data obtained on the materials used in the dental casting process and to demonstrate the application of these data in practice, test castings were made to determine the accuracy with which the dimensions of a casting could be controlled. In order to readily demonstrate the accuracy or inaccuracy of the dimensions of the castings produced, and at the same time provide a severe test, it was decided to make castings for a cavity of the mesio-occlusodistal type; that is, one that has both outside and inside dimensions to be fitted. If a casting for this type of cavity is too small, it will not seat in the cavity because it does not fit the outside dimensions, and if it is too large it will not seat because it does not fit the inside dimensions. The walls of the cavity were tapered slightly to facilitate removal of the wax pattern and to provide a means of judging the relative dimensional accuracy of the castings. In order to eliminate as nearly as practicable variations in the dimensions of the cavity, the cavity was prepared in a steel model. In Figure 67 a top view of the model is shown at $A$ and side views at $B, C$, and $D$.

By referring to the section on the casting shrinkage of gold alloys (p. 908) it will be noted that the average net casting shrinkage for these alloys was found to be 1.25 per cent, and that if no other dimensional variations are introduced in the casting process the castings will be too small by that amount. The obviously available means for compensating for this shrinkage are the thermal expansion of the wax pattern and the thermal and setting expansions of the investment mold. According to the data obtained on pattern waxes (p. 912) and on investments (p. 917) the combined expansions of these two materials may be made to total 1.25 per cent (the amount necessary to compensate for the shrinkage of the cast gold alloy) by a number of different methods. Two examples are cited to illustrate this. If investment No. 18 is used and is mixed in the proportion $100 \mathrm{~g}$. of powder to $40 \mathrm{ml}$ of water, the setting expansion will be 0.21 per cent (see Table 20) and if the investment mold is heated to $600^{\circ} \mathrm{C} .\left(1,110^{\circ} \mathrm{F}\right.$.) the thermal expansion will be 0.87 per cent. (See fig. 62.) The total expansion of the mold is the sum of these two expansions or 1.08 per cent, leaving an expansion of 0.17 per cent to be obtained from the wax pattern. If wax No. 5 is used, it is seen from Figure 43 that 0.17 per cent expansion may be obtained in numerous ways; as, for example, by making the pattern to fit at $33^{\circ} \mathrm{C}$. $\left(91^{\circ} \mathrm{F}\right.$.) and investing it at $36^{\circ} \mathrm{C}$. $\left(97^{\circ} \mathrm{F}\right.$.). If the same investment, No. 18 , is used mixed with the same proportion of water, the setting expansion again is 0.21 per cent. If the mold is heated to $315^{\circ} \mathrm{C}$. $\left(600^{\circ} \mathrm{F}\right.$.), the thermal expansion will be 0.28 per cent (see fig. 62 ) and the total expansion of the mold is 0.49 per cent, leaving an expansion of 0.76 
per cent to be obtained from the wax pattern. If the pattern is made of the same wax, No. 5, it is seen from Figure 43 that 0.76 per cent expansion may be obtained by making the pattern to fit at $27^{\circ} \mathrm{C}$. $\left(81^{\circ} \mathrm{F}.\right)$ and investing it at $40^{\circ} \mathrm{C} .\left(104^{\circ} \mathrm{F}\right.$.).

A number of the possible combinations of materials and methods of manipulation were tested and found to be satisfactory. In Figure 67 a casting made by a popular technic is shown on the model at $C$. It is obvious that this casting does not fit the model. A representative casting made by the second method described above is shown on the model at $D$. This casting was thoroughly washed to remove adhering particles of investment, but was not ground or burnished. The seating of the casting indicates the dimensional accuracy attained. The casting shown at $E$, made by the same method, indicates quantitatively the accuracy with which the original dimensions of the pattern are reproduced in the casting.

It is not intended to recommend the use of any particular materials or any one method. A variety of satisfactory combinations of materials and manipulative procedures are available. There are, however, a few general precautions which should be observed. Care should be taken to obtain a pattern that fits as accurately as possible, as no amount of expansion can compensate for inaccuracies in the pattern owing to lack of adaptation to the walls of the cavity or to distortions introduced during or subsequent to the removal of the pattern from the cavity. It is obvious that in order to obtain the best results it is necessary to exercise careful control of the various manipulative procedures in strict accordance with definite data on the properties of the materials used.

\section{SUMMARY}

The physical properties of dental gold alloys used in the wrought and cast states, of investments and of pattern waxes, were investigated. Practicable methods of testing these materials were developed, and these methods and the apparatus used are described. The properties of a large number of representative commercial materials were determined and the values obtained are reported. Especial attention was given to those properties having a direct bearing on the usefulness of these materials in the construction of mechanical dental appliances and to the effects of variations in manipulative procedures. Improvements in methods of manipulation, especially in the dental casting processes and in the heat treatment of gold alloys, were developed. It was found that the dental gold alloys on the market vary widely in their mechanical properties and fusion temperatures as well as in chemical composition. This emphasizes the necessity for selecting suitable materials for specific purposes on the basis of tests of physical properties. The methods of testing developed and de- 
scribed herein provide the dental profession and schools with a means of grading and selecting materials on this basis. Some of the more important results of this investigation may be enumerated as follows:

1. In the investigation of dental gold alloys methods of preparing suitable test specimens and special apparatus for determining the mechanical properties of these specimens were developed.

2. It was found that the mechanical properties of many of the gold alloys can be markedly improved by suitable heat treatment. Practical methods of heat treating were developed and described.

3. The porosity or internal voids prevalent in dental gold-alloy castings was found to be due largely to localized shrinkage or occluded gases or both. The usual concentration of these defects adjacent to the sprue may be avoided by the use of a short sprue of large diameter or by providing the mold with a chamber close to the pattern and large enough to supply molten metal to the casting as it shrinks during solidification.

4. Tests for segregation of the constituents of gold alloy castings indicated that no serious defects from this cause are to be expected in the ordinary dental casting processes.

5. It was found that the selective loss of constituent metals or the "unbalancing" of the composition of gold alloys caused by melting is negligible when the melting is done with reasonable care. If the alloys are heated to excessively high temperatures, loss of base metals is likely to occur.

6. The net linear casting shrinkage of an alloy containing 90 per cent gold and 10 per cent copper was found to be approximately 1.25 per cent. No significant variations in this value caused by variations in the temperature of the metal when cast, the temperature of the mold, or the casting pressure were observed. Measurements made on a number of other alloys indicated that no large variations in net shrinkage, caused by the variations in composition of the usual casting golds, is to be expected.

7. The thermal expansions of five inlay pattern waxes and one impression compound were determined. The change in linear dimensions over the temperature range $25^{\circ}$ to $40^{\circ} \mathrm{C}$. $\left(77^{\circ}\right.$ to $104^{\circ} \mathrm{F}$.) was found to be 0.4 per cent for the impression compound and to vary from about 0.7 to 0.8 per cent for the pattern waxes tested. Wax patterns were found to be subject to distortion on account of the release of internal stresses on heating. Such distortions can be minimized by working the wax at as high a temperature as possible when making the pattern and by avoiding subsequent overheating.

8. The usual investments for inlay casting expand on setting. This linear expansion is approximately 0.25 per cent.

9. The compressive strength of the usual inlay investments is not seriously affected by heating to temperatures between $200^{\circ} \mathrm{C}$. 
$\left(390^{\circ}\right.$ F.) and $800^{\circ}$ C. $\left(1,470^{\circ}\right.$ F.). Cooling from these temperatures results in a very marked loss of strength.

10. The above investments may be expanded about 0.2 to 0.3 per cent by heating to $250^{\circ}$ to $300^{\circ} \mathrm{C}$. ( $\left(480^{\circ}\right.$ to $570^{\circ} \mathrm{F}$.). Heating to $350^{\circ}$ to $450^{\circ} \mathrm{C}$. $\left(660^{\circ}\right.$ to $840^{\circ} \mathrm{F}$.) results in a contraction, the magnitude of which varies for the different investments. Heating to approximately $600^{\circ} \mathrm{C}$. $\left(1,110^{\circ} \mathrm{F}\right.$.) will cause dimensional changes ranging from an expansion of more than 1 per cent to a contraction of more than 0.5 per cent depending upon the investment used. Cooling: from any of the above temperatures is accompanied by a relatively large contraction. Varying the proportion of water within the usual limits has very little effect on the expansion of these investments. No appreciable effect on the expansion caused by variations in the fineness of the silica in the investments was observed.

11. It was found that by selecting suitable combinations of materials and manipulative procedures a total expansion of the wax pattern and the mold sufficient to compensate for the casting shrinkage of the gold alloys can be obtained. Methods of obtaining this compensation were verified and are described.

12. Two types of roughness of surface of dental castings, causing inaccuracies of dimensions, were observed. It was found that one of these was due to air bubbles in the investment and the other to the collection of water on the surface of the pattern during or soon after investing. The first type can be largely eliminated by thorough mixing of the investment, preferably with a mechanical mixer, or by mixing the investment in vacuum. The latter type can be largely eliminated by painting the pattern with a thin coat of investment and then sprinkling this coating with dry investment powder.

Washington, June 7, 1928. 